\title{
II. Aufbruch in die Normalität: ,Kaderverwaltung' und Reintegration
}

Schon kurz nach dem Ende des ,Dritten Reiches' orientierten die politischen Verantwortungsträger in der Sowjetischen Besatzungszone (SBZ) ihre Tätigkeit an einer Wiederherstellung gesellschaftlicher, Normalität'. In erster Linie ging es ihnen dabei um die Lösung der Probleme der Zusammenbruchgesellschaft, die den Menschen in allen vier Besatzungszonen das Leben schwermachten. Im vorhergehenden Kapitel zeigte sich, wie unmittelbar diese Prozesse in der SBZ bereits mit gesellschaftlichen Strukturveränderungen verbunden waren. Das Ausmaß der Veränderungen hing davon ab, welche Bedeutung die einzelnen politischen und gesellschaftlichen Bereiche für die Umgestaltungspolitik von Besatzungsmacht und deutschen Kommunisten hatten. Den zahlreichen Beispielen für eine gewisse Liberalität und Pluralität, wie sie in der Jugendarbeit, Kultur- und Kirchenpolitik zu finden waren, standen tiefgreifende und mit Vehemenz durchgesetzte Reformen wie in der Wirtschafts-, Agrar- und Verwaltungspolitik entgegen.

Bei der Durchsetzung ihrer Variante der gesellschaftlichen ,Normalisierung konnte die KPD auf die enge Zusammenarbeit mit der Besatzungsmacht vertrauen. Die in diesem Bündnis begründete Stärke wurde noch unterstützt durch den antikapitalistischen Grundkonsens der frühen Nachkriegszeit und den in der Blockkonzeption manifest gewordenen weitverbreiteten Willen zur parteiübergreifenden Zusammenarbeit. Durch ihre wiederholte Bezugnahme auf eine vermeintliche Normalität beteuerte die KPD zudem, daß sie keine revolutionären Veränderungen, sondern nur die Etablierung einer bürgerlich-demokratischen Ordnung anstrebte. ${ }^{1}$ Das Zusammenspiel von sowjetischer Besatzung, kommunistischer Hegemonie und allgemeiner Kooperationsbereitschaft war der Grund für die geringe Anzahl politischer Konflikte in der SBZ. Die in Mecklenburg-Vorpommern bereits wenige Wochen nach Installierung der Landesverwaltung durchgesetzte Vormachtstellung des ersten Vizepräsidenten Johannes Warnke ist ein herausragendes Beispiel für den Erfolg dieser Strategie der strukturellen Veränderungen unter bündnispolitischen Vorzeichen.

\footnotetext{
${ }^{1}$ Siehe z. B. Erler/Laude/Wilke, Hitler, S. 395; MLHA, MinPräs 1309, Bl. 2; MLHA, MinPräs 1458, Bl. 14; MLHA, MdI 245, Bl. 73f.; SAPMO-BA, NY 4036 (NL Pieck), 421, Bl. 147f.; Institut für Marxismus-Leninismus beim ZK der SED, Geschichte, Bd. 6, S. 403. Durch den Begriff der ,Normalität' suchten die Kommunisten ihre Zielsetzungen implizit zu verallgemeinern, ohne darüber ausdrücklich Rechenschaft ablegen zu müssen. Daß die Kommunisten die sozioökonomischen Strukturveränderungen und sogar die sowjetische Besatzung für ,normal' hielten, formulierte Wilhelm Pieck in einer KPD-Schule in der Sowjetunion im März 1945: „Das ganze Leben“ werde sich „unter der strengen Kontrolle der Besatzungsbehörden vollzieh[en]“, und „je energischer und konsequenter" die gesellschaftlichen Veränderungen "durchgeführt werden, um so schneller wird ein geordnetes, normales Leben ermöglicht werden" (Lektion am 10. 3. 1945, in: SAPMO-BA, NY 4036 [NL Pieck], 421, Bl. 147f.).
} 
Der Gebrauch zahlreicher Begriffe wie ,Antifaschismus', ,Demokratie“ und ,Neuaufbau' unterstrich den Eindruck eines übergreifenden politischen Konsenses in der SBZ und der Wiedergewinnung einer gewissen Stabilität im alltäglichen Leben. Gleichwohl bewirkten die beispielsweise im Wirtschafts-, Justiz-, Schul- oder Agrarbereich durchgesetzten Strukturreformen grundlegende gesellschaftspolitische Veränderungen. Nach den erheblichen Zerrüttungen infolge des Krieges veränderte die Bodenreform die Wirtschafts- und Sozialstruktur Mecklenburg-Vorpommerns am tiefgreifendsten, da durch sie ungefähr die Hälfte der landwirtschaftlichen Nutzfläche enteignet, parzelliert und neu verteilt wurde. Während die öffentlichkeitswirksamen Höhepunkte der Enteignungspolitik außerhalb des Agrarbereichs noch bevorstanden - der Volksentscheid in Sachsen Ende Juni 1946 und das entsprechende Gesetz vom August 1946 in Mecklenburg-Vorpommern ${ }^{2}$-, waren die wichtigsten Schritte der Bodenreform schon zum Jahresende 1945 durchgeführt; bereits Mitte November verkündete die KPD-Tageszeitung ihr Ende. ${ }^{3}$

Die Entnazifizierung hatte es ermöglicht, die Verwaltung in einem ähnlich hohen Tempo umzugestalten. Der bis Ende 1945 durchgesetzte Bruch war tiefgreifend, bestand allerdings vor allem in einer negativen Abgrenzung, nämlich den Entlassungen von NSBelasteten. So wie aber die Handels-, Handwerks-, Industrie- und Landwirtschaftspolitik nicht nur die Enteignungen, sondern auch Strukturveränderungen mit sich brachte, beschränkte sich auch die Verwaltungspolitik nicht auf den Personalaustausch. Die umfangreiche bürokratiekritische Rhetorik zeigte schon früh, daß die Kommunisten anderes als eine bloße Neuordnung der alten Verwaltungsstrukturen der Weimarer Republik und des NS-Staates im Sinn hatten. Auf dem zweiten Parteitag der SED wurde entsprechend protokolliert, daß „mit der Ausfüllung der Stellen und der Entnazifizierung [...] in keiner Verwaltung etwas entscheidendes erreicht [sei]. Wir können uns drehen und winden, wie wir wollen, der bürokratische Zopf baumelt den Verwaltungen immer noch auf dem Rücken." ${ }^{*}$ Es ging um mehr, nämlich um ,volksdemokratische Verwaltungen ohne den "alten Zopf“, die vor allem durch ihre starke politische Abhängigkeit von der kommunistischen Partei geprägt sind. Bálint Balla hat dazu den Begriff der ,Kaderverwaltung' eingeführt. ${ }^{5} \mathrm{Da}$ sich solche Tendenzen in der SBZ schon in den ersten Nach-

\footnotetext{
2 Allerdings wurde auch die Wirtschaftspolitik schon im Herbst 1945 durch die SMAD-Befehle Nr. 124 und 126 auf zonaler Ebene systematisiert, die Bestimmungen über zu enteignende Personen und Organisationen enthielten. Zahlreiche Beschlagnahmungen harrten seitdem der endgültigen Enteignung oder der Rückgabe der als unrechtmäßig sequestriert anerkannten Güter. Ende Juni 1946 fand der diesbezügliche Volksentscheid in Sachsen statt, dem das mecklenburgische „Gesetz Nr. 4 zur Sicherung des Friedens durch Überführung von Betrieben (Eigentumskategorien) der faschistischen und Kriegsverbrecher in die Hände des Volkes" vom 16. 8. 1946 entsprach (Amtsblatt, Nr. 6 [1946], S. 98ff.; siehe Badstübner, Geschichte, S. 132-138; Barthel, Ausgangsbedingungen; Erdmann, Enteignung; Errichtung, S. 153-171; Heitzer, DDR, S. 51-56; Matschke, industrielle Entwicklung; Matschke, wirtschaftliche Entwicklung; Staritz, Gründung, S. 108ff.; Wilhelm, Heranbildung; Zank, Wirtschaft, S. 47-56).

${ }^{3}$ Deutsche Volkszeitung, 15. 11. 1945.

${ }_{4}^{4}$ Zitiert nach Meinicke, Entnazifizierung (Diss), S. 127.

${ }^{5}$ Balla formuliert ,Kaderverwaltung in Abgrenzung von Max Webers Idealtypus ,Bürokratie‘ als vorwiegend in ,volksdemokratischen' Staaten auftretenden Idealtypus von Verwaltungsarbeit; dazu ausführlich Kapitel II.1, S. 130-136. Balla analysiert langjährige Entwicklungen in Ost- und Mitteleuropa, so daß zahlreiche Elemente in der SBZ und besonders im ländlichen Mecklenburg-
} 
kriegsmonaten zeigten, wird der Begriff für die folgende Untersuchung des Verwaltungsaufbaus in Mecklenburg-Vorpommern übernommen.

Die kurze Geschichte der Entnazifizierung hat bereits gezeigt, daß die kommunistische Verwaltungspolitik nach dem NS-Regime zwei starke Pfeiler brauchte: eine politische Zentrale zur Durchsetzung des personalpolitischen Monopols im Dienste der Partei und ein politisches Anforderungsprofil, durch das die Vergangenheit ,gebändigt ${ }^{*}$ wurde. Der erste Pfeiler hieß ,Personalamt', der zweite war der langlebige Begriff des ,Antifaschismus'. Seine Verwendung zielte auf eine, flexible ${ }^{\varsigma}$ Interpretation der NS-Geschichte, um die kommunistische Hegemonie zu unterstreichen und gleichzeitig der gesellschaftlichen Integration breiter Bevölkerungsschichten und selbst anpassungsbereiter ehemaliger Nazis $\mathrm{zu}$ dienen.

\section{Aufbau der Kaderverwaltung}

\section{Leistungsprämie statt Entnazifizierung}

Der sozialdemokratische Präsident der Landesverwaltung von Mecklenburg-Vorpommern, Wilhelm Höcker, hatte die Entnazifizierung bereits Ende November 1945 für abgeschlossen erklärt. Alle NS-Belasteten waren entlassen; die Ausnahmefälle basierten auf ausdrücklichen sowjetischen oder präsidentialen Genehmigungen und betrafen mit täglicher Kündigungsfrist beschäftigte ehemalige NSDAP-Mitglieder im Gesundheitswesen oder Pgs, die „ausschließlich die Tätigkeit ungelernter Arbeitskräfte [...] auf Grund einer entsprechenden Anweisung durch die jeweiligen Arbeitsämter"6 verrichteten. Das nördlichste Land der SBZ hatte sich bei der Entnazifizierung der Verwaltung als vorbildlich erwiesen, indem es die rigorosen Anforderungen der Besatzungsmacht zügig erfüllt hatte.

Aber die Verwaltung sah sich nicht belohnt: Mit dem ausdrücklichen Einverständnis der Sowjetischen Militäradministration Deutschlands (SMAD) verfügte der Präsident der Zentralfinanzverwaltung in der SBZ, Henry Meyer, am 22. Februar 1946 in einem Runderlaß,7 daß ehemalige Nazis, „soweit sie noch nicht entlassen worden sind, zu-

Vorpommern der vierziger Jahre noch nicht entwickelt waren und sich teilweise erst abzeichneten. Glaeßner, Herrschaft, S. 99ff., kritisiert Ballas Ehrgeiz und Sakrileg, ,Kaderverwaltung' als gleichberechtigten Idealtypus neben den der ,Bürokratie‘ des Vaters der Soziologie zu stellen. Seine Kritik ist hier nicht von Bedeutung, da sie sich auf die „umfassenden Veränderungen“ des Kaderbegriffs seit Mitte der fünfziger Jahre bezieht, wonach er zunehmend stärker auf fachliche statt politische Qualifikationen bezogen wurde; auch Rudolph arbeitet heraus, daß der Kaderbegriff in der Geschichte der internationalen Arbeiterbewegung und auch der DDR starken Veränderungen unterworfen war und daß jede "Phase der Begriffsentwicklung [...] eine gewisse Begriffserweiterung " mit sich gebracht habe (Rudolph, Kader, S. 124; siehe auch Schwarzenbach, Kaderpolitik, S. 46f.; Müller, Kader).

6 Personalamt am 25. 2. 1946 an die Präsidialabteilung (MLHA, MdI 761).

${ }^{7}$ MLHA, MinPräs 3, Bl. 33. Am Schluß des Schreibens wurde auf acht zusätzliche Exemplare des Erlasses und neun "Abschriften der Zustimmungserklärung der SMA“ verwiesen; dies war zur Legitimation der Zentralverwaltung notwendig, da sie für zonale Anweisungen weder die formale Befugnis hatte noch die politische Akzeptanz bei den Landespolitikern fand (siehe Kapitel III.2, S. 210-216). Dies war eine der wenigen Verordnungen einer Berliner Zentralverwaltung zur Per- 
nächst weiter verwendet werden können“. Dies galt nur für nominelle Pgs und war mit einem grundsätzlichen Einstellungsverbot für bereits Entlassene verbunden. Die Wirkung dieser großzügigen Anweisung konnte in Mecklenburg-Vorpommern nicht weit reichen, weil bereits sämtliche NSDAP-Mitglieder entlassen waren. Darum war die Freude in Schwerin auch nicht groß: Der Leiter der Finanzabteilung, Gottfried Winckler, gab das Schreiben am 26. Juni 1946 mit der Klage an Höcker weiter, daß diese Bestimmung dem Land Sachsen zum Vorteil gereiche, „denn dort werden noch viele Pg als Facharbeiter beschäftigt“. Abgesehen davon, daß sie nun weiterbeschäftigt werden könnten, hätten sie dem Land zusätzlich noch eine SMAD-Prämie von 40000,- Mark erbracht, da die sächsische Finanzabteilung bei der Eintreibung der Steuerrückstände im zonalen Vergleich gut abgeschnitten habe. Ein Jahr nach der Kapitulation hatten sich die Zeiten geändert: Die Entnazifizierung war beendet, und die Entlassung von ehemaligen Nazis wurde weder gefordert noch gelobt. Statt dessen standen fachliche Funktionstüchtigkeit und administrative Effizienz hoch im Kurs. Nicht die Entnazifizierung, sondern die Wiedergewinnung der ,Normalität‘ war Prämien wert.

Seit 1946 richtete sich das Interesse der politischen Herrscher zunehmend auf die Reaktivierung von Organisationen und Institutionen, die im Laufe des Krieges und der Besetzung ihre Tätigkeiten eingestellt hatten. Nachdem 1945 die quasistaatlichen Verwaltungsorgane wieder aufgebaut worden waren, ging es nun darum, „das normale Leben der Bevölkerung wieder in Gang zu bringen".$^{8}$ Beispielsweise etablierten sich die Parteien als privilegierte politische Subjekte so weit, daß im Januar mit der Liberal-Demokratischen Partei (LDP) Mecklenburg-Vorpommerns auch der letzte Landesverband gegründet war; in fast allen Schulen der SBZ begann am 1. Oktober 1945 wieder der Unterricht, ${ }^{9}$ die Besatzungsmacht genehmigte im Januar und Februar 1946 die Wiedereröffnung der beiden Universitäten des Landes in Rostock und Greifswald, ${ }^{10}$ und seit Anfang

sonal- und Entnazifizierungspolitik vor dem Herbst 1947, die bis dahin fast ausschließlich in den Händen der Sowjets und der Landes- bzw. Provinzialverwaltungen lag.

${ }^{8}$ Beschluß der KPD-Reichskonferenz vom 2./3. 3. 1946 über "die nächsten Aufgaben der KPD beim Neuaufbau Deutschlands“ (Institut für Marxismus-Leninismus beim ZK der SED, Geschichte, Bd. 6, S. 403).

9 Anweiler, Schulpolitik, S. 21-26; Um ein antifaschistisch-demokratisches Deutschland, S. 128ff.

${ }^{10}$ MLHA, MinPräs 1459, Bl. 140f., 144f.; MLHA, MinPräs 1463, S. 75f. In Greifswald sollten eine philosophische, medizinische, landwirtschaftliche und theologische Fakultät eingerichtet, in Rostock Philosophie, Theologie, Landwirtschaft und Jura gelehrt werden. NSDAP-Mitglieder und ehemals aktive HJler blieben ausgeschlossen; die Landesverwaltung hatte die von den Rektoren vorgeschlagenen Lehrenden und Studierenden zu prüfen und mit einer eigenen Beurteilung der Besatzungsmacht vorzulegen. Ein Verzeichnis der seit 1945 aus der Universität Greifswald ausgeschiedenen Lehrkräfte von 1946 zählt 103 Personen auf, von denen als Begründung 46mal „Pg“ angegeben wurde; etwa 15 waren geflohen oder nicht zurückgekehrt, und zwölf Personen hielten sich in einer westdeutschen Stadt auf. Die entsprechende Liste aus Rostock nannte fünfzig Personen, von denen dreißig Pgs waren, einige als Soldaten ,aus dem Wehrdienst nicht zurückgekehrt", einige geflüchtet und einige gestorben seien; nur zwei lebten in einer westdeutschen Stadt (MLHA, MfV 2419, Bl. 8-12). Zur Wiedereröffnung und der Nachkriegsgeschichte der Universitäten siehe auch: Wissenschaftliche Zeitschrift der Wilhelm-Pieck-Universität Rostock. GReihe, Jg. 35 (1986) Nr. 1, S. 1-82; Wissenschaftliche Zeitschrift der Ernst-Moritz-Arndt-Universität Greifswald. Gesellschafts- und Sprachwissenschaftliche Reihe, Jg. 23 (1974) Nr. 3/4. 
1946 wurden auch wieder Volkshochschulen, ${ }^{11}$ Berufsschulen ${ }^{12}$ und technische Berufsschulen ${ }^{13}$ eingerichtet. Dabei ging es ebenso wie bei den Universitäten und Schulen und den nicht nur Flüchtlingen angebotenen Umschulungs-, Aus- und Weiterbildungsmöglichkeiten ${ }^{14}$ um die Ausbildung qualifizierter Arbeitskräfte als Ausgleich für die im ,Dritten Reich' gestorbenen oder seitdem in den Westen geflohenen, internierten oder mit Berufsverbot belegten Fachkräfte. Entsprechend begründeten die SMAD-Befehle die Eröffnung beider Universitäten mit der „Vorbereitung deutscher hochqualifizierter Kräfte, die fähig sind, die demokratischen Grundlagen zu verwirklichen". Aber auch andere gesellschaftliche Bereiche zeugen von der wiedergewonnenen Routine und Normalisierung. Der SMAM-Befehl Nr. 42 vom 9. März $1946{ }^{15}$ verordnete eine Bestandsaufnahme der Literatur und die Überprüfung des Personals zur Wiedereröffnung der Bibliotheken im Lande; im September wurde „in Übereinstimmung mit dem Gesetz des Alliierten Kontrollrates Nr. 33 vom 20. Juli 1946“ in der ganzen SBZ eine Volkszählung angeordnet, ${ }^{16}$ deren Funktion der eines neuen Gemeindeverzeichnisses in MecklenburgVorpommern glich, das alle Städte, Kreise und Gemeinden samt Flächenangabe und Bevölkerungszahl aufführt: ${ }^{17}$ Diese Erfassung war Teil der Systematisierung und Sicherung der neuen Herrschaft, weil sie einen besseren Überblick schuf und den administrativen Zugriff auf das erst 1945 neu geschaffene Land vereinfachte. Diverse Arbeitsberichte einzelner Dienststellen, die Warnke am 5. Juni 1946 für einen Vortrag Höckers bei der SMAD anläßlich des ersten Jahrestages der Landesverwaltung angefordert hatte, ${ }^{18}$ belegen ebenfalls die zunehmende Effektivierung der administrativen und politischen Arbeit in den unterschiedlichen Ressorts. ${ }^{19}$ Ein deutliches Beispiel dafür lieferte die Feststellung der Polizei, daß auch ihr Beitrag „bedeutsam für die Normalisierung des Lebens“ sei, weil sie „durch die Einführung der Verkehrspolizei dazu beigetragen [habe], die Verkehrsdisziplin der Bevölkerung wiederherzustellen“.20

Diese ,Normalisierung' hatte auch ihre Kehrseite: Deviantem und mißliebigem Verhalten wurde mit zunehmender Schärfe die wachsende Macht der neuen Funktionsträger, vor allem der KPD, entgegengesetzt. Dies galt nicht nur parteiintern und innerhalb der Verwaltungen, sondern auch in der allgemeinen Öffentlichkeit. Die KPD demonstrierte damit ihren großen politischen Einfluß, ihre wachsende Sicherheit und ihre

${ }^{11}$ Der SMAM-Befehl Nr. 15 vom 30. 1. 1946 ordnete ihre Eröffnung in Schwerin, Rostock, Güstrow, Greifswald, Stralsund und Wismar an (MLHA, MinPräs 1463, Bl. 40).

12 SMAM-Befehl Nr. 43 vom 9. 3. 1946 (MLHA, MinPräs 1473).

${ }^{13}$ SMAD-Befehl Nr. 49 vom 12. 2. 1946 (MLHA, MinPräs 1459, Bl. 231f.).

${ }^{14}$ Siehe z. B. MLHA, MdI 31, Bl. 2-11. Auch der fast vollständige Abbau der Arbeitslosigkeit im Lande unterstreicht diesen ,Normalisierungstrend', denn Mecklenburg-Vorpommern zählte nach Angaben des Leiters des Landesarbeitsamtes, Carl Moltmann, zu Kriegsende 300000 Arbeitslose und ein Jahr später nur noch 20929 (MLHA, MdI 31, Bl. 9).

${ }^{15}$ MLHA, MinPräs 1463, Bl. 150b; das Blatt liegt zwischen $\mathrm{Bl}$. 150 und $\mathrm{Bl} .151$ und ist unpaginiert.

${ }^{16}$ SMAD-Befehl Nr. 277 vom 13. 9. 1946 (MLHA, MinPräs 1459a, Bl. 247ff.).

17 MLHA, MinPräs 201; Statistisches Landesamt, Gemeindeverzeichnis.

18 MLHA, MdI 31, Bl. 46.

${ }^{19}$ Einige Berichtsthemen: Sozialversicherung, Jugendfürsorge, Kinderheimfürsorge, Landesausschuß ,Opfer des Faschismus', Wiederaufbauamt (später: Landesbauamt), Gesundheit; Polizei; Verkehrsabteilung; Personalamt, Allgemeine und Innere Verwaltung; Umsiedler (MLHA, MdI 31, Bl. 2-180).

${ }^{20}$ MLHA, MdI 31, Bl. 2-180, Zitat Bl. 74. 
Kompetenz, die Regeln des politischen Lebens festzulegen. Nachdem 1945 zahlreiche alte Strukturen der deutschen Gesellschaft aufgebrochen worden waren, ging es nun um die Sicherung dieser Veränderungen. Dabei geriet die KPD trotz der demokratischen Volksfrontprogrammatik, durch die sie die Zusammenarbeit mit anderen politischen Kräften suchte, schon früh wieder in ihre alten Dichotomien, mit denen sie Gesellschaft nur in den Kategorien von Freund, Feind und Kampf wahrnehmen konnte. Beispielhaft ist der Aufruf der KPD-Landesleitung vom 9. Februar $1946^{21}$ an alle Kreisleitungen zum „Kampf gegen provokatorische Gerüchte“: Durch „offensives Auftreten der Kommunisten und Sozialdemokraten und aller übrigen Aktivisten“ seien die Gerüchte zu bekämpfen, ihre „Urheber“ ausfindig zu machen „und zur Verantwortung [zu] ziehen“. Da Stimmungen aber nicht mit administrativen Maßnahmen zu ändern waren, forderte die Landesleitung von ihren Subalternen, Schwierigkeiten und Gerüchte in öffentlichen Versammlungen anzusprechen, damit „die Kraft und die Zuversicht, von der die Kommunisten erfüllt sind, auf die Bevölkerung ausstrahle“.

Die Furcht vor Gerüchten entsprang keiner Einbildung, sie kursierten tatsächlich. In einem Stimmungsbericht für die KPD-Landesleitung22 wurde beispielsweise im Februar 1946 unter der eigenen Rubrik „Gerüchte“ festgehalten, daß behauptet werde, daß „alle jungen Mädchen von 14-21 Jahren [...] neuerdings nach Rußland verschickt" würden, dagegen „der Termin für den 2. Februar für den Abzug der Roten Armee aus Mecklenburg [...] nicht mehr erwähnt" werde. Beide Phantasien standen in einem eindeutigen Verhältnis zu den persönlichen Erfahrungen und Wünschen der Bevölkerung, waren aber durch örtliche Versammlungen nur schwer aufzulösen. Sie richteten sich weniger gegen Mißwirtschaft, Korruption, mangelhafte Ernährungslage oder andere Probleme vor Ort als vielmehr gegen die Besatzungsmacht und andere tragende Pfeiler der neuen gesellschaftlichen Ordnung. Da diese nicht zur Disposition stand, wurden abweichende Haltungen oder Meinungen nicht konkret behandelt, sondern nur als ausreichende oder ungenügende Loyalität zum Neuaufbau in der SBZ bewertet: So beurteilten die Kommunisten ,Gerüchte' als ,Sabotage', die die Grundlagen der neuen ,Normalität' in Frage stellten. Entsprechend dieser Politisierung der Kritik im Zeichen der sich teilenden Welt erwogen sie weniger konkrete Maßnahmen zur gesellschaftlichen Veränderung als vielmehr rigorose Maßnahmen der politischen Gegenwehr.

Diese Art der Auseinandersetzung wurde erfolgreich an die Basis vermittelt. Die KPD-Kreisleitung Demmin klagte am 21. März $1946^{23}$ gegenüber der Landesleitung über die Unsicherheit im Kreis, für die die Verantwortlichen bereits ausgemacht waren: „Außerdem hat die Polizei noch nichts gegen die Gerüchtemacher unternommen, welche aus der Westzone hier in unsere Zone zum Besuch kommen und dann wieder zurückreisen. Die Partei ist letzten Endes keine Polizei, aber sie muß verlangen, daß der Staat nicht von Elementen der Westzone am Aufbau gestört wird, und daß die Polizei alles daran setzt, um dieses zu verhindern. "Diese Wahrnehmung entsprach der neuen $\mathrm{Li}_{\mathrm{i}}$ nie: Nicht mehr Nazis und Faschisten wurden gesucht, sondern nunmehr stand die Gefahr im Westen. Selbst in diesem von der Zonengrenze weit entfernten vorpommerschen

${ }^{21}$ MLHA, LL KPD I/5, Bl. $231 \mathrm{f}$.

22 MLHA, LL KPD I/22, Bl. 289.

${ }^{23}$ MLHA, LL KPD I/10. 
Kreis und trotz der anhaltenden Schwerfälligkeit des Verkehrssystems wurden antikommunistische Propaganda auf Schaufensterscheiben und andere Unmutsäußerungen nicht auf die Unzufriedenheit der eigenen Bevölkerung, sondern auf agitatorische Polittouristen aus dem Westen zurückgeführt. Daher wurden regelmäßige Kontrollen durch die bislang zu wenig engagierte Polizei vorgeschlagen: „in Zivil“ und „insbesondere bei verdächtigen Personen".

Diese Wahrnehmung unerwünschter Meinungen und abweichenden Verhaltens in ausschließlich dichotomen Kategorien des Kampfes gab es nicht nur in der allgemeinen Öffentlichkeit. Noch stärker ausgeprägt war sie in den Verwaltungen, da von ihnen als ausführenden Organen der neuen Herrscher eine noch höhere Loyalität erwartet wurde als von der restlichen Bevölkerung. ${ }^{24}$ Zur Durchsetzung dieser verwaltungsinternen Loyalität und gegen unliebsames Verhalten wurden aber nicht nur Entlassungen im Zuge der Entnazifizierung eingesetzt. Der Bruch mit dem alten Staatsapparat aus großherzoglichen Zeiten, der Weimarer Republik und dem ,Dritten Reich' sollte sich „strukturell, personell und arbeitsmethodisch “25 bemerkbar machen. Darum veränderten sich fast gleichzeitig mit den Entlassungen die Auswahlkriterien für das neue Personal und das Anforderungsprofil an sämtliche Dienstkräfte. Es ging um mehr als den bloßen Personalwechsel; er war das Vehikel zur Durchsetzung eines neuen, an kommunistischen Parteitraditionen orientierten und für die, Volksdemokratien` des zwanzigsten Jahrhunderts maßgeblichen Verwaltungstyps.

\section{Bürokratie und Sozialismus}

Der gesellschaftlichen ,Normalisierung' entsprach die Veralltäglichung der Herrschaft. Wie sich in den ersten Nachkriegstagen gezeigt hatte, bedurfte die Etablierung der Herrschaft mit so ehrgeizigen Umgestaltungsvorhaben und in einem so umfangreichen Territorium eines stabilen Verwaltungsapparates. Die administrative Bewältigung der Probleme der Zusammenbruchgesellschaft war in der SBZ und Mecklenburg-Vorpommern durch die sozialen und politischen Umgestaltungen und die erweiterten Landesgrenzen nicht einfacher geworden. Eine besondere Behinderung verwaltungstechnischer Effizienz stellte aber das Verwaltungspersonal selbst dar, das zum größten Teil unzulängliche, zum Teil überhaupt keine Erfahrungen und Kenntnisse in den Tätigkeiten hatte, die ihm nun übertragen waren.

Das Ausmaß der Probleme, die hohe Geschwindigkeit der gesellschaftlichen Umgestaltungen und das unerfahrene Personal machten eine klassische Bürokratie mit ihrer durch hierarchische Strukturen, Entscheidungsdifferenzierung und Kontrollmechanismen geprägten schwerfälligen und langwierigen Arbeitsweise unmöglich, da schnelle Entscheidungen benötigt wurden. Warnke formulierte dies als Priorität der politischen Ausrichtung vor der fachlichen Kompetenz und stimmte vor seinen Mitarbeitern wiederholt das hohe Lied des Aktionismus, der Entscheidungsfreude und der Improvisationsbereitschaft an. Beispielsweise wurde bei den ersten Landaufteilungen im Rahmen der Bodenreform mehr Wert auf die politische Mobilisierung als auf die geographische

\footnotetext{
${ }^{24}$ Fulbrook, Herrschaft, S. 84; Lepsius, Probleme, S. $98 f$.

${ }^{25}$ Schöneburg, Staat, S. 55.
} 
Präzision und exakte Dokumentation gelegt, da die große Anzahl von Landvermessern nicht in den wenigen Tagen zwischen der Ankündigung der Bodenreform und dem Beginn der Parzellierungen zu rekrutieren war. Auch die Sequestrierungen verlangten von den verantwortlichen Bürgermeistern, Landräten und Kommissionen mehr Engagement im Bereich von Sozialpolitik und Antifaschismus als Kenntnisse der juristischen Verordnungen oder formalen Belastungskriterien. ${ }^{26}$ Außerdem fehlte dem neuen Personal meistens die Kenntnis der traditionellen Regeln bürokratischer Arbeit. Weil es zuvor häufig Arbeiten verrichtet hatte, in denen ganz andere Qualifikationen gefragt waren „Treckerfahrer Wilhelm D. als Bürgermeister eingesetzt ${ }^{\text {“ }}$-, konnte es sie auch nicht schnell lernen und praktizieren.

Die neue administrative Arbeitsweise entsprach in vielem jener der vorhergehenden Verwaltung. Die Verantwortlichen verfaßten beispielsweise zahllose Schriftstücke, arbeiteten an Schreibtischen, standen in Hierarchien, wurden kontrolliert und führten die Tätigkeiten hauptberuflich aus. All dies gleicht den Beschreibungen von bürokratischem Handeln, die Max Weber Anfang dieses Jahrhunderts vorlegt hat. 1919 gestorben, hatte er sich in seinen Arbeiten stark an der Verwaltung im deutschen Kaiserreich orientiert und keine umfassenden Analysen zu Politik und Verwaltung sozialistischer Gesellschaften vorgenommen. Seine Auseinandersetzung mit sozialistischen Alternativen bezog sich vorwiegend auf den Hang zur Bürokratisierung, der sich bereits früh in den Organisationen dieser etatistisch ausgerichteten Parteien abzeichnete. Obwohl immer wieder Korrekturen an ihr formuliert werden, bleibt Webers Beschreibung der „organisatorische[n] Struktur“ des Verwaltungstyps Bürokratie „richtungweisend“:27 Bürokratie findet als kontinuierlicher und regelgebundener Betrieb in einer durch sachliche Grenzen und beschränkte Befehlsgewalten bestimmten „Behörde“ statt; die „gesatzten Regeln“ bilden eine unpersönliche Ordnung, an die auch die Vorgesetzten gebunden sind. Zur Anwendung der Regeln sind fachlich geschulte Beamte nötig. Durch das „Prinzip der Amtshierarchie" steht jede Behörde in einer „Ordnung fester Kontroll- und Aufsichtsbehörden [...] mit dem Recht der Berufung oder Beschwerde“. Es gibt keine Appropriation von Amtsstellen; Ausnahmen wie bei Richtern dienen „der Sicherung der rein sach-

${ }^{26}$ Beispielhaft für diesen Aktionismus und die schnelle, zuweilen überstürzte Handlungsweise ist ein Vorfall in Güstrow, wo sich der 22jährige Oberbürgermeister und NKFDler, Klaus Sorgenicht, im November 1945 persönlich darum kümmerte, ausreichend Personen für die Entladung von Getreide für die Besatzungsmacht zwangszuverpflichten. Dafür wählte er die Mitarbeiter des zu spät informierten Arbeitsamtes aus, die seinen Ärger so sehr erregten, daß er den 62jährigen erkrankten Arbeitsamtsleiter aus dem Bett holte und dann verhaften und ebenfalls zur Arbeit zwangsverpflichten lassen wollte. Obwohl sich der Betroffene bei Warnke über diese Vorgehensweise beschwerte, behielt Sorgenicht, dem noch eine politische Karriere in der DDR bevorstehen sollte, weiterhin die volle Unterstützung aus Schwerin (MLHA, MdI, 197, Bl. 119ff.).

${ }^{27}$ Lipp, Bürokratie, S. 9; Eisenstadt/von Beyme, Bürokratie, Sp. 958; Mayntz, Idealtypus; Schluchter, Bürokratie, S. 81. Lipp, Bürokratien und Kader, S. 252f., weist in seinen Studien zu unterschiedlichen Typen administrativer Organisationen darauf hin, daß soziale Steuerung niemals „nur in zugespitzter, funktional vereinseitigter Form [...] auftritt“. Die Leitungen administrativer Apparate belegen dies besonders augenfällig: Wie sich in den volksdemokratischen Staaten und auch in der SBZ deutlich zeigte, steht , an der Spitze unvermeidlich ein mindestens nicht rein bureaukratisches Element" (Weber, Wirtschaft, S. 127; ähnlich Weber, Typen, S. 477, 484). Weber beschreibt ausdrücklich eine idealtypische Bürokratie; zum Nutzen und Nachteil des methodischen Mittels des ,Idealtypus' siehe Weber, Wirtschaft, S. 4, 10; Weber, Aufsätze, S. 190-210. 
lichen (,unabhängigen"), nur normgebundenen Arbeit". Verwaltungs- und Beschaffungsmittel, Amts- und Privatvermögen sowie die Arbeits- und Wohnstätte sind grundsätzlich voneinander getrennt. Durch das „Prinzip der Aktenmäßigkeit" werden alle Vorgänge schriftlich festgehalten. „Akten und kontinuierlicher Betrieb [...] ergeben zusammen: das Bureau, als den Kernpunkt jedes modernen Verbandshandelns. "Das Personal wird nach Fachqualifikation und „kraft Kontrakts, also (prinzipiell) auf Grund freier Auslese“ angestellt, erhält „feste Gehälter in Geld, meist mit Pensionsberechtigung"; der Vertrag ist stets kündbar von seiten des Beamten, teilweise kündbar von seiten des Herrn. Das Amt ist der Hauptberuf, und die Laufbahn bestimmt sich nach Leistungen und/oder Amtsalter. Der „,ideale Beamte“ waltet „sine ira et studio, ohne Haß und Leidenschaft, [...] ,ohne Ansehen der Person', formal gleich für ,jedermann““.28

Nicht nur organisatorische und personelle Schwierigkeiten verhinderten die Übernahme dieses Modells in der SBZ, sie war auch politisch nur begrenzt intendiert. Neben der Summe der aufgezählten Kriterien zeichnet den Weberschen Idealtyp von Bürokratie noch sein generelles Verhältnis zur Gesellschaft aus, das die ,Modernität' sowohl der Bürokratie als auch der Gesellschaft auf die Probe stellt: „Bürokratisches Handeln impliziert, systemtheoretisch verallgemeinert, daß die $\mathrm{Z}$ wecke der Organisation gegenüber Störgrößen der, äußeren ' wie insbesondere der, inneren' Umwelt [...] weitgehend abgeschirmt und neutral verfolgt werden können. An die Stelle korruptionistischer, nepotistischer etc. Tendenzen treten Sachorientierungen; an die Stelle personengebundener, offener Durchsetzungs- und Aufstiegskämpfe treten geregelte, im Prinzip kalkulierbare Karriereverläufe."29 Diese Art der Verwaltung, die Eigengesetzlichkeit und Abschirmung nach außen bedeutet, zeichnet die "spezifisch moderne Form der Verwaltung“ aus. ${ }^{30}$

Die KPD, die sich gezielt und schon zu Beginn der Besatzung für die Personalpolitik verantwortlich machte, stand ebenso wie die Besatzungsmacht in einer anderen Tradition administrativer und auch politischer Arbeit. Diese war weniger durch gewachsene Verwaltungsapparate schon lange bestehender Staaten als durch die Erfahrungen der kommunistischen Parteien im teilweise illegalen politischen Kampf und beim Aufbau der Sowjetunion bestimmt. Daher zielte der Neuaufbau in der SBZ auf eine Übernahme des sowjetischen Verwaltungstyps, dem die Mitglieder und Strukturen der KPD als Teil der internationalen kommunistischen Bewegung bereits seit den zwanziger Jahren und besonders im sowjetischen Exil angepaßt worden waren.

Kaderverwaltungen in ,Volksdemokratien" zeichnet eine Dimension aus, die der Beurteilung von Bürokratie durch Karl Marx entspringt und eine Tradition der linken antibürokratischen Polemiken prägte. ${ }^{31}$ Marx hat Bürokratie im Kapitalismus als Exempel

${ }^{28}$ Zitate aus Weber, Wirtschaft, S. 124-130; siehe auch ebenda, S. 551-579.

${ }^{29}$ Lipp, Bürokratie, S. 10, Anmerkung 24.

${ }^{30}$ Weber, Wirtschaft, S. 124. Diese Eigengesetzlichkeit und die mit der starken Bürokratisierung verbundene hochgradige Arbeitsteilung markieren die Modernität der betroffenen Gesellschaften. „Wie der sogenannte Fortschritt zum Kapitalismus [...] der eindeutige Maßstab der Modernisierung der Wirtschaft, so ist der Fortschritt zum bürokratischen [...] Beamtentum der ebenso eindeutige Maßstab der Modernisierung des Staates" (Weber, Wirtschaft, S. 825; siehe ähnlich Weber, Typen, S. 477).

${ }^{31}$ Allerdings sind antibürokratische Ressentiments ein „probates Herrschaftsmittel aller bürokratischen Regime: Die einzelnen Bürokraten können sich nie sicher fühlen, solange die Spitze in der 
der gesellschaftlichen und individuellen Entfremdung analysiert: als Organ des staatlichen Zugriffs auf die Menschen und als Beispiel für die hochgradige Arbeitsteilung und Reduktion menschlicher Arbeit auf wenige Tätigkeiten..$^{32}$ Gegen die täglich gleiche und sehr beschränkte Beschäftigung setzte er die Utopie der allseitig gebildeten und tätigen Menschen. Die Kaderverwaltung entstand unter dem Anspruch dieser Entfremdungskritik und dieses Humanisierungsideals: „Faßt man das Selbstbild zusammen, so ist Kaderorganisation zunächst von einem forcierten, antibürokratischen Affekt getragen: [...] ihr Leitbild ist es, gegen rein technische Verwaltung, also ,Fachidiotie (Marx), Humanisierungsprozesse einzuleiten; gegen Arbeitsteilung und ,Partialisierung' schlechthin gewendet, wie sie bürokratisch geregelte Lebensprozesse betreffen, ist sie bestrebt, menschlich-soziale ,Allseitigkeit' herzustellen." ${ }^{33}$

Ganz offensichtlich beurteilen Weber und Marx die Folgen gesellschaftlicher Arbeitsteilung grundlegend unterschiedlich: Während Marx sie als Entfremdung beschreibt, die er im Ideal einer kommunistischen widerspruchsfreien Gesellschaft aufgehoben sehen möchte, bestimmte Weber sie als Beleg für moderne, nämlich ausdifferenzierte Gesellschaften. ${ }^{34}$ Weber postulierte dabei den Primat der differenzierten Fachaufgaben und unterschiedlichen Logiken der gesellschaftlichen Bereiche und negierte eine der $\mathrm{Ge}-$ samtgesellschaft übergeordnete Instanz, Ideologie oder Logik. Marx' Kritik verband das Ende der Bürokratie mit seinem Ideal eines letztlich harmonischen Ausgleichs der gesellschaftlichen Widersprüche. In den Mittelpunkt des Interesses rückten infolge dieser unterschiedlichen Beurteilung bei Weber primär administrative Funktionalität und technische Qualität zur Lösung von fachlichen Problemen, beim Marxismus hingegen, besonders seit Lenin, stärker die Fragen der Herrschaft und des von Marx hervorgehobenen Humanisierungsideals.

Das zentrale Instrument in Lenins Vorstellungen gesellschaftspolitischer Veränderungen war die Partei, die die Gesellschaft zu revolutionieren hatte. Mit dieser Aufgabe bezeichnete Lenin gleichzeitig eine bestimmte Form der Herrschaft, denn sein „Modell steht und fällt mit [...] der Frage, wie die Menschen diesen Transmissionsprozeß organi-

Lage ist, antibürokratische Säuberungskampagnen anzuzetteln“ (Krätke, Bürokratie, S. 420; siehe Thamer, Verführung, S. 355).

32 Marx, Brumaire, S. 196f., beschreibt die Arbeit der „ungeheuren bürokratischen und militärischen Organisation, mit ihrer weitschichtigen und künstlichen Staatsmaschinerie", als "fabrikmäßig geteilt und zentralisiert“". Ebenso wie in der Manufaktur "verkrüppelt" diese Arbeitsteilung „den Arbeiter in eine Abnormität, indem sie sein Detailgeschick treibhausmäßig fordert durch Unterdrückung einer Welt von produktiven Trieben und Anlagen" (Marx, Kapital, S. 381). Dazu ausführlich Balla, Kaderverwaltung, S. 16-42, besonders S. 36-42, und Krätke, Bürokratie, S. 405-415; siehe auch Krätke, Beamte, S. 89f.; Lazzeri, Arbeitsteilung; Robelin, Bürokratie; Schwarzenbach, Kaderpolitik, S. 15f.

${ }^{33}$ Lipp, Bürokratie, S. 17. Der Versuch von Balla, Kaderverwaltung, S. 7ff., die Humanisierung neben der Lösung von Fachproblemen und der Herrschaftssicherung zur dritten, alle Verwaltungen betreffenden Dimension zu erklären, ist wenig überzeugend, da sie primär zur Verwaltungs-

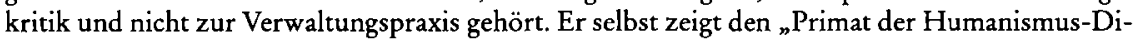
mension" vor allem im Marxschen Denken und verdeutlicht ihren Bedeutungsverlust in marxistischer, vor allem leninistischer Verwaltungspraxis (Balla, Kaderverwaltung, S. 36; Balla, Bürokratische, S. 108-111; ähnlich Balla, Kaderverwaltung, S. 14).

34 Zu Weber siehe Balla, Kaderverwaltung, S. 47-62; Balla, Bürokratische, S. 104ff.; Mayntz, Bürokratie; Mayntz, Idealtypus; Schluchter, Aspekte. 
sieren und wie sie in ihm organisiert werden ". ${ }^{35}$ Mit dieser Priorität vernachlässigte Lenin den utopisch-kritischen Zug des Marxschen Universalismus und suchte statt dessen die Effizienz der Partei durch Organisation, Arbeitsteilung und Spezialistentum zu steigern. ${ }^{36}$ Die kommunistische Partei einer der am wenigsten modernen Gesellschaften Europas entwickelte damit Elemente (,Berufs'-Revolutionäre, Hierarchien, lebenslängliche ,Anstellung', Arbeitsteilung und Spezialisierung, Besoldung, Ablehnung des Wahlbeamtentums etc.), die Weber als Teile moderner Verwaltungsapparate beschrieben und Marx als Entfremdungsphänomene analysiert hatte: Lenin, der „Revolutionär mit bürokratischem Geist“. ${ }^{37}$

Nach der Revolution wurde das Kaderkonzept der bolschewistischen Partei auf den Staatsapparat der jungen Sowjetunion übertragen, ${ }^{38}$ deren Verwaltung sich bis in die zwanziger Jahre vor allem während des Bürgerkriegs auch mit Aufgaben beschäftigen mußte, die denen der Bürokratien in den mitteleuropäischen Ländern wenig glichen. Während Lenins Konzept von Bürokratie aber noch offen war, weil die Revolution auch in den anderen europäischen Ländern erwartet wurde, zerschnitt Stalins Konzept des ,Sozialismus in einem Land' jeden konkreten Bezug zur Idee universaler Humanisierung und erklärte die gegenwärtige zur besten aller möglichen Welten. Auch die Bürokratie war in diesem System festgelegt. Politik und Bürokratie strebten nunmehr nicht mehr nach einer Aufhebung des spezialisierten und arbeitsteiligen Verwaltungstyps, sondern ordneten sich in ihrer Arbeit und Zielsetzung vollkommen der kommunistischen Partei unter. ${ }^{39}$ Der Staatssozialismus hatte das kritische Potential des Humanisierungsideals stillgelegt. Jeder war wieder „Jäger, Fischer oder Hirt oder kritischer Kritiker und muß[te] es bleiben“, während doch verheißen gewesen war, daß im Kommunismus „die Gesellschaft die Produktion regelt und mir möglich macht, heute dies, morgen jenes zu tun, morgens zu jagen, nachmittags zu fischen, abends Viehzucht zu treiben, nach dem Essen zu kritisieren, wie ich gerade Lust habe" ${ }^{40}$

Lenins Unterordnung der Kaderverwaltung unter eine ausschließlich von der Partei vertretene und aufgezeigte Universalität bestimmte nach der Regierungsübernahme durch die kommunistische Partei - seit 1917 in Rußland ebenso wie seit 1945 in der SBZ - das Verhältnis zwischen der Herrschaftssicherung und der Bewältigung von sachli-

${ }^{35}$ Balla, Bürokratische, S. 106; Schwarzenbach, Kaderpolitik, S. 17ff.; Rudolph, Kader, S. 124.

${ }^{36}$ Er würdigte die „Arbeitsteilung, die, wie allgemein anerkannt, eine der lebenswichtigsten praktischen Erfordernisse unserer Bewegung ist“, als Voraussetzung, „alle Räder und Rädchen der Parteimaschine" zentralistisch anleiten und überwachen zu können (Lenin, Brief, S. 241).

${ }^{37}$ Meyer, Leninism, S. 98. Lenin entwarf diese Anforderungen unter den Bedingungen des konspirativen Kampfes gegen den zaristischen Repressionsapparat; dennoch erklärte er sie in seinen Schriften zu allgemeinen Tugenden und bereitete so ihre Übernahme in die Zeit nach der Revolution vor. Siehe z. B. die Aufzählung dieser Elemente in seiner berühmtesten Organisationsschrift, in der er an der Akzeptanz dieser Grundsätze die „Schlauköpfe" von den „Dummköpfen " unterschied; gleichzeitig legte er damit auch die Priorität der Effizienz gegenüber der Demokratie fest (Lenin, Was tun?, S. 478-481). Marx' Kritik an der „Fachidiotie“ bezogen die neuen Parteibürokraten nicht auf sich selbst, weil sie sich durch das Ziel ihrer revolutionären Tätigkeit als Träger von universaler Humanisierung verstanden.

${ }^{38}$ Zur historischen Entwicklung des Kaderbegriffs siehe Müller, Kader; zu seiner Geschichte innerhalb der KPD siehe Zimmermann, Überlegungen, besonders S. 351ff.

${ }^{39}$ Siehe zu dieser „Ontologisierung der Avantgardekonzeption“ Glaeßner, Herrschaft, S. 65-73.

${ }^{40}$ Marx/Engels, Ideologie, S. 33; siehe auch Marx, Kapital, S. 512. 
chen Problemen als den beiden traditionellen Aufgaben von Verwaltung: Die Lösung von Fachaufgaben wurde der Sicherung der Parteiherrschaft nachgeordnet; ihr kam die oberste Priorität zu, der sich alles andere, auch die fachliche Qualifikation und die Utopie einer Humanisierung der Gesellschaft unterzuordnen hatte.

In der SBZ gründete die Vormachtstellung der Kommunistischen Partei gegenüber der Verwaltung in ihrem engen Bündnis mit der Besatzungsmacht, welche - genauso wie die westlichen Alliierten - ihr eigenes administratives System, nämlich die aus dem Leninismus gewachsene Kaderverwaltung, auf ihre Besatzungszone übertrug. Als Bündnispartner stand dabei die KPD/SED zur Verfügung, die in die internationale Hierarchie der kommunistischen Parteien eingebunden war und daher auch an deren Macht und Erkenntnis teilhatte. Obwohl die Verwaltungen infolge der Zunahme gesellschaftlicher Regelungskompetenz des Staatsapparates und seines Dualismus mit der hegemonialen Partei quantitativ ständig anwuchsen, ${ }^{41}$ reduzierte sich ihre Rolle auf die eines bloß ausführenden Organs der Partei: „Die allgegenwärtige Möglichkeit von ,außerordentlich”, das heißt parteimäßig motivierten Entscheidungen beraubt die Bürokratie ihrer in Sachkompetenz verankerten überparteilichen Autonomie und verwandelt sie [...] in ein bloßes Instrument einer im Prinzip nicht kalkulierbaren Macht." ${ }_{42}$

Diese "Privatisierung des Staates "43 wurde in Mecklenburg-Vorpommern besonders deutlich, weil dort eine ausgebildete Parteiorganisation fehlte, ${ }^{44}$ so daß sich die KPD/ SED vorerst damit begnügte, den Regierungs- und Verwaltungsapparat unter die Kontrolle eines ihrer loyalen Mitglieder, Warnke, zu bringen. ${ }^{45}$ Die von der Partei ge-

${ }^{41}$ Dies zeigte sich schon im Laufe der ersten Monate und Jahre der Volksdemokratien; für Mecklenburg-Vorpommern siehe den statistischen Anhang.

${ }^{42}$ Srubar, Sozialismus, S. 419; siehe auch Lepsius, Institutionenordnung, S. 18.

${ }^{43}$ Srubar, Sozialismus, S. $418 \mathrm{ff}$., unterscheidet zwischen der „erste[n] Stufe der Privatisierung des Staates im realen Sozialismus, die wir die politische Privatisierung nennen können" und die "durch das Machtmonopol herrschender kommunistischer Parteien“ durchgesetzt wird, und der zweiten Stufe, „die man als persönliche Privatisierung bezeichnen kann; sie vollzieht sich in Gestalt der Korruption und der Patronage“.

${ }^{44}$ Mecklenburg-Vorpommern wurde in der KPD/SED immer wieder als organisatorisches Sorgenkind der Partei genannt; siehe z. B. das Protokoll der Arbeitstagung der Organisationsleiter und Kassierer der Landes- und Provinzialvorstände am 13. und 14. 8. 1946“ in Berlin (SAPMO-BA, DY 30/IV2/5, 62, besonders B1. 31ff.; ähnlich Warnke und Gottfried Grünberg am 21. 10. 1946 in: MLHA, LL SED IV 2/3/77, Bl. 127f.; siehe auch die Sonderausgabe der SED-Zeitschrift Weg und Ziel. Organ für Theorie und Praxis unserer Parteiarbeit vom Oktober 1947 über „Entwicklung und Stand der Parteiorganisation von der Vereinigung bis zum 2. Parteitag“). Die von Kluttig, Mitgliederschulung, dargestellten Schwierigkeiten bei der Etablierung eines parteiinternen Schulungssystems unterstreichen den ungenügenden Aufbau der Landesparteiorganisation und zeigen, wie schwer die Kaderkonzeption in der KPD/SED zu realisieren war; zur Gründung der SED in Mecklenburg-Vorpommern siehe Malycha, Weg, S. 3-18, 117-133, 244-267, 367-392; Schwabe, Zwangsvereinigung; Voßke, Hinüberwachsen; Voßke, Kampf.

${ }^{45}$ Die militärische Tradition des Begriffs, Kader' wurde nicht nur durch die Anwesenheit der Roten Armee gestärkt, sondern auch durch die Biographie Warnkes, der ebenso wie Erich Mielke, Kurt Fischer und andere Kommunisten, die in der SBZ für den Aufbau der Inneren Verwaltung zuständig waren, auf militärische und konspirative Erfahrungen zurückblicken konnte. 1923 war er von der KPD-Bezirksleitung zum militärischen Leiter des illegalen Parteiapparates in Mecklenburg-Schwerin bestimmt worden (Mühlstädt, Warnke, S. 45). Die Niederlage von 1933 wurde von vielen Kommunisten nicht als Folge der ungenügenden demokratischen Partizipation, sondern der mangelhaft ausgebauten Konspiration interpretiert. Außerdem hatte Warnke 
wünschte Landespolitik wurde durch den Verwaltungsapparat erfüllt, der ihr via Warnke ohne nennenswerte Widerstände zur Verfügung stand. Warnkes wichtigstes Mittel war der Einfluß auf das Personal. Obwohl nur selten und in geschlossenen Funktionärskreisen der KPD/SED expliziert, wurden in den staatlichen Verwaltungen bereits 1945/46 Anforderungen gestellt, die ausdrücklich in der Tradition leninistischer Parteiapparate standen. ${ }^{46}$

Trotz der Priorität politischer Vorgaben stimmte die Arbeitsweise der neuen Kaderverwaltung in zahlreichen Punkten mit der von Weber beschriebenen überein: Beispielsweise bildeten die Aktenmäßigkeit, die Trennung von Wohn- und Arbeitsstätte sowie Hierarchien und Kontrollsysteme auch dort den üblichen Standard. Das Personal mußte daher beim Aufbau der neuen Verwaltung seit 1945 zweierlei lernen: erstens die Regeln bürokratischer Arbeit, die Übersichtlichkeit, Effizienz und Produktivität sicherten, und zweitens die ausdrückliche Relativierung und Unterordnung dieser Arbeitsweise, der jeweiligen dienstlichen Ziele und der eigenen Person unter die Herrschaftssicherung und Weisungskompetenz der KPD/SED.

Bevor im folgenden die Einführung der neuen personalpolitischen Anforderungen dargestellt wird, zeigt das Beispiel einer Behörde, welche Probleme durch die Veränderungen der ersten Nachkriegsmonate auftraten und was, wie und von wem neu gelernt werden mußte. Als Beispiel für diese Anfangsschwierigkeiten wird eine detaillierte Anweisung für die Zollverwaltung vorgestellt. Die Beanspruchung dieser Behörde war zwar infolge von Krieg, Zerstörungen und Besatzung stark zurückgegangen, ganz offensichtlich war aber auch sie von den typischen Schwierigkeiten des Neubeginns geprägt. Die Finanzabteilung schickte den ihr zugeordneten Zollämtern am 4. Februar $19466^{47}$ ein umfangreiches Schreiben mit Vorschlägen zur Lösung der Personalknappheit. Sie beschreiben im Detail die Probleme und Chancen der "nachrevolutionäre[n] Aufsteigergesellschaft" der SBZ/DDR, in der "die Plätze auf der Aufstiegsleiter freigeräumt“ wurden und "für die qualifizierungsfähigen Arbeiter ein Aufwind" entstand. ${ }^{48}$ Während im Justiz- und Schulbereich schon früh eigene Ausbildungskurse angeboten wurden, zeigen die Vorschläge der Finanzabteilung die eher improvisierten, dezentralen und praxisorientierten Maßnahmen in der Verwaltung.

Abteilungsleiter Winckler legte den Schwerpunkt auf die Einstellung neuer, hauptsächlich fachfremder Kräfte. Deren Anfangsschwierigkeiten seien weniger durch theoretische Schulungen als durch die Unterstützung aller Weiterbeschäftigten zu bewältigen, weil die zolltechnischen Tätigkeiten "noch nicht derartig vielseitig sind wie zu normalen Friedenszeiten“. Zuerst seien „erfahrene Beamte des mittleren Dienstes“ in höheren Stellen einzusetzen und durch Unterweisung sowie „fleissiges Studium der Gesetzesvorschriften und der Fachliteratur fortlaufend weiterzubilden". Darüber hinaus seien

einige Jahre in Gefängnissen und im $\mathrm{KZ}$ verbringen müssen, deren stärkende Wirkung auf Selbst- und Parteidisziplin vieler Genossen Niethammer beschrieben hat (Niethammer, Antifaschismus).

${ }^{46}$ Siehe Kurt Bürgers Erläuterungen im Sekretariat des ZK der KPD im November 1945 über die Einsetzung eines neuen Leiters des Personalamtes (SAPMO-BA, RY 1/I2/5, 40, Bl. 178f.; siehe Kapitel II.2, S. 155ff.).

47 MLHA, MdI 729.

48 Niethammer, Glasnost, S. 44f. 
auch vollkommen fachfremde Kräfte für den unteren und mittleren Dienst auszuwählen und auszubilden. Um eine Konkurrenz zwischen verschiedenen Dienststellen oder eine bloße Verschiebung des Fachkräftemangels zu verhindern, wurde die Einstellung „brauchbare[r] Fachkräfte aus Mangelberufen, die sich aus eigensüchtigen Gründen für den Verwaltungsdienst melden", untersagt. Winckler nannte recht bescheidene Mindestanforderungen für die neuen Mitarbeiter: „schreibgewandt, aufnahmefähig, charakterlich gefestigt und körperlich und geistig rüstig“. Ihren Einsatz empfahl er vorwiegend in Bereichen wie der Kasse und der Geräteverwaltung, wo kein steuer- und zolltechnisches Fachwissen notwendig sei. Die langfristig auch bei ihnen unabdinglichen Spezialkenntnisse seien im Dienst durch die kollegiale Unterrichtung seitens älterer Dienstkräfte zu erwerben: „Für die Einarbeitung in die Überwachungstätigkeit in den Brennereien wird z. B. im Anschluß an die Branntweinabnahmen stets Zeit und Gelegenheit sein."49

Entnazifizierung, Westflucht und Krieg hatten den öffentlichen Dienst personell so stark ausgedünnt, daß mehr neue Mitarbeiter als jemals zuvor eingestellt wurden. Neben den praxisbezogenen Elementen wurde im Laufe der folgenden Jahre auch ein eigenes Ausbildungs- und Schulungssystem für Verwaltungsdienstkräfte ausgebaut, ${ }^{50}$ dessen Verantwortung bald beim Personalamt lag. ${ }^{51}$ Nun ging es um die Ausrichtung des neuen Personals, das von dem arbeitsmarktpolitischen „Aufwind“ und „Sog“ profitierte und zur ersten Gründergeneration der DDR wurde. ${ }^{52}$

\section{Anforderungen einer Kaderverwaltung}

Warnke teilte allen Dienststellen am 10. Januar 1946 über das Verfahren bei der Einstellung von neuem Personal mit, daß nun „in den Verwaltungen wieder eine gewisse Stabilität“ erreicht werden sollte, nachdem „die Bereinigungsaktion zu einem Abschluß gekommen ist" ${ }^{\text {" }}{ }^{53}$ Daher plädierte er - ohne parteipolitische Rhetorik - für Leistungsbereitschaft, Effizienz, eine besondere Überwachung der neu Eingestellten und ihre Ermutigung zu größerem Eifer. Da sich gewöhnlich schon nach wenigen Tagen die Tauglichkeit des neuen Personals zeige, Kündigungen und Herabgruppierungen aber nach Abschluß des Arbeitsvertrags „aus nichtpolitischen Gründen, z. B. wegen unbefriedigenden Leistungen, nur unter Innehaltung der tariflichen Kündigungsfrist“ realisierbar seien, sei „zunächst eine tägliche Kündigungsfrist zu vereinbaren“.

Die Forderung nach Effizienz und Leistungsbereitschaft richtete sich aber nicht nur gegen die Unerfahrenheit der neuen Dienstkräfte. Warnke ging es auch um die von der Besatzungsmacht immer wieder geforderte Reduzierung des Verwaltungspersonals, die Beschränkung des Landeshaushalts und den Kampf gegen ,Bürokratismus‘. Dem steti-

49 MLHA, MdI 729.

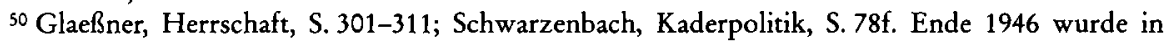
Schwerin eine Verwaltungsschule für Mecklenburg-Vorpommern errichtet, die bereits seit Jahresbeginn vorbereitet worden war (MLHA, MdI 1406; MLHA 1025; SAPMO-BA, DY 30/IV2/ 5, 84, Bl. 7-12; Seitz, Verwaltungskörper).

${ }^{51}$ Siehe Kapitel II.2.

52 Niethammer, Glasnost, S. 45.

${ }^{53}$ MLHA, MinPräs 1025. Bereits auf der Konferenz der Landräte und Oberbürgermeister im Januar 1946 tauchte die Entnazifizierung nicht mehr auf; als erster Tagesordnungspunkt wurde der Verwaltungsaufbau behandelt (MLHA, MdI 246). 
gen Anwachsen des Personalbestands stand die Landesverwaltung hilflos gegenüber, denn Klagen über ausufernde Verwaltungstätigkeit und zu umfangreiches Verwaltungspersonal bildeten eine Kontinuität in der SBZ: In den ersten Wochen und Monaten der Besatzung wurden alle Dienststellen mit Hinweisen auf die ungeklärte Finanzsituation der öffentlichen Hand dazu angehalten, Planstellen zu streichen und Personal zu entlassen; aus den folgenden Jahren finden sich zahllose Variationen derselben Forderung von Regierungs- und Verwaltungsstellen an die jeweils nachgeordneten Behörden. Durch die Übernahme von zunehmend mehr gesellschaftlichen Bereichen in die Verantwortung staatlicher Organe schwoll der Personalbestand aber ununterbrochen an. ${ }^{54}$ Außer den wiederholten Klagen subalterner Stellen über zu umfangreiche Berichtsanforderungen, die die Arbeit lähmten, tauchten keine eingehenderen Überlegungen zu der wie von selbst wachsenden Bürokratie auf: Nirgends wurde über die zunehmenden staatlichen Eingriffe in bislang zivilgesellschaftlich geregelte Lebensbereiche nachgedacht, und nirgends wurden Reflexionen über den Dualismus zwischen Staatsapparat und KPD/SED angestrengt, der zu zahlreichen Doppelungen führte.

Diese Entwicklung änderte sich auch nicht dadurch, daß die Besatzungsmacht wiederholt die Haushaltsbelastung kritisierte. Statt dessen nutzte die Landesverwaltung das Problem zur Kritik am ,Bürokratismus', die sich aber nicht auf die Anzahl der Dienstkräfte, sondern auf die Eigenständigkeit der bereits vor 1945 Beschäftigten bezog. Die Politisierung der Dienstkräfte wurde ebenso schnell angestrebt, wie ihre Verweigerung kollektiv diffamiert wurde. Beispielsweise wurden die fachfremden Kräfte in einem Tätigkeitsbericht des Personalamtes vom Juni 1946 gegenüber dem übernommenen Personal als „unbelastet von jedem volksfremden Bürokratismus“ gelobt. ${ }^{55}$

Die Anpassung und Disziplinierung der staatlichen Dienstkräfte wurde eines der obersten Ziele der Abteilung Innere Verwaltung, weil neben der fachlichen Qualifizierung häufig auch die Verankerung in einer durch Standesbewußtsein und Sekundärtugenden geprägten Bürokratie- und Verwaltungstradition fehlte, die nicht nur Effizienz, sondern auch Unbestechlichkeit und Objektivität bei der Behandlung des Publikums zu sichern vermocht hätte. Übergriffe von Funktionsträgern waren daher nicht zufällig: Schon die ersten Verordnungen zur Sequestrierung im August 1945 waren auch gegen zu weitgehende Übergriffe der neuen lokalen Politikeliten wie Landräte und Oberbürgermeister gerichtet gewesen. Im Mai 1946 nahm Höcker die Entlassung eines Angestellten wegen Lebensmittelkartenfälschung zum Anlaß, um „eine ernste Mahnung an alle Dienstkräfte der Verwaltung“ auszusprechen: „Die Landesverwaltung muß in Bezug auf Sauberkeit und Disziplin beispielgebend sein. ${ }^{56} \mathrm{Er}$ drohte, daß jeder Verstoß

${ }^{54}$ Siehe dazu den statistischen Anhang: Auf der Ministerialebene stieg das Personal von 563 zum Jahresende 1945 auf 1230 Ende 1946 und 1467 Ende 1947; in den Kreisen und kreisfreien Städten stieg die Anzahl der Dienstkräfte von 10534 im November 1946 auf 16570 im Dezember 1947; der folgende quantitative Sprung ist darauf zurückzuführen, daß seitdem auch die Mitarbeiter der kreisangehörigen Städte und Gemeinden hinzugerechnet wurden.

${ }^{55}$ MLHA, MdI 31, Bl. $75 \mathrm{ff}$.

${ }^{56}$ MLHA, MdI 615, Bl. 37. Eine ähnliche disziplinierende Funktion hatten die wiederholten Hinweise auf die Schweigepflicht der Beschäftigten der Landesverwaltung (z. B. MLHA, MdI 615, Bl. 54f.). 
nicht nur strafrechtlich verfolgt, sondern auch mit sofortiger Entlassung geahndet werde.

Solche Probleme der ,Sauberkeit' und Disziplin bereiteten der Abteilung Innere Verwaltung größere Schwierigkeiten als politische Devianz. Die zahlreichen Entlassungen, das bestimmte Auftreten der neuen Herren, die vielen Flüchtlinge, die sich keiner Rükkendeckung in einem heimatlichen Milieu sicher sein konnten, die Möglichkeiten zur Flucht in den Westen und die große SED-Loyalität aller Parteiführungen reduzierten die politische Konfliktbereitschaft. Die allgemeine Not, die neue Unübersichtlichkeit und die gesellschaftlichen Umbrüche boten dagegen zahllose Anlässe zu Übergriffen vor allem in Eigentumsfragen. Im September 1946 erließ Höcker eine Bekanntmachung über das "Verhalten der Beamten und Angestellten der Verwaltung ", 57 in der er "vorbildliche Arbeit und [...] eine tadellose persönliche Haltung“ forderte. Dazu gehöre eine „einfache und bescheidene Lebensweise" der leitenden Dienstkräfte, damit kein Unwille in der Bevölkerung auftrete; außer ,aus Anlaß staatlicher Feiern“ untersagte er jegliche Betriebsfeier, denn „erst wenn die Not des Volkes überwunden ist, dann wollen wir feiern!“ Vorerst gehe es um „die durch Pflichtbewußtsein, Sauberkeit und Einfachheit gewonnene Achtung der Bevölkerung“, die „jedem Beamten und Angestellten der Verwaltung Ausgleich und Gegenwert für seine Mühe und Arbeit sein“ möge.

Auch bei der Vorbereitung der Wahlkämpfe der SED im Herbst 1946 spielte die ,Säuberung ' der Partei von korrupten und anderen unzuverlässigen Personen in staatlichen Ämtern eine bedeutende Rolle. Bereits einen Tag nach der Vereinigung der Arbeiterparteien hatten sich die beiden paritätischen Landesvorsitzenden Kurt Bürger und Carl Moltmann in einem Rundschreiben an alle Kreisvorstände scharf gegen die Anmaßung von Kompetenzen durch SED-Mitglieder ausgesprochen; Hausdurchsuchungen, Verhaftungen, die Entbindung vom Ablieferungssoll oder Beschlagnahmungen stünden nicht der Partei, sondern nur der Besatzungsmacht oder den Verwaltungsorganen zu. ${ }^{58}$ Die SED werde gegen alle Funktionäre vorgehen, die „in Angelegenheiten eingreifen und Entscheidungen treffen, die Sache der Verwaltungsorgane" seien. Der Erfolg war nur beschränkt. Zwei Monate später forderte Moltmann zur Vorbereitung der Wahlen in der SED-Sekretariatssitzung, „daß die Bereinigung in der Verwaltung rücksichtslos in jedem Einzelfalle durchgeführt werden müsse im Interesse des Ansehens unserer Partei und vor allem auch in Rücksicht auf die bevorstehenden Wahlen, an die wir gar nicht erst heranzugehen brauchen, wenn unsere Partei in vielen Dörfern und Gemeinden durch schlechte Genossen unserer Partei in Mißkredit gebracht wird. Jeder jetzt noch schlechte Gemeindevorsteher oder Bürgermeister usw. - der willkürlich handelt, der die Leute tyrannisiert und anderes mehr - hat sich unbedingt umzustellen und wo dies nicht möglich ist, muß er schleunigst entfernt werden, das wird jetzt allerhöchste Zeit. " 59 Bei den Unregelmäßigkeiten der neuen Funktionsträger ging es nicht immer um persönliche Bereicherung oder Vorteilnahme, sondern auch um übereifrige Maßnahmen oder um vor-

\footnotetext{
${ }^{57}$ Amtsblatt, Nr. 11 (1946), S. 129.

${ }^{58}$ MLHA, LL SED IV/2/5/158, Bl. 4. Ein Beispiel für solche Übergriffe war die Verletzung des Postgeheimnisses und die Zensur von Briefen durch Kommunisten mit Polizisten, über die sich die SMAM am 15. 2. 1946 bei der mecklenburgischen Post- und Telegrafenverwaltung und der Landesverwaltung beschwerte (MLHA, MinPräs 1444).

${ }^{59}$ MLHA, LL SED IV/2/3/77, Bl. 96.
} 
auseilenden Gehorsam über vorgegebene politische Linien hinweg. ${ }^{60}$ Beispielsweise wurde den lokalen Funktionsträgern am 27. Februar 1946 von seiten der Landesverwaltung untersagt, Nazis weiterhin mit finanziellen Sondererhebungen zu belegen. ${ }^{61}$

Um politisch, moralisch oder strafrechtlich deviantes Verhalten auch jenseits der bloßen Einzelfallbekämpfung ahnden und unterbinden zu können, wurden Beschwerden gegen Bürgermeister und Gemeindevorsteher - „soweit es sich um persönliche Angelegenheiten handelt" - seit September 1945 von der Personalabteilung zentral behandelt. ${ }^{62}$ Zur „schnelle[n] und korrekte[n] Erledigung aller dieser Angelegenheiten für die Säuberung der Verwaltung von korrupten Elementen [...] vernotwendigt sich die Anlegung einer besonderen Akte für alle diese Vorfälle." Um die Übergriffe der lokalen Politiker, die auch eine Mißachtung der übergeordneten Autorität, sprich der Landesverwaltung waren, zu unterbinden, entstand eine zentrale Sammlung belastender Informationen. Damit sammelte das Personalamt Wissen, mit dem in beliebigen Situationen gegen Funktionsträger vorgegangen werden konnte, indem ihnen ihr registriertes, aber noch nicht veröffentlichtes oder geahndetes abweichendes Verhalten vorgehalten wurde. ${ }^{63}$

Solche Maßnahmen zielten in erster Linie nicht auf die administrative Stringenz und Leistungsfähigkeit der Funktionsträger, sondern auf ihre politische und soziale Homogenisierung. Nach den ersten Wochen und Monaten der vielfach spontanen Herrschaftsausübung wurde nun der unregelmäßige Lebensstil den moralischen und politischen Anforderungen von Partei und Landesverwaltung angeglichen. ${ }^{64}$ Trotz der Abschaffung des Berufsbeamtentums wurden Anforderungen an die neuen Dienstkräfte und Funktionsträger gestellt, die denen des klassischen Beamtentums glichen. ${ }^{65}$ Dabei wurde auch an die Staatsnähe des alten Beamtentums angeknüpft, denn das vorherrschende Kriterium zur Kontrolle der angeforderten Loyalität war die Mitgliedschaft in einer der neuen Parteien.

${ }^{60}$ In idealistischer Manier führten viele Kommunisten die Mißstände auf die mangelhafte politische Einsicht einzelner Funktionsträger zurück. Dies zeigt ein Gespräch der Deutschen Verwaltung des Innern (DVdI) am 23. 9. 1946 mit Oberst P. M. Malkow von der SMAD, dessen Vertrauen in das richtige politische Bewußtsein so groß war, daß er ihm sogar die Heilung von Geschlechtskrankheiten zutraute. Er führte die ungenügende Polizeiarbeit darauf zurück, "daß all die neuen Leute noch nicht genug politisch durchgeschult wurden, so daß eine ganze Reihe von kompromittierenden Fällen eingetreten ist. Ich habe Meldungen von unrechtmäßiger Möbelbeschaffung, ungesetzlicher Untersuchung, Beschlagnahme von Lebensmitteln; außerdem gibt es Zersetzungserscheinungen, Geschlechtskrankheiten innerhalb der Polizei, und das ist es, was durch politische Schulung behoben werden muß" (BAP, DO1/7, 5, Bl. 18).

${ }^{61}$ MLHA, MinPräs 1446a; siehe Anmerkung 303 in Kapitel I.2.

62 Rundschreiben von Erich Kundermann vom 27. 9. 1946 (MLHA, MdI 691).

${ }^{63}$ Entsprechend zog Warnke auch am 26.11. 1947 alle Entnazifizierungsverfahren gegen Prominente an sich (MLHA, MdI 654); den Erfolg der frühen Übernahme geheimdienstlicher Methoden zeigt die von Walter Ulbricht betriebene Verhinderung einer erneuten Kandidatur des CDUWirtschaftsministers Siegfried Witte für die DWK (MLHA, LL SED IV/2/3/123, Bl. 59f.; siehe Anmerkung 407 in Kapitel III.4).

${ }^{64}$ So wie sich schon das Leben der revolutionären Kader nicht durch Extravaganz und Individualität ausgezeichnet hatte, wurden nun auch die neuen Funktionsträger einer konservativen Moral unterworfen (Hinweise zum Lebensstil der KPD-Funktionäre in: Kapitel I.1, S. 58f.).

${ }^{65}$ Schneider, Innere, S. 207ff.; Schwarzenbach, Kaderpolitik, S. 37-45, 81. 
Im September 1945 verfügte das Personalamt, ${ }^{66}$ bei Neueinstellungen in der Verwaltung nicht mehr wie bisher „Militäranwärter“ zu bevorzugen, sondern „in der unteren Dienstlaufbahn [...] vielmehr vorwiegend Bewerber aus dem Arbeiterstande - Eignung vorausgesetzt - einzustellen, in erster Linie bewährte Angehörige antifaschistischer Parteien“. Die Tradition, via Militär nationalistisches Gedankengut und autoritäre Verhaltensweisen in die Verwaltungen zu tragen, hatte stetig das Selbstverständnis und die Selbstdarstellung der Verwaltungen als vermeintlich ,unpolitische' konterkariert. Nun wurde dies explizit umgekehrt: Eindeutig wurden Auswahlkriterien benannt, die dem politischen Standort und der sozialen Herkunft Rechnung tragen sollten. Angesichts der politischen Hegemonie der Arbeiterparteien und der primär auf das cui bono sozialer Klassen und Bündnisse abzielenden marxistischen Faschismustheorie spielte die Angabe einer proletarischen Familientradition eine wichtige Rolle. ${ }^{67}$

Die Verordnung sah die bevorzugte Einstellung von Arbeitern besonders für die untere Dienstlaufbahn vor; der einschränkende Hinweis „Eignung vorausgesetzt“ signalisiert die damit verbundenen Schwierigkeiten. Die viel länger als zwölf Jahre währenden Hemmnisse und Verhinderungen der politischen und administrativen Qualifizierung von Mitgliedern der Arbeiterklasse machten es - trotz aller nachträglichen Rhetorik der DDR-Historiographie - schwer, kompetente und, klassenbewußte 'Verantwortungsträger einzustellen. Die entsprechende Erfahrung machten Niethammer, von Plato und Wierling in den achtziger Jahren nachträglich bei ihrer vergeblichen „Suche nach alten (und nicht nach ehemaligen) Arbeitern": Durch Westflucht und Entnazifizierung waren seit 1945 so viele Posten neu zu besetzen, daß nicht nur die ausgewiesenen linken, sondern fast sämtliche qualifizierungsbereiten Arbeiter die Aufstiegsmöglichkeiten nutzten. ${ }^{68}$

Der Kontinuitätsbruch war in der Verwaltung mehr als nur ein neues politisches Programm. Das durch Hunger, Wohnungsnot oder Zerstörungen jedem sinnlich wahrnehmbare Scheitern des ,Dritten Reiches' führte viele Deutsche nicht nur zu einer politisch, sondern auch zu einer lebensweltlich motivierten Abkehr vom Faschismus, der viele durch eine rigorose Umkehr zu entsprechen suchten. Dabei entschieden sich viele in der SBZ nicht für eine politische und gesellschaftliche Abstinenz, wie sie vielfach im Westen ausgemacht wurde, sondern für eine ebenso entschiedene Politisierung wie bis 1945, dieses Mal aber gegen den Nazismus, also für den Antifaschismus, dessen rigoroseste Ausprägung die Kommunisten erfolgreich zu vertreten vorgaben. Die Orientierungslosigkeit nach dem Krieg, die von früh und entschieden auftretenden Parteivertretern genutzt werden konnte, zeigen die zahlreichen Bewerbungen für die neuen Ausbildungsplätze als Volksrichter oder Neulehrer. Ein 14jähriger Junge aus Strelitz-Alt schilderte darin im August 1945 seinen bisherigen Lebenslauf: In der Oberschule zu Neustrelitz eingeschult, konnte er „aber durch Feindeinwirkung nicht weiterlernen. Durch den großen Brand im Mai 1945 habe auch ich mein Elternhaus verloren, und bin nicht

\footnotetext{
${ }_{66}$ MLHA, MinPräs 752.

${ }^{67}$ Dadurch kamen autoritäre Traditionen und Verhaltensweisen nicht abhanden, speisten sich aber eher aus Traditionen der deutschen Arbeiterbewegung und des sowjetischen Sozialismusmodells und vermischten diese mit älteren militärischen und bürokratischen Traditionen (Fenske, Bürokratie, S. 18; Wunder, Geschichte, S. 127ff.).

${ }^{68}$ Niethammer, Glasnost, S. 45.
} 
mehr im Besitze meiner Schulbücher. Ebenso sind meine Zeugnisse verbrannt. Vom 20. April 1941 mußte ich in das Jungvolk eintreten, doch habe ich mich nie als Führer einsetzen lassen. Es war schon immer mein sehnlichster Wunsch, Lehrer zu werden. "69 Diese schlichte Bewerbung zeigt einen der zahllosen existenz- und orientierungslosen Deutschen, denen das Ausbildungsangebot des neuen Staates den Einstieg in ein neues Leben versprach. Diese Offerte förderte bei vielen eine rigorose Entschiedenheit, die ihren Ausdruck in politischer Eindeutigkeit und fleißiger Arbeit fand. Die zerstörten Vorstellungen aus dem, Dritten Reich' und die Notwendigkeit des Neuaufbaus führten seltener zu kritischer Reflexion ${ }^{70}$ als zur Wiederholung der bereits seit 1933 bewährten aktionistischen Grundhaltung unter umgekehrten politischen Vorzeichen. Beispielhaft ist der Berufsschullehrer Hermann T., der nach Kriegsende unverzüglich an den Aufräumarbeiten teilnahm und dessen Geschichte viel vom weiteren Verlauf der Entnazifizierung vorwegnimmt:

1938 in die NSDAP eingetreten, wurde der westmecklenburgische Schlosser und Berufsschullehrer T.71 unmittelbar nach der Besatzung aus seiner Stelle als Gewerbeoberlehrer für Metall entlassen. Daraufhin arbeitete er als „Milchfahrer und dann als Beifahrer und Autoreparaturschlosser bei einem Lastzug“, wo er "die schwerste und schmutzigste Arbeit Tag und Nacht unverdrossen verrichtete“. „Er hat auch sofort Verbindung mit den sozialistischen Parteien gesucht und sich jederzeit bei vorkommenden Sonder einsätzen zur Verfügung gestellt“, wo er sich wie andere Pgs bei schweren körperlichen Arbeiten ,bewährte'. Wegen seiner vorbildlichen Haltung nach Kriegsende nahm ihn seine alte Berufsschule im Dezember 1945 wieder in den Lehrkörper auf, zum Bedauern der Schule mußte er allerdings schon bald darauf „auf Grund einer Verfügung der Landesverwaltung “ wieder entlassen werden. ${ }^{72}$ Die Schule der kleinen Stadt blieb weiterhin mit ihm verbunden, da er neben seiner wiederaufgenommenen Tätigkeit als Autoschlosser der "Schulleitung mit Rat und Tat zur Seite" stand - wahrscheinlich also ohne Erlaubnis und unter anderer Bezeichnung seine Lehrtätigkeit fortsetzte. Außerdem wurde er nach Auskunft der SED-Ortsgruppe schon bald wieder politisch „aktiv und sowohl er wie seine Frau waren ständig für die SED und die Volkssolidarität tätig (Wahlarbeiten, Antifa-Nähstube usw.). Auf Grund dieser politischen Einstellung wurde T. als erster der ehemaligen Pgs in die Sozialistische Einheitspartei Deutschlands aufgenommen." Mitte 1947 wurde erneut seine Wiedereinstellung als Lehrer angestrebt. Neben diversen anderen legte auch die SED Zeugnis ab. Nachdem sie bereits einige Monate zuvor bescheinigt

${ }^{69}$ MLHA, RdK Neustrelitz 281, Bl. 21.

${ }^{70}$ Mitscherlich/Mitscherlich, Unfähigkeit, haben gezeigt, wie sehr der frühe Arbeitseifer mit der Verleugnung der NS-Vergangenheit zusammenhing. Dennoch ist hervorzuheben, daß sowohl in West- als auch in Ostdeutschland zahllose Menschen seit 1945 keinen Anschluß mehr an den wirtschaftlichen Aufschwung und die gesellschaftliche ,Normalität' fanden. Der erste DEFAFilm Die Mörder sind unter uns (1946) zeigt die Schwierigkeiten eines ehemaligen Soldaten und Arztes in Berlin, der erst durch den tätigen Beistand von einer von Hildegard Knef dargestellten jungen Frau aus dem Zustand menschlicher und politischer Umnebelung gerettet wird. Weniger glücklich endet die literarische Verarbeitung des Themas bei Peter Härtling, Eine Frau.

71 MLHA, MfV 537, Bl. 51-64. Die Zitate sind verschiedenen Bescheinigungen der SED und einzelner Bürgen entnommen.

72 Anfang Januar 1946 ordnete die Abteilung Kultur und Volksbildung die Entlassung aller Lehrer an, die NSDAP-Mitglied gewesen waren (siehe MLHA, MfV 48, Bl. 18f.). 
hatte, daß T. „aus seiner antifaschistischen Einstellung [...] niemals einen Hehl gemacht “ habe ("was besonders in den verflossenen Wahlkämpfen zum Ausdruck kam “), konstatierte ein Oberstudienrat als Bürge für den SED-Eintritt, daß er T. „als einen fleißigen, braven Schüler, der für nationalsozialistische Ideen keinen Sinn hatte“, kenne.

Dieses Engagement und T.'s Leumund, der politische Anpassung, Arbeitseifer und kleinbürgerlichen Anstand hervorhob, zeigen, daß es ihm nicht um eigenständige politische Vorstellungen ging, sondern um die schnelle Rückkehr in die veränderten gesellschaftlichen Verhältnisse: Antifaschismus als neue Lebensperspektive, als Möglichkeit, auf die, richtige ‘ Seite zu wechseln und die Verfehlungen der NS-Vergangenheit, wiedergutzumachen“. Die SED-Zeugnisse zeigen paradigmatisch, wie stark das individuelle Verhalten dabei vergessen oder tabuisiert werden konnte. Diese Gesamthaltung förderte die Bereitschaft, Orientierung bei der hegemonialen Kraft des neuen Konsenses zu suchen, und bildete den Resonanzboden für die Anforderungen an das neue Personal im öffentlichen Dienst: Als Gegenleistung für den beruflichen und vielfach auch persönlichen Neuanfang wurde ein hohes Maß an politischer Loyalität erwartet. Während die Entnazifizierung bis Ende 1945 an der NS-Mitgliedschaft Maß genommen hatte, so daß es ausgereicht hatte, politisch unbelastet gewesen zu sein, stand an ihrem Ende die Forderung nach aktiver Beteiligung. Wichtigstes Auswahlkriterium war nicht die soziale Familientradition und schon gar nicht die fachliche Qualifikation, sondern die Bereitschaft zur politischen Stellungnahme und Mitarbeit auch jenseits der eigentlichen Verwaltungstätigkeit.

Eine verschärfte Variante der Verordnung des Personalamtes vom September über die bevorzugte Neueinstellung von Arbeitern in der Verwaltung kündigte Höckers handschriftliche Weisung vom 23. Januar 1946 an, ${ }^{73}$ "bei Neueinstellungen [...] darauf zu achten, daß nach Möglichkeit Bewerber einer antifa[schistischen] Partei angehören. Sog[enannte], Unpolitische' möchte ich nicht mehr einstellen, da die Gefahr besteht, den Ver[waltungs]App[arat] faschistisch zu verseuchen." Damit war die Verbindung von Entnazifizierung und Herrschaftssicherung ausgesprochen und politisch radikalisiert, da es nicht mehr ausreichte, politisch unbelastet zu sein. Die neu Herrschenden verlangten von ihrem Verwaltungsapparat, den sie zur Durchsetzung ihrer Politik benötigten, aktive Loyalitätsbekundungen. Nicht nur Nazis waren von Stellen im Staatsapparat fernzuhalten, sondern Höcker formulierte den darüber hinausgehenden Verdacht, daß alle, die ihre Zustimmung zum neuen Gesellschaftssystem nicht offen und in den besonders in Mecklenburg-Vorpommern gut kontrollierten und SED-loyalen Parteien ausdrückten, staatsfeindlich seien; der Staatsapparat benötigte nur eindeutig linientreue Mitarbeiter. $^{74}$

${ }^{73}$ MLHA, MdI 759. Das Rundschreiben wurde Ende März 1946 der SMAM zur Genehmigung vorgelegt und allen Verwaltungsstellen zugesandt (MLHA, MdI 759; MLHA, MinPräs 1445).

${ }^{74}$ Die enge Verbindung von Blockparteien und Staatsapparat wurde auch dadurch deutlich, daß allen Bediensteten der Landesverwaltung im August 1946 vom Personalamt „selbstverständlich das Recht der politischen Betätigung“ zugesprochen wurde: „insbesondere gilt das für die bevorstehenden Wahlen" (MLHA, MinPräs 720). Diese Verbindung erleichterte nicht nur den Zugriff auf das Verwaltungspersonal, sondern auch auf CDU und LDP, da dadurch zahlreiche ihrer Mitglieder durch kommunistische Vorgesetzte am Arbeitsplatz beeinflußt werden konnten. 
Diese Ausrichtung prägte die Personalpolitik der neuen Verwaltung und setzte die im Rahmen der Entnazifizierung durchgeführte politische Kontrolle und Beurteilung der Belegschaften bruchlos fort. In den ersten Januartagen stellte der Leiter der Abteilung Forsten, Paul Holtz, fest, ${ }^{75} \mathrm{daß}$ sämtliche Forstämter „mit Beamten, Angestellten, Haumeistern oder Waldarbeitern besetzt [sind oder werden], die nicht Mitglieder der NSDAP waren“. Nur zwanzig Prozent der Dienstkräfte seien von der alten Belegschaft übernommen und die bisherigen Einstellungen vorerst noch provisorisch, „um zunächst die politische, moralische und fachliche Eignung der in Aussicht genommenen Kräfte oder Bewerber zu überprüfen. [...] Zusammenfassend kann gesagt werden: Es wird in Kürze erreicht sein, daß alle Forstdienststellen mit antifaschistischen Kräften besetzt sind. “ Unmittelbar nach dem vorläufigen Ende der Entnazifizierung zielte die Forstabteilung damit auf eine vollständige Besetzung durch Personen, die nicht nur NS-unbelastet waren, sondern sich durch aktive Loyalität gegenüber dem neuen Gesellschaftssystem auszeichneten. Dieser ehrgeizige Plan zwischen parteibezogenen Entlassungen und parteibezogener Neubesetzung bildete ein beispielhaftes Scharnier zwischen der Entnazifizierung und dem Neuaufbau eines politisch linientreuen Staatsapparates. Die neue Parteimitgliedschaft demonstrierte und sicherte die Akzeptanz gegenüber dem für eine Kaderverwaltung konstitutiven Primat der Politik und der Herrschaftssicherung vor den fachlichen Aufgaben und administrativen Arbeitsmethoden. Die Landesverwaltung forderte selbst für Waldarbeiten die ausdrückliche politische Loyalität ihrer Dienstkräfte.

Höckers Anordnung und Holtz’ ehrgeiziger Plan waren keineswegs exzeptionell, sondern entsprachen der allgemeinen Politik in der SBZ. Walter Ulbricht gab seinem Parteigenossen Schramm im Januar 1946 anläßlich seiner Versetzung in eine der Berliner Zentralverwaltungen Entsprechendes als politische Aufgabe mit auf den Weg: „Notwendig ist, daß eine schnelle Beförderung zuverlässiger Antifaschisten in höhere Dienststellen erfolgt. Mit den paar Kommunisten in der Zentralverwaltung kann auf die Dauer nicht gearbeitet werden. Hilf bitte mit, damit eine schnelle Beförderung von Kommunisten und anderen zuverlässigen Antifaschisten erfolgt und diese Genossen so geschult werden, daß sie leitende Funktionen ausüben können."76 Die bewußte Förderung eigener Parteifreunde und das Mißtrauen gegenüber Parteilosen fanden sich nicht nur bei den Kommunisten, sondern in allen Parteien: Auch die CDU entwickelte beispielsweise ähnliche Maßnahmen zur gezielten Karriereförderung und Stellenbesetzung und polarisierte ebenfalls öffentlich zwischen Mitgliedern der neuen Parteien und Parteilosen. Auf der ersten Seite der ersten Ausgabe ihrer Landeszeitung erhob sie diese Politisierung der Bevölkerung in den Rang einer patriotischen Pflicht und bezweifelte die Moralität der

75 MLHA, MinPräs 1436.

76 SAPMO-BA, RY 1/I2/5, 43b, Bl. 560. Obwohl bei der Neugründung der Zentralverwaltungen nur ausnahmsweise auf das Personal der entsprechenden bis 1945 tätigen Reichsbehörden in Berlin zurückgegriffen worden war, sah Ulbricht den Einfluß der KPD als ungenügend an (Welsh/ Zank, Zentralverwaltungen). 
Außenstehenden: „Wer in Notzeiten seines Volkes parteilos bleibt - ist unwert bürgerlicher Ehre!" 77

Die statistische Entwicklung der Parteimitgliedschaften im öffentlichen Dienst bestätigt den Erfolg dieser Kampagnen. ${ }^{78}$ Allerdings erschrak der Präsident nun über die einseitige Wirkung dieser von ihm selbst initiierten und mitgetragenen Politik: Am 10. April $1946^{79}$ wies er den betrieblichen Gewerkschaftsausschuß und das Personalamt darauf hin, daß es bei Betriebsversammlungen und „sonstigen neutralen Zusammenkünften“ unzulässig sei, die Nichtorganisierten zum Beitritt in eine bestimmte Partei aufzufordern oder von Stellenbewerbern zuerst den Nachweis der Parteizugehörigkeit zu fordern. Damit deutete er zwei Methoden der Mitgliederwerbung an, die den quantitativen Erfolg erklären: Einstellungshindernisse für Parteilose und Druck in Betriebsversammlungen gegenüber bereits Angestellten. Dagegen mahnte der Präsident, daß die „Unorganisierten [...] durch das gute Beispiel und die Arbeit der Parteien leichter zu überzeugen seien, als durch Druck und Zwang “. Ferner entscheide nicht die Zahl der Mitglieder, sondern deren Überzeugung, weshalb „im demokratischen Staat [...] in dieser Hinsicht jeder Zwang vermieden werden" solle. Höckers Hinweis auf die verschiedenen Parteien war vor allem eine Kritik an der KPD. In der End- und Hochphase der Vereinigungsdynamik der Arbeiterparteien betonte er Valenz und Bedeutung der anderen drei Parteien: zugunsten von CDU und LDP gegenüber einer bald mächtigen SED und zugunsten der SPD gegenüber den frühen Versuchen zur Verdrängung und Bekämpfung sozialdemokratischer Traditionen in der SBZ. ${ }^{\circ}$ Allerdings blieb Höcker gegen die Stärke der Kommunisten nicht mehr als ein Appell; die im selben Monat begonnenen allgemeinpolitischen Schulungen für alle Verwaltungsdienstkräfte zeigten den überragenden Einfluß der KPD:81 Das Personalamt teilte den Fachabteilungen Anfang April im Auftrag der Organisationsleitung der KPD-Betriebsgruppe mit, daß alle Dienstkräfte nunmehr an einer wöchentlichen Schulung teilnehmen müßten. Sie werde von der KPD/SED-Parteigruppe organisiert, da es nicht vorwiegend um verwaltungstechnisches Wissen, sondern um die politische Erziehung und Bildung gehe.

Nachdem bereits in den ersten Wochen und Monaten der Besatzung bei der Auswahl der Oberbürgermeister, Landräte, Bürgermeister und Gemeindevorsteher Wert auf deren politische Loyalität und parteipolitische Bindung gelegt worden war, setzte sich dieser Trend nun auch in den subalternen Verwaltungsbereichen zunehmend stärker durch. Fast alle Oberbürgermeister und Landräte waren SED-Mitglieder, und von 76 Bürger-

77 Der Demokrat, 15. 12. 1945. Im Kreis Güstrow setzten SED und CDU im Juni 1947 gemeinsam eine Verstärkung der politischen Werbung und Schulung der Verwaltungsmitarbeiter durch (MLHA, RdK Güstrow 14, Bl. 96-101).

${ }^{78}$ Ende 1945 und Anfang 1946 stieg die Zahl der Mitglieder der neuen Parteien im öffentlichen Dienst stark an; siehe statistischen Anhang.

79 MLHA, MdI 759.

${ }^{80}$ 'Tatsächlich bemühte sich die KPD vor der Vereinigung zur SED (erfolglos) darum, ihr Selbstverständnis als Führungskraft durch einen Mitgliedervorsprung gegenüber der SPD quantitativ zu untermauern (Müller, KPD, S. 449). Der Erfolg war auch in der Verwaltung nur begrenzt: Auf Ministerialebene waren im März 1946 von insgesamt 725 Mitarbeitern und Mitarbeiterinnen 72 KPD- und 170 SPD-Mitglieder, in den Kreisen und kreisfreien Städten 1813 Kommunisten und 2651 Sozialdemokraten (statistischer Anhang).

${ }^{81}$ MLHA, MdI 175, Bl. 1f. 
meistern der kreisangehörigen Städte waren am Jahresanfang 58 in der KPD, 14 in der SPD, zwei in der CDU und zwei parteilos, so daß die SED nach der Vereinigung der Arbeiterparteien fast 95 Prozent aller Bürgermeister stellte. ${ }^{82}$ Diese Übermacht gestaltete sich in den Kreisen nicht ganz so eindeutig: In den 202 Gemeinden des Kreises Güstrow gab es unter den Bürgermeistern 68 Kommunisten, 49 Sozialdemokraten, neun CDUMitglieder und 71 Parteilose; von ihren Stellvertreterposten besetzte die KPD nur noch 40, die SPD 49, die CDU einen, und ungefähr die Hälfte verantworteten Parteilose. ${ }^{83}$ Nicht nur die Inhaber politischer Ämter, sondern auch die Mitarbeiter der staatlichen Verwaltungsstellen wählten beim Parteieintritt bevorzugt die SED: In den Verwaltungen der Kreise und kreisfreien Städte gab es Ende 19466202 Sozialisten gegenüber 541 Christdemokraten und 266 LDP-Mitgliedern, und auf Ministerialebene wurden zum selben Zeitpunkt 533 Sozialisten, 86 Christdemokraten und 25 Liberale gezählt. ${ }^{84}$

Selbstverständlich klagten die beiden bürgerlichen Parteien über diesen Parteienproporz - erfolglos. Der LDPD-Vorsitzende Wilhelm Külz forderte am 14. Dezember 1945 - also noch vor der Gründung des LDP-Landesverbandes Mecklenburg-Vorpommern - von der Landesverwaltung eine stärkere „Beteiligung der LDP an der Besetzung der leitenden Posten in der öffentlichen Verwaltung ". ${ }^{85}$ Das Problem änderte sich dadurch aber nicht: Landesgeschäftsführer Jäkel erläuterte seiner Partei im April 1946, ${ }^{86}$ $\mathrm{daß}$ die Vertretung der LDP in verschiedenen örtlichen Verwaltungsbehörden nicht möglich sei, da die Berufung von Landräten, Oberbürgermeistern, Bürgermeistern und Stadträten von der Besatzungsmacht vorgenommen werde, wodurch sich für die LDP nur infolge von Versetzungen, Entlassungen oder Tod Nachrückmöglichkeiten ergäben. Auch im CDU-Vorstand wurde im April 1946 eine Strategie gegen die „Benachteiligung der CDU gegenüber anderen Parteien bei Zulassungen und Einstellungen“ vorgeschlagen, die dem im ganzen vorsichtigen und zurückhaltenden Verhalten gegenüber KPD/ SED und Besatzungsmacht entsprach: Die Kreis- und Landesverbände hätten jedem Einzelfall nachzugehen, und „erst bei gravierenden Vorkommnissen bestehe die Möglichkeit eines Schrittes der Reichsgeschäftsstelle in Karlshorst" ${ }^{87}$ Daß sich diese Situation für CDU und LDP auch später nicht änderte, zeigt der eindringliche Brief des CDU-Landesvorsitzenden Reinhold Lobedanz vom folgenden November an alle Kreisverbände über die Stellenbesetzung, der allerdings stärker den eigenen Personalmangel als die Benachteiligung reflektierte: Bei Besetzungsschwierigkeiten sei kein Verzicht zu üben, sondern beim Landesvorstand nach geeigneten Personen nachzufragen. „Die unserer Union nach dem Ergebnis der Wahlen zustehenden Ämter müssen unter allen Umständen von uns besetzt werden. “88

82 Siehe Anmerkung 204 in Kapitel I.1; MLHA, MdI 139, Bl. 1f.

${ }^{83}$ MLHA, RdK Güstrow 113, Bl. 40-45.

${ }^{84}$ Statistischer Anhang.

${ }^{85}$ MLHA, MinPräs 1375.

${ }^{86}$ ADL, LDP 18656. Im Januar 1947 beantragte die LDPD erfolglos, in der Landesverfassung festzuschreiben, „daß die Zulassung zum öffentlichen Dienst nicht von parteipolitischen Gesichtspunkten abhängig gemacht werden" dürfe (Akten und Verhandlungen, Bd. 1 [1. Wahlperiode], Sp. 111).

${ }^{87}$ ACDP, 07/010, 2179, Bl. 178ff.

${ }^{88} \mathrm{ACDP}$, III/036, A075. Auch am 26. 4. 1947 beschwerte sich die CDU-Hauptgeschäftsstelle in einem Rundschreiben über Benachteiligungen von LDP und CDU gegenüber der SED in den 
Diese personalpolitischen Auseinandersetzungen zeigen, daß es im Frühjahr 1946 bei den Veränderungen in der Verwaltung nicht mehr um die Entnazifizierung ging, sondern um die Positionierung der neuen Parteien und um die große SED-Majorität infolge der Vereinigung der Arbeiterparteien. Die Entnazifizierung spielte keine Rolle mehr, da sie beendet war. Es ging nicht mehr um das Verhalten im ,Dritten Reich', sondern neben der Einflußsicherung der einzelnen Parteien um die Ausgrenzung von Personen, die nicht bereit waren, sich den neuen Anforderungen anzupassen.

\section{Verschiebung des,Säuberungs'-Profils: SED-statt NS-Bezug}

Mit dem Ende der Entnazifizierung und der zunehmenden parteipolitischen Homogenisierung der Verwaltungen und lokalen Funktionsträger endeten die politischen Überprüfungen keineswegs. Die umfangreichen Entlassungen von NS-Belasteten, die Einsetzung des neuen Personals und die damit verbundene Machtdemonstration zwecks Disziplinierung der verbliebenen Dienstkräfte wurden nicht mit der von Höcker angestrebten Ruhe zum reibungslosen Neuaufbau abgeschlossen, sondern mit einer politischen Verschiebung des ,Säuberungs'-Profils: Es ging seit Ende 1945 zunehmend um die Loyalität zur Besatzungsmacht, zur neuen hegemonialen Partei und zum angeordneten gesellschaftlichen Neuaufbauprogramm. Gleichzeitig nahmen innerhalb der KPD und der anderen Parteien Diskussionen über die gesellschaftliche Reintegration derjenigen Pgs zu, die sie nicht als aktive Nazis identifizierten. Ebenso wie beim Volksentscheid in Sachsen und dem mecklenburgischen Enteignungsgesetz vom 16. August 1946 bedurfte es einer Klärung der Belastungsmomente und des von Sanktionen betroffenen Personenkreises. ${ }^{89}$

Bereits auf der, Reichsberatung der KPD am 8./9. Januar 1946 in Berlin wurden entsprechende Richtlinien diskutiert. Franz Dahlem hielt ein umfangreiches Referat über „einige Fragen der Parteiorganisation", 90 in dem er sich gleichzeitig über den Umgang mit ehemaligen Nazis sowie mit „Separatisten [...] in unserer Partei“ äußerte. Die Aufnahme ehemaliger Nazis in die KPD sei „aus politischen Gründen noch nicht möglich“. Diese Ablehnung sah er aber als zeitlich befristet an und autorisierte die Zuhörer ausdrücklich, diesen Beschluß zu umgehen, indem er eine klandestine Großzügigkeit vorschlug, die er unmittelbar mit der Warnung vor Abweichlern und gegen „Agenten“ des Westens in der KPD verknüpfte: Die ehemaligen NSDAPler, „die schon in der Partei sind, muß man auf geschickte Weise in Bezirksausschüsse oder andere Ausschüsse bringen, wo sie sich bewähren können und den Nachweis erbringen, daß sie wirklich aktiv

Kreisverwaltungen (ACDP, 07/011, 1286). Am 11. 6.1947 wandte sich Lobedanz mit diesem Anliegen erneut an die Kreisverbände und empfahl, die SED im Kreistag zu einer Verpflichtungserklärung zu bewegen, die Einstellung von CDU- und LDP-Bewerbern bei gleicher Qualifikation so lange zu bevorzugen, bis der Parteienproporz den Wahlergebnissen entspreche; zur Unterstützung dieser Initiative zitierte er eine entsprechende Entscheidung aus dem Kreis Weimar (ACDP, III/036, A075).

${ }^{89}$ Amtsblatt, Nr. 6 (1946), S. 98ff. Die Rückgabe vieler sequestrierter Güter an ehemalige NSDAPMitglieder, die für bloß nominelle Nazis gehalten wurden, machte die Unterscheidung zwischen aktiven und bloß nominellen Nazis materiell sichtbar und gewährte zudem durch die Klärung der Eigentumsverhältnisse ökonomische Sicherheiten, ohne die der Neubeginn stark beeinträchtigt war.

${ }^{90}$ SAPMO-BA, RY 1/I2/2, 17, Bl. 21-43, im folgenden Bl. 33-36. 
am Neuaufbau im Dorf oder im Kreis mitarbeiten. Weiter muß man das Augenmerk auf die Tätigkeit der Angehörigen ehemaliger Oppositionsgruppen in unserer Partei richten. "Bei diesem Kampf um „die innere Festigkeit und Reinheit der Partei“ ging es nur nebensächlich um die „Menge zweifelhafter und schlechter Elemente: Abenteurer, sogar zum Teil Kriminelle, Verbrecher“. Diese wurden für "Verbürokratisierung, Hochmut, Entartung von Kommunisten in bestimmten Verwaltungen “ verantwortlich gemacht, aber generell als harmlos eingeschätzt. Umfangreicher waren Dahlems Vorschläge gegen Linke und Kommunisten, die sich nicht ausreichend dem demokratischen Zentralismus unterwarfen. In diesen Vorschlägen wurde der Argwohn gegen den Nazismus von jenem gegen den Westen ersetzt: „Wo Genossen von früher her zur Widerstandsbewegung, besonders zur französischen Widerstandsbewegung, aber auch in Zusammenarbeit mit England und Amerika in irgendwelchen vertraulichen Beziehungen stehen, können sie abgebrochen werden. Es sind noch Hunderte und Tausende von Genossen, die solche Beziehungen haben. Es ist absolut notwendig, damit Schluß zu machen." ${ }_{11}$

Noch vor dem Beginn der Teilung der Welt bestimmten die kommunistischen Dichotomien die Innenpolitik der SBZ: Die Geister wurden nicht mehr am ,Dritten Reich', sondern an der Loyalität zur KPD und dem Verhältnis zum Westen unterschieden. Die beendete Entnazifizierung sollte durch eine langsame Reintegration der von ihr Sanktionierten in die veränderten gesellschaftlichen Verhältnisse abgelöst werden. Der Vorstand der inzwischen vereinigten Arbeiterparteien stellte entsprechend in einer programmatischen Erklärung über „SED und nominelle Pgs“ am 20. Juni $1946{ }^{92}$ fest, daß es inzwischen primär um den gesellschaftlichen Aufbau, nicht die Abrechnung mit politischer Belastung aus der Zeit bis 1945 gehe. Auch Piecks handschriftliche Notizen enthalten programmatische Aussagen über diese veränderte Verbindung von gesellschaftlichem Neuaufbau, politischen Überprüfungen, Herrschaftssicherung und Entnazifizierung. In der SMAD-Schule in Königs Wusterhausen äußerte er sich am 3. August $1946^{93}$ explizit gegen den Vergangenheitsbezug: Sein Anliegen galt dem „Demokratie sichern“, wozu er "feste demokr[atische] Mehrheiten", "Fübrung der SED-Mehrheit" sowie "Reaktion schlagen - Frieden sichern" aufzählte und dies mit Hinweisen auf "Monopolkapitalisten“, „Konzernherren“ und „Großgrundbesitzer" verband. Es ging nicht um den Blick zurück auf das ,Dritte Reich“ und nicht um die Entfernung der NS-Belasteten aus ihren Stellungen, also nicht um die Entnazifizierung, sondern um die Gestaltung der Zukunft, und dabei vor allem um die nach dem Ersten Weltkrieg mißlungene Übernahme und Sicherung der Herrschaft: „Säuberung, Entnazifizierung' falscher Begriff PGs nominell Nicht Fehler von 1918 wiederholen.“

${ }^{91}$ Dies hatte auch Konsequenzen für die politische Arbeit der KPD im Westen, da Dahlem und Ulbricht dort jede Mitarbeit im Bereich der Entnazifizierung ausdrücklich untersagten; dem bayerischen KPD-Mitglied und Entnazifizierungsminister, Heinrich Schmitt, untersagte die Partei allerdings erst Mitte 1946, diese Funktion weiterhin auszuüben (Niethammer, Mitläuferfabrik, S. 374f.).

92 Dokumente der Sozialistischen Einheitspartei Deutschlands, Bd. 1, S. 50f.; zur gesellschaftlichen Reintegration der Pgs siehe Kapitel II.3.

${ }^{93}$ SAPMO-BA, NY 4036 (NL Pieck), 428, Bl. 15. Nach Glaeßner, Herrschaft, S. 302, wurden dort "vor allem Angehörige der bürgerlichen Parteien und Massenorganisationen" ausgebildet, die von den SED-Schulungen nicht erreicht wurden. Zur Parteischulung siehe ausführlich Schultz, Funktionär, S. 51-101. 
Dazu war die Hegemonie der Avantgardepartei notwendig, deren Weisungsrecht gegenüber der Verwaltung auf einer Sitzung des SED-Landesvorstandes mit Kreissekretären am 18./19. Mai 1946 beschworen wurde. ${ }^{94}$ Einen Monat nach der Vereinigung der beiden Arbeiterparteien formulierten prominente Kommunisten wie Warnke, Bürger, Jonny Löhr und Ernst Goldenbaum ihre Zentralisierungsvorstellungen, gegen die sie nun keine Opposition der Sozialdemokraten mehr erwarten mußten, da diese integriert waren und an der anvisierten Machtfülle teilhaben konnten. Löhr äußerte sich angesichts der gerade eingerichteten zentralen Planungsstelle beim Präsidenten eindeutig: „Die Planung des ganzen Landes [ist] unter aller Kanone. “ Noch seien „verschiedene Stellen“ für die notwendige „klare Planung“ verantwortlich, aber: „Den Neuaufbau muß unsere Partei übernehmen. “ Neben dieser eher allgemein gehaltenen Forderung des Wirtschaftsfachmanns Löhr bezog Warnke sich auf die Personalpolitik und forderte, $\mathrm{da}$ nicht die Verwaltung, sondern die SED zu bestimmen habe, wer zu entlassen sei. Damit identifizierte er das von ihm und Erich Kundermann geleitete Personalamt ausdrücklich mit der SED: Es übernahm den Part in der Landesverwaltung, zu dem die erst schwach ausgebaute Landespartei und ihre mangelhaft funktionierende Personalabteilung unter Aenne Kundermann nicht in der Lage waren. ${ }^{95}$ Das starke Mitgliederwachstum der SED erschwerte den Aufbau einer funktionierenden Organisationsstruktur, ${ }^{96}$ und nichts deutet auf eine direkte kaderpolitische Zusammenarbeit der Personalabteilungen von Landesverwaltung und Landespartei. Da diese beiden Ämter allerdings von den Eheleuten Aenne und Erich Kundermann geleitet wurden, die 1945 beide als linientreue Kommunisten aus dem sowjetischen Exil zurückgekehrt waren, kann von der

${ }^{94}$ MLHA, LL SED IV/2/1/9, Bl. 7-89, Löhr Bl. 45, Warnke Bl. 74ff., Bürger Bl. 82f. Da zum Zeitpunkt der Vereinigung der Arbeiterparteien mehr Sozialdemokraten als Kommunisten in der staatlichen Verwaltung beschäftigt waren, diente diese Tagung kurz nach der SED-Gründung auch der Durchsetzung kommunistischer Standpunkte.

${ }^{95}$ Kluttig, Mitgliederschulung, S. 46, 102, 128, enthält wiederholte Hinweise auf die Schwäche und den mangelhaften Einfluß dieser Abteilung. Das Konzept der Kaderverwaltung implizierte ein klares Hierarchieverhältnis zwischen SED und Staatsapparat, wofür in Mecklenburg-Vorpommern aber die organisatorische Grundlage fehlte. Dies führte wiederholt zu Unklarheiten, die sich zusätzlich aus der landespolitischen Unkenntnis des führenden Kommunisten im Lande, Bürger, speisten und Warnkes Selbständigkeit gegenüber seiner Partei, in der er keine zentrale Rolle spielte, hervorhoben. Während der Diskussion im SED-Landesvorstand am 18./19. 5. 1946 über die ehemaligen Nazis reflektierte Bürger das Thema beispielsweise sehr allgemein, während Warnke direktiv bestimmte, in welcher Form Entnazifizierung und Sequestrierungen abzulaufen hätten. Warnke legitimierte sein Handeln nicht einmal mit Vorgaben der Partei, sondern mit der eigenen Autorität: „Genossen, ich habe auf diesem Gebiet meine Erfahrungen gemacht." Entsprechend forderte er angesichts des strukturellen Dualismus zwischen Partei- und Staatsapparat die Stärke der staatlichen Stellen: Selbstverändlich sind „wir als Partei [...] die Führerin des Volkes", aber sie habe „diszipliniert" zu arbeiten: „Kein Kreissekretär kann querschießen. Im Landratsamt beschließt der Landrat und sonst niemand" (MLHA, LL SED IV/2/1/9, Bl. 74ff.). Einen ähnlichen Eindruck vermittelte die Eröffnungsansprache des langjährigen Sozialdemokraten Willi Jesse auf der SED-Sekretariatssitzung am 29. 5. 1946: „Insbesondere muß die Linie der Partei in Einklang gebracht werden mit der Linie der Landesverwaltung, also eine Koordinierung der politischen Arbeit zwischen Verwaltung und Partei" (MLHA, LL SED IV/2/3/77, Bl. 40).

${ }_{96}$ Bis Ende 1947 hatte die SED in Mecklenburg über 200000 Mitglieder; im April 1946 waren es nur 154800 gewesen (Müller, SED, S. 510). 
nicht vorhandenen Korrespondenz nur schwer auf das Ausmaß an realer Kommunikation und Absprache geschlossen werden.

Die anhand des festen Kriteriums der Mitgliedschaft in NS-Organisationen durchgeführte Entnazifizierung gewährte bei Personalentscheidungen nur einen geringen Interpretationsspielraum. So war kein umfassender Einfluß der SED auf die Personalpolitik zu sichern, der zur Durchsetzung der Kaderverwaltung konstitutiv war. Daher lehnte Warnke auch die Festlegung eines Stichtages für den Abschluß aller politischen Überprüfungen ab und projektierte statt dessen einen langen Weg: Er entwarf das später vor allem von ihm und Kundermann vertretene Konzept einer permanenten ,Säuberung ${ }^{6}{ }^{77}$ das sich in der SBZ zwar nicht in dieser Form durchsetzte, seit 1948 aber durch die ,Parteisäuberungskommissionen“ unter anderem Namen realisiert wurde: „Wenn wir so die Frage [auf einen Stichtag bezogen] stellen, würden wir erklären, unser Verwaltungsapparat ist ein Schweinehaufen. Das stimmt nicht. Unser Verwaltungsapparat steht gesund da. [...] Wenn wir gesund an die Aufgabe herangehen, werden wir etwas gesundes erreichen. [...] Ich bin überzeugt, daß, wenn wir die Frage allgemein demokratisch stellen, unser Verwaltungsapparat gesund ist." Warnke erkannte, daß die ,richtige ' Frage entscheidend war; daher sicherte nach dieser Ausführung allein die Hegemonie der SED die ,Gesundheit' der mecklenburgischen Verwaltungen und Politik. ${ }^{98}$

Diese Ausrichtung ermöglichte Beurteilungen des neuen Personals und des politischen Belastungsgrades einzelner, die durch keine Entnazifizierungsregeln oder feste Belastungskategorien eingeengt waren. Einen ähnlichen Rahmen hatte der Alliierte Kontrollrat etwa zeitgleich in seiner Direktive Nr. 24 vom 12. Januar 1946 für die Entnazifizierung vorgegeben, deren Realisierung in der SBZ allerdings erst mit einigen Monaten Verzögerung angegangen wurde. ${ }^{99}$ Es ging nicht mehr um das einfache Kriterium der Mitgliedschaft in einer NS-Organisation, sondern um einen weit aufgefächerten Belastungskatalog, der den Urteilenden einen erheblich größeren Entscheidungsspielraum überließ und die Entnazifizierung dadurch noch stärker als bisher von dem jeweiligen Verständnis des ,Dritten Reiches', das heißt von der hegemonialen Faschismustheorie, und von den eigenen gesellschaftspolitischen Vorstellungen abhängig machte.

Die SED konnte beide Gebiete erfolgreich besetzen: Sie hatte bereits früh das Personalamt übernommen und dort die gesamte Personalpolitik des Landes konzentriert. Mit diesem Amt bestimmte sie die politischen Maßstäbe, anhand derer die neuen und alten Dienstkräfte ausgewählt, beurteilt, geschult und ausgerichtet wurden. Gegenüber leichten Widerständen im Präsidialkollegium wurde es zur ideologischen und vor allem organisatorischen Zentrale beim Aufbau der neuen, primär am Herrschaftsinteresse der SED orientierten Administration.

\footnotetext{
${ }^{97}$ Siehe Kapitel III.1.

${ }^{98} \mathrm{Z}$ wei Monate nach dieser Sitzung formulierte Warnke die Gefahr allgemeiner Überprüfungen, die nicht von der SED kontrolliert seien, noch deutlicher: Gegenüber parteiinternen Kritikern von Amtsanmaßung und deviantem Verhalten seitens einiger SED-Funktionäre warnte er den Landesvorstand am 15. 7. 1946, daß ,die augenblickliche Säuberungssache [...] unter Umständen zu einer Gefahr für uns werden “ könne (MLHA, LL SED IV/2/1/10, Bl. 109f.).

${ }^{99}$ Abgedruckt in: Rößler, Entnazifizierungspolitik, S. 64-81; siehe Kapitel III.
} 


\section{Das Personalamt}

Das Land Mecklenburg-Vorpommern war eine Neuschöpfung des Jahres 1945. In Schwerin konnten die mecklenburgischen Ministerial- und Verwaltungsstrukturen übernommen werden; die für Vorpommern verantwortlichen Behörden waren aber bis zum Kriegsende auf das nunmehr an Polen abgetretene Stettin ausgerichtet gewesen und wurden daher endgültig aufgelöst. Weil das Personalwesen in der mecklenburgischen Verwaltung bis 1945 dezentral bei den einzelnen Fachabteilungen des Staatsministeriums verwaltet worden war und das für die Personalpolitik in Vorpommern verantwortliche Oberpräsidium und die Provinzialverwaltung in Stettin nicht mehr existierten, ${ }^{100}$ wurde 1945 „aus dem Nichts heraus ein zentrales Personalamt für den gesamten Bereich der Landesverwaltung "101 geschaffen. Die Ansprechpartner dieses Amtes waren in den Landesbehörden die jeweils zuständigen (Vize-)Präsidenten Höcker, Warnke, Grünberg oder Otto Möller und in den Städten, Kreisen und Gemeinden die Oberbürgermeister, Landräte und Bürgermeister.

Die Position des bei der Abteilung Innere Verwaltung angesiedelten Personalamtes weist auf die Stärke Warnkes in der Landespolitik. Wie sich bereits seit Beginn der Besatzungszeit zeigte, verdankte Warnke seine Position nicht alleine der Besatzungsmacht. Höcker und die anderen führenden Landespolitiker setzten sich auch deshalb nicht gegen ihn durch, weil sie zu keiner Koordination ihrer Kritik und zu keinem gemeinsamen Widerspruch fanden. Entsprechend den Worten eines britischen Geheimdienstberichts über die mecklenburgische Landesregierung von 1948, gewährten sie Warnke statt dessen die Rolle des „Schiedsrichters bei jeder Auseinandersetzung zwischen anderen Ministern und ihren Vertretern; sein Wort ist Gesetz". 102

Komplementär zu Warnkes Position war die vergleichsweise marginale Rolle Hökkers, dem nicht nur die Unterstützung der KPD und der Sowjets, sondern auch die Hilfe politisch erfahrener Verwaltungsfachleute fehlte. Ende November 1945 berief Höcker

${ }^{100}$ Fenske, Verwaltung, S. $89 f$.

101 Tätigkeitsbericht des Personalamtes (MLHA, MdI 31, Bl. 75ff.).

${ }^{102}$ Der Berichterstatter hielt ferner fest, daß Warnke als Agent des NKWD und aufgrund seiner Ehe mit Emma Warnke, deren Vater bereits in den frühen zwanziger Jahren in die Sowjetunion emigriert sei, „die Zügel der Regierung in der Hand [halte], und alle größeren Entscheidungen von ihm nach einer entsprechenden Anweisung durch die SMA gefällt" würden ( Regional German Administrations in the Soviet Zone. Land Mecklenburg“, in: PRO-FO 1030, 110). In dieser teilweise sehr detaillierten Analyse der Landesverwaltung in Schwerin vom März 1948, nach der Warnkes Position innerhalb der Landespolitik und gegenüber der eigenen Partei nicht hoch genug eingeschätzt werden könne, finden sich außer einigen statistischen Irrtümern hinsichtlich der Personalverteilung zwischen den einzelnen Ressorts fast keine Fehler, was auf einen guten Informanten auf Ministerialebene deutet und gleichzeitig die Exklusivität des Personalamtes unterstreicht. Dieser und weitere Berichte in den Unterlagen der britischen und US-amerikanischen Militärregierungen zeugen von der westlichen Spionage gegen die SBZ, die immer wieder zur Legitimation drastischer Sanktionen gegen tatsächliche und vermeintliche Spitzel genutzt wurde (siehe beispielsweise IfZ, OMGUS 3/162-1/9; IfZ, OMGUS 7/28-3/24; PRO-FO 1005, 1633; PRO-FO 1005, 1741; PRO-FO 1005, 1747; PRO-FO 1005, 1748; PRO-FO 1005, 1749; PRO-FO 1005, 1750; PRO-FO 1030, 110; PRO-FO 1050, 467; PRO-FO 1051, 1088; PRO-FO 1056, 456). Die US-amerikanischen Dienste konzentrierten sich weniger auf den Norden der SBZ als auf Berlin und die an ihre Zone angrenzenden Länder. 
zwar Ministerialdirektor Lobedanz zum Leiter seiner Präsidialabteilung und Ministerialrat Max Suhrbier zu seinem „persönlichen Referenten in allen das Finanz- und Haushaltswesen der Landesverwaltung betreffenden Fragen", ${ }^{103}$ aber auch sie konnten ihn nicht nennenswert stärken. ${ }^{104}$ Das nicht nur in Mecklenburg-Vorpommern angewandte Konzept von KPD und Besatzungsmacht, die Landespräsidentschaft einem schwachen nichtkommunistischen Politiker zu übertragen, um die eigenen Vorstellungen durchsetzen zu können, hatte Erfolg. Dies verdankte sich vor allem der spezifischen landespolitischen Konstellation, die in hohem Maße von Höckers mangelhafter Konfliktbereitschaft, seiner Zurückhaltung und seinem Schweigen sowie der mangelhaften Koordination möglicher oppositioneller Zusammenhänge geprägt war. Die bereits in Güstrow erprobte Zusammenarbeit zwischen dem Sozialdemokraten und dem Kommunisten konnte in Schwerin trotz der Umkehrung der formalen Hierarchie fortgesetzt werden. In den Worten der britischen Agenten: Höcker „ist vollkommen abhängig von Hans Warnke [...] und tut nichts, ohne ihn vorher um Rat zu fragen ". 105

Seit der Entlassung der rechten Hand Höckers, Hans Jeß, im Juli 1945 hatte Warnke die eigene Position systematisch ausbauen und zentrale politische Bereiche der Landesverwaltung unter seine Kontrolle bringen können. Die Landesverwaltung war inzwischen so weit ausdifferenziert, daß er die Personalangelegenheiten im Laufe der Monate immer weniger persönlich bearbeitete, sondern an loyale Kommunisten in seiner Abteilung delegierte. Auch für die Beschlagnahmungen und die Bodenreform gab es eigene Ämter, die Goldenbaum, Löhr, Wilhelm Spreche und andere durchsetzungsfähige und KPD-loyale Fachleute unter Warnkes Aufsicht leiteten. Diese Sonderstrukturen waren so wichtig, daß sie auch beibehalten wurden, als die Landesverwaltung Ende 1945 entsprechend der Gliederung der Berliner Zentralverwaltungen umgestellt werden mußte: „Für die Abt. Bodenreform, Personalamt usw. sind keine Direktoren vorgesehen, sondern diese unterstehen dem Vizepräsidenten Warnke."106

Warnkes Handschrift war in diesen Bereichen nicht nur durch seine Unterschrift unter den zahlreichen Verordnungen zu erkennen: Entschiedenheit, Vehemenz und Strin-

${ }^{103}$ Höcker am 26. 11. 1945 an alle Fachabteilungen: „Zur Erfüllung dieses Auftrages kann Ministerialrat Dr. Suhrbier von allen Dienststellen die erforderlichen Auskünfte verlangen" (MLHA, MdI bis 1945 20).

${ }^{104}$ Ihre Rolle unterstreicht vielmehr die Ähnlichkeiten zwischen dem Landespräsidenten und der blassen Position der beiden bürgerlichen Parteien, in denen sie hohe Ämter bekleideten: Lobedanz war erster Vorsitzender der CDU Mecklenburg-Vorpommern, Suhrbier wurde im April 1947 Landesvorsitzender der LDP.

105 "Gedeckt durch die SMA in Schwerin und Karlshorst, lenkt Warnke sie alle, einschließlich den Ministerpräsidenten Höcker." Die Schwierigkeiten nahmen derart große Ausmaße an, daß Warnke nach diesem Bericht von 1948 Höckers Flucht in den Westen fürchtete (PRO-FO 1030, 110). Das Gerücht über seine, Moltmanns oder Warnkes Flucht in den Westen war im Herbst 1948 so verbreitet, daß Höcker es am 1.11. 1948 öffentlich dementierte. Dabei ging er auch auf die Westflucht anderer SED-Funktionäre in den Westen ein und nannte namentlich das Mitglied des mecklenburgischen Landtags und des ZS der SED, Erich Walter Gniffke (MLHA, MinPräs 1059a, Bl. 44). Siehe auch die Unterlagen über die Westflucht des ehemaligen Leiters des Amtes für Wirtschaftsplanung, Wolf Reichardt (KPD/SED), und die Deckung seiner zurückgelassenen Schulden (MLHA, MinPräs 956, Bl. 6-31).

${ }^{106}$ MLHA, MinPräs 642, B1. 152f. Seit dieser Umstellung bis zur Gründung der Landesregierung und ihrer neun Ministerien gab es nicht mehr acht, sondern 15 bis 17 Fachabteilungen. 
genz des Personalamts entsprachen der Durchsetzungskraft der anderen Warnke unterstellten Institutionen. Schon im August 1945 hatte er seinen Mitarbeitern ein straffes Informationssystem auferlegt, durch das er stets rechtzeitig unterrichtet war und mitbestimmen konnte: Nach allen persönlichen Verhandlungen mit Sachbearbeitern der SMAM sei ihm „ein kurze[r] stichwortartige[r] Bericht vorzulegen“, weil dies zu „einer einheitlichen Ausrichtung der Arbeit der ganzen Abteilung [...] unbedingt notwendig“ sei. ${ }^{107}$ Während Höcker die Informationen aus den untergeordneten Dienststellen wiederholt anmahnen mußte, ${ }^{108}$ war Warnkes Appell langfristig wirksam. Es gibt keine Hinweise auf Informationsdefizite oder verpaßte Interventionsmöglichkeiten und auch keine weiteren Aufforderungen zur Verbesserung der internen Kommunikation oder Disziplinierung der eigenen Behörde.

\section{Die Informationszentrale}

Grundlage für die zentrale politische Stellung des Personalamtes waren nicht nur die formalen Einstellungs- und Entlassungskompetenzen, sondern vor allem sein über jede Person in der Verwaltung gesammeltes Wissen. Dies betraf die alten und neuen Dienstkräfte auf subalternen Positionen in verschiedenen Landesabteilungen, Städten und Kreisen ebenso wie die neuen Funktionsträger auf herausgehobenen Posten wie Dezernenten, Abteilungsleiter, Oberbürgermeister und Landräte. Vorerst bewegten sich die Schritte zum Ausbau des Informationsstandes nur im Rahmen der üblichen Aufgabenstellung dieses Amtes, das allen anderen Dienststellen in Personalangelegenheiten übergeordnet war. Die organisatorische Basis für die im Laufe der folgenden Jahre sukzessive vergrößerte Informationssammlung, die später gegen unliebsame oder, aufmüpfige einzelne zur Verfügung stand, wurde im Herbst 1945 gelegt. ${ }^{109}$

Bereits am 19. September 1945, während der ersten landesweit vereinheitlichten entnazifizierungsbedingten Entlassungswelle, sandte der Chef des Personalamtes, Paul Lau, den Fachabteilungen das Muster eines einheitlichen Personalfragebogens für alle staatlichen Dienststellen in Mecklenburg-Vorpommern zu, ${ }^{110}$ in dem durch eidesstattliche Unterschrift beglaubigte Informationen über folgende Bereiche abzugeben waren: Name, Vorname, Geburtsort, Familienstand, Ehepartner, Kinder, Schulausbildung, Ausbildung, Studium und Tätigkeit seit der Schulentlassung, Militär- und Kriegsdienst, Partei- und Gewerkschaftszugehörigkeit vor 1933 und nach dem 2. Mai 1945; Mitgliedschaft in NSDAP, SA, SS, NSKK, NSFK, NS-Frauenschaft; kriminelle und politische Strafen, Zuchthaus-, Gefängnis- oder KZ-Aufenthalte; Name und Parteizugehörigkeit von Vater, Ehepartner und erwachsenen Kindern. Keine zwei Monate später, am 13. November 1945, erging eine erneute allgemeine Anfrage an alle Fachabteilungen über die Personalverhältnisse in ihren und den nachgeordneten Abteilungen, 111 in der zum Mo-

\footnotetext{
107 MLHA, MdI 60, Bl. 332.

108 Siehe Kapitel I.2, S. 92.

${ }^{109}$ Siehe Anmerkung 63 in Kapitel II.1. Die Vermischung des administrativen Personals mit dem der späteren Landesregierung und der lokalen Politiker basierte auf der Nähe zwischen Regierung, Verwaltungsapparat und Parteien, deren unscharfe Grenzen auch daran zu erkennen sind, daß die Regierung bis Ende 1946 als Landesverwaltung firmierte.

110 MLHA, MinPräs 947, Bl. 27, das Muster ebenda, Bl. 28.
} 
natsende Nachweisungen aller beschäftigten Dienstkräfte nach dem Stand vom 30. November 1945 angefordert wurden. Außerdem wies Lau auf die Pflicht des Personals hin, „Änderung der persönlichen Verhältnisse jeweils unverzüglich dem Personalamt“ zu melden: Es ging nicht nur um Beförderungen, Abmahnungen oder Versetzungen, sondern auch die Eheschließungen, Geburten, Umzüge oder Parteieintritte fanden Interesse. Zur einfacheren Verwaltung und besseren Handhabung dieser Informationsfülle forderte Lau am 15. November 1945 „von allen Beamten und Angestellten [... ] je 3 Fragebogen und Lebensläufe“..112 Am 13. Februar 1946 suchte der Mitarbeiter des Personalamtes, Regierungsdirektor Romahn, wiederum einen personalpolitischen Überblick, diesmal bei Oberbürgermeistern, Landräten und Bürgermeistern über die Kreise und Städte, ${ }^{113}$ und obwohl das Amt nun schon seit längerer Zeit die Personalakten aller Fachabteilungen führte und bereits am 19. September 1945 Personalfragebögen mit ähnlichen Fragen versandt worden waren, erinnerte er alle Fachabteilungen am 19. Februar 1946 noch einmal daran, jede Änderung bei allen Dienstkräften (Familienstand, Wohnungswechsel, Beitritt zu einer politischen Partei, Krankheit) zu melden. ${ }^{114}$

Das Interesse des Personalamtes beschränkte sich nicht auf die dienstlichen Belange, sondern forderte auch Einblick in verschiedene außerdienstliche und private Angelegenheiten. Die Landesverwaltung stellte soziale, parteipolitische und moralische Standards für ihre Mitarbeiter nicht nur auf, sondern suchte sie auch durchzusetzen. Der weitgehende informationelle Zugriff ermöglichte Sanktionen oder Korrekturen bei mißliebigem Verhalten, diente aber auch der präventiven Disziplinierung: Jeder Mitarbeiter akzeptierte durch seine Unterschrift die strukturelle und weitreichende Neugierde des Arbeitgebers und wußte von der für den einzelnen unzugänglichen Informationslage, die bei Differenzen eventuell belastendes Material zur Verfügung stellte. ${ }^{115}$

Die informationelle Erfassung der Dienstkräfte war nur ein Teil der Aufgaben des Personalamtes; darüber hinaus bestimmten die regulären Überprüfungs- und Genehmigungsprozeduren seine tägliche Arbeit, für die es bei jeder Einstellung und Entlassung in den staatlichen Dienststellen verantwortlich war. Beides, die umfassenden Informationserhebungen und die Routineuntersuchungen bei jeder Personalveränderung, waren zentrale Instrumente des Personalamtes bei der Entnazifizierung und der Veränderung der Administration im Sinne der Kaderverwaltung. Der bereits im November festgelegte technische Standard - dreifache Ausfertigung und „mit der Schreibmaschine geschrieben " - förderte die Effizienz und zeugt - trotz der wiederholt vorgetragenen Rhetorik wider den ,Bürokratismus` - von der Übernahme administrativer Arbeitsweisen, die auf

111 MLHA, MdI 1297.

112 MLHA, MdI 614.

${ }^{113}$ MLHA, MdI 903.

${ }^{114}$ MLHA, MdI 615, Bl. 20. Das Personalamt versandte bis zum Frühjahr 1946 noch weitere Anfragen, die - ebenso wie die beklagte Mißachtung des Amtes - sowohl von den Anfangsschwierigkeiten als auch von seiner penetranten und letztlich erfolgreichen Durchsetzung zeugen $(z . B$. MLHA, MinPräs 211b; MLHA, MdI 613).

${ }^{115}$ Die präventive Sammlung belastenden Materials zeigt die frühen Verbindungen der Entnazifizierungs- und Personalpolitik in der SBZ zu geheimdienstlichen Tätigkeiten; die Exklusivität und Unzugänglichkeit dieses Geheim- und Machtwissens betonte das Personalamt auch in einer Stellungnahme vom 4. 4. 1946 zu den Besoldungsrichtlinien (MLHA, MdI 759, siehe Kapitel II.2, S. 164f.). 
eine prinzipielle Ordnung und eine umfassende Erfassung gerichtet waren. Diese Effizienz und Ordnung war angesichts des weitreichenden Anspruchs des Personalamtes notwendig, denn es beschränkte sich nicht auf die Ansammlung von Informationen, sondern suchte sie auch zur Durchsetzung der politischen Richtlinien für die personelle Zusammensetzung der neuen Verwaltungen einzusetzen. Dazu sicherte es sich umfangreiche Eingriffs- und Vetomöglichkeiten, so daß keine Einstellung im öffentlichen Dienst ohne seine explizite Zustimmung möglich wurde.

Bereits durch die Verfügung vom 21. August $1945^{116}$ hatte die Abteilung Innere Verwaltung festgelegt, daß ihr bei jeder Einstellung und Entlassung auch „eine fachliche und charakterliche Beurteilung" einzureichen sei, womit sie sich angesichts des hohen und öffentlich betonten Politisierungsgrades der staatlichen Dienststellen ein Vetorecht zusprach. Ende Oktober 1945 sah sich Lau durch eine Initiative der Abteilung Kultur und Volksbildung veranlaßt, die Gültigkeit dieser Verfügung erneut und prinzipiell zu bestätigen und zu erweitern: ${ }^{117}$ leitende Personen nachgeordneter Dienststellen bestelle der Präsident, Hilfsarbeiter die Dienststellenleiter - allerdings immer erst nach der Prüfung durch das Personalamt. Ferner sei „der betriebliche Gewerkschaftsausschuß vorher gutachtlich zu hören“. Zusammengefaßt zählte er folgende Schritte für alle Einstellungen in nachgeordneten Dienststellen auf: Zuerst sei durch den Dienststellenleiter eine Vergütungsberechnung aufzustellen und ein vorläufiger Arbeitsvertrag abzuschließen, dessen Wirksamkeit nach der präsidentialen Genehmigung eintrete; Arbeitsvertrag und Vergütungsberechnung seien dann mit einem gewerkschaftlichen Gutachten, dem Personalfragebogen „nebst sonstigen Personalunterlagen (Lebenslauf, etwaige Zeugnisse usw.) mit einer kurzen fachlichen, charakterlichen und politischen Beurteilung unter Angabe der geplanten Verwendung " und einem Hinweis auf die vakante Planstelle durch die Fachabteilung beim Personalamt zur Prüfung vorzulegen. Dort erhalte der Vertrag gegebenenfalls einen Genehmigungsvermerk und gehe an die Dienststelle zurück. Bei Entlassungen sei ebenso zu verfahren: Die Dienststelle habe eine Erklärung über die dienstlichen, persönlichen oder politischen Gründe der Entlassung vorzulegen; bei politisch motivierten Entlassungen seien die Gründe sogar „eingehend“ zu erläutern.

Damit erhielt das Personalamt Einblick und Entscheidungskompetenz bei jeder einzelnen Einstellung. Zahlen belegen die umfangreiche Zunahme des Personalbestandes im ersten Jahr der Besatzung, der die politische Relevanz der Auseinandersetzungen um die Einflußnahme auf Einstellungsverfahren verdeutlicht: Die Anzahl der Dienstkräfte in der Zentralverwaltung stieg von 304 am 1. August 1945 auf 821 Dienstkräfte am 25. Mai 1946. Angesichts der vielen Entlassungen wurden noch mehr Einstellungen und Versetzungen vorgenommen, als der absolute Personalanstieg angibt. ${ }^{118}$ Ähnlich war die Personalentwicklung in den Landratsämtern und Stadtverwaltungen, die Ende 1946 (ohne die Verwaltungen in den kreisangehörigen Städten und Gemeinden) 16570 Dienstkräfte zählten. ${ }^{119}$ Das Personalamt konnte jede Personalveränderung beeinflus-

\footnotetext{
116 MLHA, MinPräs 947, Bl. 16; siehe Anmerkung 328 in Kapitel I.2.

117 MLHA, MdI 615, Bl. If.

${ }^{118}$ Nach einem Bericht Romahns vom 23. 5. 1946 über die Entwicklung des Personalamtes belief sich in den Zentralverwaltungen „die Zahl der aus politischen Gründen entlassenen Beamten und Angestellten auf rd. 300" (MLHA, MinPräs 1309, Bl. 156f.; siehe auch MLHA, MdI 31, Bl. 75 ff.).
} 
sen, weil die obligatorische Prüfung ermöglichte, ,fachliche‘, ,charakterliche‘ oder ,politische' Einwände gegen Bewerber zu erheben und dem Präsidenten die Anstellungsanträge nicht zur Genehmigung vorzulegen. Damit hatte sich die Informationszentrale in allen Personalfragen zur entscheidenden Verbindungsstelle zwischen dem Präsidenten und den Dienststellen seiner Verwaltung gemacht. Sie erließ nicht nur allgemeine politische Vorgaben, sondern hatte sich auch formal das Recht gesichert, jede mißliebige Abweichung zu verhindern. So konnte es die politischen Vorstellungen und Vorgaben über das Personal der neuen Verwaltung gezielt realisieren.

Nach dieser Regelung für die Fachabteilungen erließ Warnke am 28. November 1945 eine ähnliche Verordnung an die Landräte und Oberbürgermeister: ${ }^{120}$ Seit dem 13. September 1945 seien der Aufbau und die Aufgaben der Landes- und Kommunalverwaltungen festgelegt. ${ }^{121}$ Für eine "geordnete Verwaltung“ sei nun „vor allem eine einheitliche Lenkung des Personalwesens erforderlich“, weswegen das Personalamt mit der „zentralen Leitung und Bearbeitung der Personalangelegenheiten der Oberbürgermeister und Landräte beauftragt" sei. Danach würden Oberbürgermeister, Landräte, ihre Stellvertreter und die leitenden Mitarbeiter vom Präsidenten ernannt. Alle sonstigen Einstellungen und Entlassungen auf Stadt- und Kreisebene entsprachen dem für die Fachabteilungen festgelegten Prozedere: Mit Ausnahme der subalternen Dienstkräfte der kreisangehörigen Städte überwachte das Landespersonalamt nun das gesamte Personal des öffentlichen Dienstes im Land. ${ }^{122}$

Selbstverständlich spiegeln Verordnungstexte nicht das Maß ihrer Verwirklichung wider. Während sie den Einfluß des Personalamts formal ausbauten, wurden in Schwerin Auseinandersetzungen über ihre Realisierung und die weiteren Rahmenbedingungen der Personalpolitik ausgetragen. Einerseits klagte das Personalamt über die mangelhafte Achtung seiner Autorität, andererseits ging es um verschiedene Versuche, weitere Instanzen verantwortlich in die Einstellungsverfahren einzubeziehen.

\section{Monopolisierung trotz präsidialer Kritik}

Das Landessekretariat der KPD beauftragte Warnke in seiner Sitzung am 22. November 1945,123 den Remigranten Kundermann als Leiter des zentralen Personalamtes einzusetzen. Damit folgte Kundermann seiner Ehefrau Aenne, die bereits im Mai 1945 mit der Initiativgruppe Sobottka nach Mecklenburg eingeflogen worden war, zur ersten dreiköpfigen provisorischen Landesleitung der KPD gehört hatte und deren Personalabteilung leitete. Warnkes Politik stimmte generell mit der der KPD überein, in der er selbst eine vergleichsweise marginale Stellung einnahm; aber nur selten intervenierte die

\footnotetext{
${ }^{119}$ Siehe den statistischen Anhang und MLHA, MinPräs 1309, Bl. 154-157.

120 MLHA, MdI 760.

121 MLHA, MdI bis 1945 84, Bl. 64-68; siehe Anmerkung 223 in Kapitel I.1.

122 Die Korrespondenzen des Personalamtes waren jeweils ohne spezifischen Ansprechpartner formuliert oder an die Leiter der Fachabteilungen beziehungsweise die Oberbürgermeister und Landräte gerichtet und wurden von diesen an die Leiter der jeweils nachgeordneten Behörden weitergeleitet. Weil es in den einzelnen Behörden nur geringfügige Ansätze eigener personalpolitischer Abteilungen gab, konnte das Personalamt unmittelbar in die Angelegenheiten jeder Dienststelle eingreifen.

${ }^{123}$ MLHA, LL KPD I/2, Bl. 234.
} 
Landesleitung ausdrücklich in einer Verwaltungsangelegenheit oder verpflichtete Warnke zu bestimmten politischen Schritten. ${ }^{124}$ Die überragende Bedeutung der Personalpolitik machte die Besetzung der dafür verantwortlichen Behörde zu einer Angelegenheit, die sich der ausschließlichen Kompetenz Warnkes und der SMAM entzog. Weil das zentrale Personalamt der Landesverwaltung beim Aufbau des Staatsapparates in Mecklenburg-Vorpommern als Ersatzorgan für die mangelhaft einsatzfähige Landespartei fungierte, wurde dafür ein hochgradig zuverlässiger und in der zwölfjährigen Emigration in der Sowjetunion erprobter Genosse ausgewählt. ${ }^{125}$ Während Lau im Januar 1946 in den Vorsitz der Sozialversicherung wechselte, ${ }^{126}$ übernahm Kundermann die Leitung des Personalamts und wurde in den folgenden Monaten und Jahren zu einer zentralen Figur der Personal- und Entnazifizierungspolitik in Mecklenburg-Vorpommern.

Das Protokoll vom 22. November 1945 enthielt nur eine knappe Begründung des Wechsels von Lau zu Kundermann: „Das Personalamt muß jedoch einen anderen Charakter tragen als bisher." Es wurde nicht festgehalten, welche Bereiche der bisherigen Arbeit des Amtes als defizitär oder gar konfliktiv galten, aber ein Bericht Bürgers über den Verwaltungsaufbau auf der erweiterten Sitzung des Sekretariats des Zentralkomittees der KPD am 19./20. November 1945 in Berlin ${ }^{127}$ zeigt, daß es dabei auch um die Durchsetzung kommunistischer Hegemonie gegenüber politischem und administrativem Eigensinn ging: „Ich will nur ein Beispiel anführen, um Euch zu zeigen, wie wir kämpfen müssen. Wir hatten schon vor Monaten vorgesehen, daß der Gen[osse] Kundermann Kaderchef in der Verwaltung werden sollte. Das war alles besprochen. Dort hat jeder Vizepräsident und jeder Regierungsdirektor seine eigene Kaderabteilung, und unser Bestreben geht jetzt darauf hin, eine zentrale Kaderabteilung für die Verwaltung zu bekommen, und als Chef haben wir Gen[osse] Kundermann vorgesehen. Ich will Euch nicht erzählen, welche Schwierigkeiten wir mit dem guten Gen[osse] Warnke haben, daß diese Stelle überhaupt geschaffen wird. Acht Tage ist der Genosse da, und wir können ihn nicht durchdrücken. Warum? Weil die Vizepräsidenten, die bisher ihren ei-

${ }^{124}$ Einzigartig war der Vorgang allerdings nicht: In der gleichen Sitzung wurde beispielsweise der für Justiz verantwortliche Vizepräsident Grünberg „verpflichtet, schnellstens eine Verordnung herauszubringen, die es ermöglicht, Faschisten abzuurteilen. Es ist ein unhaltbarer Zustand, daß bis jetzt noch kein einziger Faschist abgeurteilt ist, angeblich gibt es keine Paragraphen, um diese Leute abzuurteilen" (MLHA, LL KPD I/2, Bl. 234). Während der Anforderung, Lau durch Kundermann auszutauschen, nachgekommen wurde, waren die geforderten Verurteilungen hier nicht möglich, da das Kontrollratsgesetz Nr. 10 zur Bestrafung von NS- und Kriegsverbrechern bestimmte, daß deutsche Gerichte dafür von den Besatzungsbehörden jeweils ausdrücklich für zuständig erklärt werden müßten (Amtsblatt des Kontrollrats, Nr. 3 [1946], S. 52); entsprechend uneinheitlich wurde zwischen den Ländern und Provinzen der SBZ verfahren (Zur Geschichte der Rechtspflege, S. 215). Mit dieser Anweisung an Grünberg zeigte sich die KPD-Landesleitung wiederum in einer entscheidenden politischen Angelegenheit mangelhaft informiert, was wohl auch einer der Gründe ihrer weitgehenden landespolitischen Abstinenz war.

${ }^{125}$ Der britische Bericht über die Landesregierung Mecklenburg zählt Kundermann zu den NKWD-Agenten, was angesichts seiner Emigration und seiner Tätigkeit in den folgenden Jahren nicht verwundert (PRO-FO 1030, 110).

126 MLHA, MdI 702.

${ }^{127}$ SAPMO-BA, RY 1/I2/5, 40, Bl. $178 \mathrm{f}$. 
genen Laden hatten, sagen, sie wollen über Einstellungen natürlich mitbestimmen, und der sozialdemokratische Präsident Höcker hat auch seinen eigenen Schädel."

Die parteiintern gebrauchte Sprache war ehrlich: Es wurde nicht nur der zumeist vermiedene Kader-Begriff benutzt, der die KPD-Konzepte für den Verwaltungsaufbau präziser benannte als der allgemeine Personal-Begriff, sondern auch darüber geklagt, daß der Präsident der Landesverwaltung eine eigene Meinung, „seinen eigenen Schädel“, habe. Deutlicher konnten das Selbstverständnis als Avantgardepartei und der Anspruch auf konkrete politische Weisungsberechtigung nicht formuliert werden. Es ging in diesem zentralen Politikbereich nicht um Mehrheiten oder Konsensbeschlüsse, sondern um das „Durchdrücken" eigener Positionen. Daß es sich dabei nicht um eine private Verärgerung irgendeines Landespolitikers handelte, sondern um einen grundsätzlichen $Z$ weifel an der Legitimität anderer politischer Akteure - in diesem Fall des Landespräsidenten -, zeigt die unmittelbare Reaktion Walter Ulbrichts, der die politische Funktionalisierung der Entnazifizierung selbst in der Spitze der Landesverwaltung als probates Mittel vorschlug, um Gegner gefügig zu machen: „Wenn nachgewiesen werden kann, daß in der Verwaltung Nazis sind und daraus Sabotage resultiert, so soll die Presse das veröffentlichen, dann werden die Leute von der Zentralabteilung leichter überzeugt sein. Die Presse erfüllt ihre Pflicht nicht. “128 Dieser antisozialdemokratische Vorschlag Ulbrichts unterstreicht die bewußte Strategie, Höckers Einfluß systematisch zurückzudrängen, und stieß im Sekretariat des Zentralkomittees der KPD keineswegs auf kritische oder beschwichtigende Reaktionen. Vielmehr bedauerte Bürger, daß die Zensur jede Kritik an der SPD streiche, weil dies die Einheitsfrontpolitik störe. Trotz der beklagten Schwierigkeiten erreichte die KPD ihr Ziel: Kundermann übernahm das Amt, arbeitete im folgenden eng mit Warnke zusammen und setzte bis zum Sommer 1946 durch, daß alle anderen Behörden im Land die privilegierte Position des Personalamtes anerkannten. ${ }^{129}$

Am 1. Oktober 1945 kritisierte der Direktor der Abteilung Inneres, Franz Ballerstaedt, die Mißachtung des Personalamtes bei Neueinstellungen. ${ }^{130}$ Dies war die erste einer Vielzahl von Rügen, die den Behörden aus dem immer gleichen Grunde erteilt wurden und in penetranter Weise Kompetenzen und Einfluß des Amtes einklagten und betonten. Ähnlich eine Woche später: Warnke schickte am 8. Oktober 1945 wiederum eine Verfügung über Einstellungen und Entlassungen an alle Fachabteilungen, ${ }^{131}$ in der die Häufung von selbständigen Einstellungen und wiederholten Abschlüssen von Arbeitsverträgen bei den Fachabteilungen moniert wurde, obwohl dafür ausschließlich das Personalamt zuständig sei. In diesem Schreiben ersuchte der Vizepräsident um Verständnis für diese Regelung und beschränkte sich nicht auf Anweisungen und Verbote. „Zum Verständnis der unbedingten Notwendigkeit dieser Zuständigkeitsregelung und ihrer Einhaltung" erläuterte er die Bindungen, die sein Amt zu respektieren habe: eine freie Planstelle, die Zustimmung des Arbeitsamtes ${ }^{132}$ und das Gutachten des gewerkschaftli-

128 SAPMO-BA, RY 1/I2/5, 40, Bl. 179.

129 Auch in den anderen Landesinnenministerien der SBZ konnte die Hegemonie der KPD bis zum Frühjahr 1946 durchgesetzt werden (Meinicke, Entnazifizierung [Diss], S. 100).

130 MLHA, MinPräs 947, Bl. 26.

131 MLHA, MinPräs 947, Bl. 35. Siehe ähnliche Verordnungen u. a. in: MLHA, MinPräs 211; MLHA, MdI 613; MLHA, MdI 615; MLHA, MdI 759.

132 Die Arbeitsämter besaßen seit dem 21. 9. 1945 das Arbeitsvermittlungsmonopol und die Zu- 
chen Betriebsausschusses. Weil Warnke einsah, daß in „Zeiten des Umbruchs" nicht jede Verordnung „auf das Genaueste innegehalten werden“ könne, gewährte er einen gewissen Spielraum: Es sei gestattet, in Ausnahmefällen die Zustimmung des Personalamtes für vorläufige Beschäftigungen nur fernmündlich einzuholen und die Unterlagen mit einer Begründung der Umgehung der Vermittlung durch Arbeitsamt und Personalamt erst später nachzureichen. Abschließend drohte Warnke den Fachabteilungen, sie würden die Folgen von Verstößen gegen die ergangenen Verfügungen tragen müssen. Zum Jahresende beschwerte er sich erneut über „Unklarheiten“ bei Einstellungen und Entlassungen und forderte wiederum eine straffere Personalpolitik. ${ }^{133}$ Durch die Übernahme neuer, zeitbedingter Aufgaben habe „sich der Personalbestand der Landesverwaltung in den letzten Wochen stark vergrößert", so daß „unbedingt ein einheitliches Verfahren eingehalten werden“ müsse, weshalb Einstellungen - weiterhin - „einzig und allein vom Personalamt vorzunehmen" seien und eine "straffe Personallenkung" not tue. Die Zielsetzung war klar, weil neben diesen ständig wiederholten Hinweisen auf die Einheitlichkeit der Personalpolitik auch die selbständige Werbung von Fachkräften und die Ausstellung von Zeugnissen untersagt wurden: Hauptsächlich ging es um die Unterordnung der Behörden unter die Weisungskompetenz des Personalamtes. Die Vielzahl der Ermahnungen spiegelt aber auch die geringe Bereitschaft der Fachabteilungen und anderen Behörden, sich in Zeiten des Umbruchs und Personalmangels durch zentralistische und starre Verfahrensregelungen fachlich und personell einengen zu lassen; die von Bürger im Zentralkomitee des KPD erwähnten Auseinandersetzungen im Präsidialkollegium markieren ferner die Ablehnung der mit diesem Zentralismus verbundenen politischen Folgen.

Personalpolitik konnte nicht nur von einem zentralen Amt aus geregelt werden, sondern benötigte die Unterstützung in den Betrieben und Behörden. Dazu boten sich die Betriebsräte und Gewerkschaften an, die nicht mehr als Gegenpol des Arbeitgebers, sondern als politischer Bündnispartner der hegemonialen Partei und des Staatsapparates verstanden wurden. ${ }^{134}$ Dies wurde in der Landesverwaltung möglich, als ihr betrieblicher Gewerkschaftsausschuß und sein Vorsitzender, Saul, am 10. September 1945 gewählt und vom FDGB-Ortsausschuß bestätigt wurden. In seinem ersten Bericht zählte Saul die Betriebsratsaufgaben auf und nannte noch vor der Verantwortung des Betriebsrats für die Effektivierung der Verwaltungsarbeit die Verhandlungen mit dem Arbeitgeber und die politische Organisierung der Beschäftigten im FDGB, die „Bereinigung bezw. Freihaltung des Betriebes von nazistischen Elementen und jeder nazistischen oder militärischen Ideologie“ und das Recht zur Mitwirkung bei Entlassungen und Einstellungen.

stimmungspflicht für jede nicht automatische Lohn- und Gehaltsänderung sowie für alle nicht entnazifizierungsbedingten Entlassungen und Kündigungen (Amtsblatt, Nr. 1 [1946], Bl. 13f.).

133 MLHA, MdI 615, Bl. 5f. Dieses Mal erklärte er die sofortige Meldung für notwendig, um alle Angehörigen der Zentralverwaltung mit einem „Dienstausweis in deutscher und russischer Sprache [...], dessen Besitz unbedingt notwendig ist", auszustatten.

134 Das ZK-Mitglied Dahlem hatte in Mecklenburg schon vor der Gründung des FDGB auf den regierungsnahen Charakter der neuen Gewerkschaft hingewiesen (MLHA, LL KPD I/3, Bl. 28f., 40; siehe Kapitel I.2, S. 98). 
Bei der allgemeinen Aussprache in der ersten Ausschußsitzung wurde dies dahingehend konkretisiert, „daß es besonders zur ,Mitwirkung bei Einstellungen und Entlassungen " unbedingt erforderlich sei, daß der Betriebsausschuß ab sofort vor Entlassungsverfügungen oder Einstellungsgenehmigungen gehört wird“. ${ }^{135}$ Drei Tage später, der Betriebsrat existierte seit gerade sieben Tagen, bat Saul Warnke darum, dem Personalamt die „Anweisung zu geben, daß der betriebliche Gewerkschaftsausschuß ab sofort vor Entlassungsverfügungen und Einstellungsgenehmigungen gehört “ werde. ${ }^{136}$ Ballerstaedt bestätigte diesen Brief am 25. September 1945 gegenüber Lau, und nachdem sich am 26. September 1945 auch Höcker einverstanden erklärt hatte, ${ }^{137}$ wurden alle Fachabteilungen am 1. Oktober $1945^{138}$ von Ballerstaedt informiert, daß bei allen Einstellungen und Entlassungen in der Landesverwaltung der betriebliche Gewerkschaftsausschuß vorher gutachterlich zu hören sei. Die nachgeordneten Dienststellen hatten also ab sofort bei der Vorlage von Personalunterlagen beim Personalamt ein Gutachten des betrieblichen Gewerkschaftsausschusses beizulegen.

Damit hatte sich der Betriebsrat durch eigene Initiative das Recht erwirkt, über Einstellungen und Entlassungen in der Zentralverwaltung mitzubestimmen. ${ }^{139}$ Für die gesamte Landesverwaltung zeichnete dabei der zentrale Betriebsrat verantwortlich, dessen Leitung in den Händen von Warnkes Vertrautem Saul lag, der ihm schon in der Zeit als Oberbürgermeister von Güstrow als persönlicher Sekretär nahegestanden hatte. Von den sieben gewählten Mitgliedern des Betriebsausschusses (darunter zwei Frauen) waren je drei Sozialdemokraten und Kommunisten und ein Christdemokrat. Die Nähe dieser Massenorganisation zu den Arbeiterparteien stützte die zentrale Position der Abteilung Innere Verwaltung in Personalfragen, denn FDGB und Betriebsausschuß stellten das Entscheidungsmonopol des Personalamtes nicht in Frage, sondern dienten ihm vielmehr durch ihre intimen betriebsinternen Kenntnisse. ${ }^{140}$

Anders als bei Betriebsräten und Gewerkschaft, deren Partizipation bei der Entnazifizierungs- und Personalpolitik nicht als Bedrohung, sondern Effektivierung des Aus-

135 MLHA, MinPräs 1032, BI. 2. Dies entsprach den Ausführungen des Leiters der Propagandaabteilung beim ZK der KPD, Fred Oelsner, über die politischen Aufgaben der neuen Gewerkschaften auf einem Schulungsabend am 21. 9. 1945: Einerseits hätten sie in den Betrieben demokratische Verhältnisse herzustellen ("Führer befiehl, wir folgen" galt auch im Betrieb. Dieser Geist der Unterordnung muß aus den Betrieben völlig verschwinden“), andererseits ihre Entmilitarisierung und Entnazifizierung voranzutreiben und dabei „nicht locker zu lassen und die Leute unter ständigen Massendruck zu setzen“ (SAPMO-BA, RY 1/I2/2, 27, Bl. 42f.).

136 MLHA, MdI 759.

137 Ballerstaedt und Höcker verfaßten ihre Notizen handschriftlich auf dem Brief von Saul.

138 MLHA, MinPräs 947, Bl. 26.

${ }^{139}$ Dies entsprach dem späteren Betriebsrätegesetz des Alliierten Kontrollrats vom 10. 4. 1946, in dessen Artikel V.1.e dem Betriebsrat zur Aufgabe gemacht wurde, "mit den Behörden bei der Verhinderung aller Rüstungsindustrie und bei der Denazifizierung von öffentlichen und privaten Betrieben zusammenzuarbeiten “; Funktionären der DAF und NSDAP-Mitgliedern wurde in Artikel 2.2 die Mitgliedschaft in Betriebsräten untersagt (MLHA, MinPräs 84).

140 Der FDGB und andere, überparteiliche` Massenorganisationen wurden im Laufe der Entnazifizierung und der Sequestrierungen wiederholt auf Initiative von KPD/SEDlern in parteipolitisch paritätisch besetzte Gremien aufgenommen. Da die meisten Aktivisten und Funktionäre der Massenorganisationen Mitglieder der hegemonialen Partei waren, besorgten diese Erweiterungen vielfach eine Majorität der KPD/SED. 
schließlichkeitsanspruchs des Personalamtes angesehen wurde, verhinderte die Abteilung Inneres die Integration weiterer Beteiligter in die Personalpolitik. Nachdem die Gewerkschaften im September hinzugezogen waren, suchte Höcker im Oktober 1945 auch den Parteien einen Einfluß auf die Einstellungsverfahren einzuräumen. Sie waren im gemeinsamen Blockausschuß zusammengeschlossen und bemühten sich, alle Entscheidungen einstimmig zu treffen, wodurch jeder Partei ein zumindest theoretisches Vetorecht zustand. Noch weitergehende Abkommen waren zwischen den beiden Arbeiterparteien abgeschlossen: Die Vereinbarung der KPD-Landesleitung und des SPDLandesvorstandes vom 5. Oktober $1945^{141}$ legte zum Beispiel eine „enge Zusammenarbeit" „unter Achtung der demokratischen Grundsätze“ bei gemeinsam beschlossenen Aufgaben fest, die unter anderem die „endgültige Liquidierung des Faschismus“, den „Wiederaufbau des Landes“, die „Schaffung einer antifaschistisch-demokratisch-parlamentarischen Republik“ und die Vermeidung der „Fehler und Schwächen der Vergangenheit" vorsah. Ebenso wie mit Höckers Versuch, die Parteien in die Personalpolitik einzubeziehen, suchte sich die Sozialdemokratie auch durch diese Abkommen vor dem übermächtigen Einfluß der KPD abzusichern. Zur Einhaltung demokratischer Grundsätze strebte der sozialdemokratische Präsident nicht nur die Stärkung seines eigenen Amtes innerhalb der von Warnke dominierten Landesverwaltung an, sondern auch die der Parteien.

Am 26. Oktober 1945 veranlaßte Höcker ${ }^{142}$ eine bedeutende Veränderung in der Einstellungspraxis von leitendem Personal: Obwohl die Forderung in keiner bisherigen Verordnung aufgestellt worden war, kritisierte er, daß bei Einstellungen ,auch in der Landesverwaltung nicht immer nach dem Grundsatz verfahren [wurde], den Block der antifaschistischen Parteien vorher anzuhören“. Daher ordnete er an, daß die Besetzung von Hilfsreferentenstellen und höheren Posten nur mit seiner Zustimmung und der des Antifablocks möglich sei. Dies bedeutete die Einführung einer neuen Instanz in das ohnehin umfangreiche Einstellungsverfahren. ${ }^{143} \mathrm{Daß}$ es ihm um die Position der Parteien in der Landespolitik ging, zeigt die zweite Anordnung der Verordnung, wonach der Antifablock bei allen wichtigen Landeskonferenzen eingeladen werden müsse. Ähnlich wie Höckers wiederholte Forderungen nach mehr Transparenz, klareren Kommunikationsstrukturen und umfangreicheren Informationen in den ihm unterstellten Dienststellen blieb auch dieser Vorstoß weitgehend erfolglos, da er schon bald rückgängig gemacht wurde:

Das Personalamt schlug ihm am 2. Januar 1946 vor, das Zustimmungsrecht der Blockparteien wieder abzuschaffen; ${ }^{144}$ aufgrund der privilegierten Rolle der Parteien im politischen Leben der SBZ argumentierte es nicht mit seinem exklusiven Einfluß, sondern rein verfahrenstechnisch: die Anstellungsverfahren und ersten Gehaltszahlungen würden erheblich verzögert und freie Planstellen sowieso dem antifaschistischen Block gemeldet. Dazu schlug Romahn eine geheime Verfahrensänderung vor, die nicht mit den betroffenen Parteien abgestimmt und diskutiert werden sollte: „Nachdem nach mündlicher Anordnung des Herrn Präsidenten davon Abstand zu nehmen ist, Einstellungen von Hilfs-

141 MLHA, LL KPD I/4, B1. 85f.

142 MLHA, MdI 615, Bl. 3.

${ }^{143}$ Siehe oben die von Lau aufgezählten Einstellungsschritte (MLHA, MdI 615, Bl. 1f.).

144 MLHA, MdI 759. 
referenten dem antifaschistischen Block zu unterbreiten, bitte ich, sich stillschweigend damit einverstanden zu erklären, daß in Zukunft auch von einer Vorlage der Einstellungsunterlagen von Referenten abgesehen wird." Der personalpolitische Einfluß der Parteien sollte mit einer verwaltungstechnischen Begründung untergraben werden, ohne sie davon in Kenntnis zu setzen.

Der Präsident stimmte nicht zu, lehnte das Ansinnen aber auch nicht ab, sondern reagierte überhaupt nicht. Einen Monat später, am 5. Februar 1946, wandte er sich an sämtliche Fachabteilungen ${ }^{145}$ und verwies auf seinen Erlaß vom 26. Oktober 1945, mit dem er die Einstellungen in leitenden Positionen von seiner Zustimmung und der des Parteienblocks abhängig gemacht hatte, und bekräftigte damit seinen Standpunkt, den Romahn am 2. Januar 1946 abzuschaffen versucht hatte. Höcker richtete sein Schreiben aber nicht an das Personalamt, sondern nur an die Leitungen der Fachabteilungen, was Romahn ihm wenige Wochen später vorhielt: Mit dem Hinweis, von der Verfügung erst "auf dem Umwege über die Abt. Allgemeine und Innere Verwaltung Kenntnis erhalten “ zu haben, wies Romahn Höcker am 22. Februar 1946 auf sein Schreiben vom Januarbeginn hin. ${ }^{146}$ Das Ausbleiben eines Widerspruchs habe er als Zustimmung zu seinem Vorschlag des „stillschweigend[en]“ Einverständnisses gewertet und „seitdem die Einstellungsunterlagen nicht mehr dem antifaschistischen Block unterbreitet“. Das Personalamt hatte sich damit Höckers mangelhafte Bereitschaft zum Konflikt zur Durchsetzung eigener Positionen zunutze gemacht, indem sein Vorschlag so formuliert war, daß Hökkers Zögern und Schweigen einer Zustimmung gleichkam; und tatsächlich hatte der Präsident keinen direkten Widerspruch gewagt, sondern einen indirekten Weg gesucht. Sein Erfolg war allerdings nur begrenzt, denn Romahn bat ihn „dringend, es bei dem bisherigen Verfahren zu belassen“, zumal Höcker in Zweifelsfällen jederzeit Stellungnahmen des Parteienblocks herbeiführen könne. Außerdem seien aufgrund der eigenmächtigen Verfahrensänderung inzwischen die zuvor beklagten verwaltungstechnischen Verzögerungen behoben. Eine Antwort Höckers blieb wiederum aus - nun endgültig. Als Gegenspieler zu Höcker war nicht einmal Warnke persönlich notwendig; der Präsident der Landesverwaltung kapitulierte sogar vor den ,Sachargumenten' des Regierungsdirektors Romahn.

Trotz der Vormachtstellung Warnkes in der Landespolitik und auch im Präsidialkollegium und trotz der Sachargumente für mehr administrative Effizienz aufgrund einer möglichst weitreichenden Zentralisierung wurde diese Einseitigkeit nicht vorbehaltlos akzeptiert. Einzelne Behörden umgingen selbständig die Personalamtsrechte bei Einstellungen; und im Frühjahr 1946 artikulierte sich der Unmut im obersten landespolitischen Gremium, obwohl die KPD mit Grünberg und Warnke die Hälfte des Präsidialkollegiums stellte. Am 8. März 1946 informierte Höcker das betroffene Amt davon, ${ }^{147}$ $\mathrm{daß}$ in der Präsidialsitzung desselben Tages festgestellt worden sei, „daß die Aufgabe des Personalamtes u. a. auch darin besteht, neueinzustellendes Personal auf die politische Zuverlässigkeit zu prüfen. Zur Entlassung von Personal hat das Personalamt jedoch kein Recht, auch nicht im Einverständnis mit dem betrieblichen Gewerkschaftsausschuß. Die

\footnotetext{
145 MLHA, MdI 615, Bl. 18.

146 MLHA, MdI 759.

147 Ebenda.
} 
Entlassung von Beamten und Angestellten ist ausschließlich eine Angelegenheit des zuständigen Ressortchefs, d. h. des Vizepräsidenten oder des Präsidenten. Über die Einstellung von Personal hat ebenfalls nicht das Personalamt zu entscheiden, sondern der zuständige Ressortchef mit Zustimmung des Präsidenten. “ Diese Entscheidung der Präsidialsitzung war eine Veränderung der Verordnung Warnkes vom 27. Dezember 1945 über die „Einstellungen und Entlassungen von Dienstkräften für die Zentralverwaltung“, nach der Einstellungen und Entlassungen „einzig und allein vom Personalamt vorzunehmen“ waren, ${ }^{148}$ dessen Kompetenzen dadurch deutlich eingeschränkt wurden.

Keinen Monat später, am 3. April 1946, unterrichtete das Personalamt Warnke ${ }^{149}$ ausführlich über die Schwierigkeiten bei der Arbeit; diese seien so groß, daß „ein reibungsloses Funktionieren" noch nicht möglich sei. ${ }^{150}$ Der Grund liege in der Mißachtung der Kompetenzen des Personalamtes durch die anderen Abteilungen, die ihre Personalangelegenheiten zu selbständig handhabten und Ernennungen und Höhergruppierungen „meist handelt es sich um einflußreiche Persönlichkeiten“ - über das Personalamt hinweg durch persönlich eingeholte Zusagen des Präsidenten durchsetzten, obwohl teilweise weder Planstellen noch Planmittel zur Verfügung stünden. Dadurch sei das Amt „immer wieder vor Tatsachen gestellt und hat nur nachträglich, möglichst schnell, die ,Formalitäten" in Ordnung zu bringen“. Von Versetzungen erfahre das Amt häufig gar nichts, „wenn die abgebende Abteilung nicht befürchten würde, daß der Versetzte unnötig Planmittel und Planstelle in Anspruch nimmt". In diesen Fällen könne das Personalamt „nur nachträglich - wirkungslos - Einspruch erheben“.

Das Motiv für Romahns Kritik war keine reine Ordnungsliebe: Während die Personalangelegenheiten von den meisten Abteilungen nur im Hinblick auf die eigene Arbeitseffizienz betrachtet wurden, sicherte gerade die allgemeine Einhaltung der „Formalitäten “ die Position des Personalamtes. Eine effiziente Kontrolle und die Einflußnahme auf sämtliche Dienststellen des Landes waren nur möglich, wenn die vorgegebenen Verfahrenswege strikt eingehalten wurden. Deren Mißachtung hatte konkrete politische Konsequenzen: Aufgrund der mangelhaften Disziplin einzelner Dienststellen sei es nicht möglich, Höckers Anordnung, keine „Parteilosen“ und „Unpolitischen“ mehr einzustellen, durchzuführen, wodurch nur die Möglichkeit bleibe, nachträglich zum Eintritt in eine Partei aufzufordern. ${ }^{151}$ Indem sich das Personalamt für die Erfüllung dieser politischen Vorgaben verantwortlich erklärte, formulierte es auch sein Selbstver-

148 MLHA, MdI 615, Bl. 5f.

149 MLHA, MinPräs 947, Bl. 267-272.

150 Auch der Berliner KPD-Inspektor Ulbrieg beklagte nach seiner Inspektionsreise nach Schwerin Mitte April zu viele administrative Eigenständigkeiten einzelner Abteilungen, die nstark selbständig handeln, während die Personalverwaltung übergeordnet entscheiden müßte " (SAPMOBA, NY 4182 [NL Ulbricht], 954, Bl. 5f.).

151 Obwohl Höcker auf der Landesdelegiertenkonferenz von SPD und KPD am 23./24. 2. 1946 behauptet habe, daß die Arbeiterparteien, in unserer Verwaltung den größten Teil der Beamten und Angestellten " stellten, entspreche dies nicht den Tatsachen: bei der Zentralverwaltung seien nur $36 \%$ politisch organisiert, das heißt $64 \%$ parteilos, bei den nachgeordneten Stellen in Schwerin (ohne Stadtverwaltung) seien 32\% organisiert, also 68\% parteilos. Dem FDGB gehörten bei der Zentralverwaltung 68\%, bei den nachgeordneten Stellen in Schwerin 55\% an; diese Zahlen entsprechen in etwa denen im statistischen Anhang, die vom Personalamt erstellt wurden. 
ständnis als alle Dienststellen übergreifende politische Kontrollinstanz: Die einzelnen Dienststellen waren für die Fachkompetenz ihrer Ressorts zuständig, wie Finanzen, Kultur oder Gesundheit, und das Personalamt sicherte via Personalauswahl die gewünschte politische Ausrichtung. „Um nicht nur Kritik zu üben“, machte es abschließend Vorschläge, die es ,in die Lage versetzen [sollten], seine Aufgaben zu erfüllen“: Es sei - erneut - eine Verfügung an sämtliche Abteilungen herauszugeben, „die die Bedeutung des Personalamtes unterstreicht und den Abteilungen nochmals die selbständige Einstellung von Dienstkräften verbietet“.

Die Koordination in Warnkes Haus funktionierte reibungslos: Schon drei Tage später, am 6. April 1946, verfaßte der erste Vizepräsident das entsprechende Schreiben und berechtigte darin Kundermanns Amt, die Bezahlung der ohne sein Wissen eingestellten Personen abzulehnen: „Es muß dann denjenigen, die die Einstellung veranlaßt haben, überlassen bleiben, für die Besoldung dieser Dienstkräfte zu sorgen. “ Höcker unterrichtete er dagegen von der Kritik des Personalamtes erst sechs Tage nach Romahns Stellungnahme und drei Tage nach seinem eigenen Brief. ${ }^{152}$ Die Kritik enthalte „sehr viel Wahres“, „was von keinem von uns gebilligt wird“; außerdem habe ihn die SMAM in einer Aussprache „nochmals verantwortlich gemacht für das Anwachsen des Apparates“ und die politische Zuverlässigkeit der Dienstkräfte. In allgemeiner Form verwies er auf die privilegierte Stellung des Personalamtes und den Aufbau einer neuen, am Kaderkonzept orientierten Verwaltung: „Dazu bediene ich mich des Personalamtes, welches in der heutigen Zeit eine andere Aufgabe hat als in den früheren Jahren." Sein eigenes Schreiben vom 6. April 1946 verschwieg er, nannte abschließend aber eines der Beispiele, weswegen geklärt werden müsse, „wie sich das Personalamt in solchen Fällen verhalten soll“: die vorgeschlagene Höhergruppierung Suhrbiers, für die keine Planstelle frei sei. Mit diesem Abschluß des Briefes markierte Warnke politische Differenzen, da Suhrbier, von Höcker im November $1945 \mathrm{zu}$ seinem persönlichen Referenten in Finanz- und Haushaltsfragen ernannt, ${ }^{153}$ schon seit den zwanziger Jahren für die Landesverwaltung arbeitete und daher ein exponiertes Beispiel für die personellen Kontinuitäten war, die bei mangelhafter Loyalität sofort sanktioniert werden konnten. Höcker versah Warnkes Schreiben am 13. April 1946 mit dem kurzen Hinweis: „Zur Sitzung“ und zog das Problem damit ins präsidiale Kollegium.

Am 25. April 1946 befaßte sich die Präsidialsitzung mit der Angelegenheit. ${ }^{154}$ Entsprechend der Kritik Romahns, daß einzelne Höhergruppierungs- und Einstellungsanliegen unter Umgehung des Personalamtes an Höcker herangetragen würden, wurde festgelegt, daß sich die einzelnen Fachabteilungen nicht direkt an den Präsidenten, sondern an den jeweils für sie zuständigen Vizepräsidenten zu wenden hätten. Höckers Informationsbasis und seine Eingriffsmöglichkeiten beschränkten sich dadurch in zunehmend mehr Bereichen auf die unmittelbare Unterrichtung durch seine präsidialen Kollegen und die Kenntnisnahme aller Verordnungen und Erlasse, die zur Vorlage bei der SMAM zuvor in seiner zentralen Dolmetscherabteilung übersetzt wurden. ${ }^{155}$

152 MLHA, MinPräs 947, Bl. 266.

153 MLHA, MdI bis 194520.

${ }^{154}$ MLHA, MinPräs 642, Bl. 132ff. Siehe die von Höcker am 27. 4. 1945 abgezeichnete Protokollfassung (MLHA, MinPräs 947, Bl. 265).

${ }^{155} \mathrm{Da}$ die politisch einflußreichsten Aufgaben in den Händen Warnkes lagen, diente die Betonung 
Der zweite Tagesordnungspunkt behandelte den Brief des Personalamtes. Die (Vize-)Präsidenten hielten fest, daß dieses Amt bei Neueinstellungen „die betreffende Abteilung zu beraten und ihr aus etwa vorhandenen Bewerbern Vorschläge zu machen “ habe und daß es die politische Zuverlässigkeit prüfe. Bei Dienstkräften „vom Sachbearbeiter aufwärts" entscheide der Präsident über die endgültige Einstellung. Abschließend hieß es im Protokoll zusammenfassend: „Über die Einstellung oder Entlassung entscheidet in keinem Fall das Personalamt, dagegen darf zukünftig bei der Landesverwaltung niemand beschäftigt werden, der nicht über das Personalamt eingestellt worden ist. “ $\mathrm{Da}$ mit war dem Amt die souveräne Einstellungs- und Entlassungspolitik untersagt, da der Präsident für höhere Dienstkräfte und die Ressortchefs für die unteren Dienstkräfte verantwortlich zeichneten. Immerhin sicherten ihm das Vorschlagsrecht, die Vetomöglichkeit und vor allem das Monopol beim Abschluß von Arbeitsverträgen weiterhin einen sehr großen Spielraum.

Dem ersten Vizepräsidenten mißfiel diese protokollierte Entscheidung, so daß er sich schon bald mit einem alternativen Formulierungsvorschlag an Höcker wandte. ${ }^{156}$ Die neue, fast doppelt so lange Protokollfassung begann mit der Feststellung, daß Kundermanns Amt „das gesamte Personal in politischer Hinsicht zu überwachen, die Personalbewegung in den Abteilungen und Dienststellen zu beobachten und dem Präsidenten bezw. Vizepräsidenten ständig hierüber zu berichten " habe; darüber hinaus habe es „für die richtige Eingruppierung Sorge zu tragen“, einen politisch und fachlich qualifizierten „Stamm von Reserven bezw. Nachwuchs heranzuziehen“ und jede Behörde bei Neueinstellungen „zu beraten und ihr aus vorhandenen Bewerbern Vorschläge zu machen“: sämtlich Aufgaben, die dem Amt einen konstanten Einfluß über die bewegte Phase des umfangreichen Personalaustauschs der ersten Nachkriegsjahre hinaus sicherten und den Charakter einer allen anderen Abteilungen übergeordneten Behörde stärkten. ${ }^{157}$

Die eher passiv anmutenden Tätigkeiten des „Überwachen[s]“, „Beobachten[s]“ und „Berichten[s]“ gestatteten ohne formale Legitimation oder explizite politische Begründung selbständige Eingriffe und Maßnahmen gegenüber sämtlichen Behörden im Land. $\mathrm{Da}$ die Personalangaben nicht allgemein zugänglich waren und die internen Maßstäbe, Kriterien und Arbeitsanweisungen des Personalamtes geheim blieben, entzog es sich jeder Kontrolle. Romahn erläuterte am 4. April 1946,158 warum selbst die Besoldungsrichtlinien exklusives Geheim- und Herrschaftswissen des Personalamtes bleiben mußten: „Die hier aufgestellten Richtlinien über die Berechnung des Besoldungsdienstalters für Dienstkräfte, die während der Nazizeit gemaßregelt bezw. aus politischen Gründen nicht angestellt wurden, geben nur Anhaltspunkte für einen begrenzten Kreis der frag-

der Ressortgrenzen dazu, seinen Kollegen keinen Einfluß auf Bodenreform, Verwaltungsaufbau, Personalpolitik und Sequestrierungen zuzugestehen. In der gleichen Sitzung wurde entsprechend mitgeteilt, daß die SMAM alle mit der Sequestrierung verbundenen Aufgaben ausschließlich der Abteilung Inneres zugewiesen habe, so daß es allen anderen Abteilungen untersagt sei, sich in diesen Bereich einzumischen.

156 MLHA, MinPräs 642, Bl. 135.

${ }^{157}$ Damit entwarf er bereits Grundzüge des Konzepts einer permanenten ,Säuberung', die er im Mai im erweiterten SED-Landesvorstand ausführte (MLHA, LL SED IV/2/1/9, Bl. 74ff.); siehe Kapitel II.1, S. 149 und Kapitel III.1.

158 Antwort auf eine Anfrage der Abteilung Arbeit und Sozialfürsorge vom 22. 3. 1946; beide Briefe in: MLHA, MdI 759. 
lichen Arbeitskräfte und sind nur für den Gebrauch in der Abt. Finanzen und im Personalamt bestimmt. Eine Bekanntgabe der Richtlinien soll zur Vermeidung weiterer Erörterungen in dieser Frage nicht erfolgen, zumal es sich auch nur um Anhaltspunkte für eine voraussichtlich kurze Zeit handelt.“ Der Bitte um Übersendung der Richtlinien könne er daher nicht entsprechen, und in Zweifelsfällen seien dem Personalamt die Akten zur Festlegung des Besoldungsdienstalters vorzulegen. Die mit diesem Geheimwissen verbundenen umfangreichen Einflußmöglichkeiten machten nicht nur einzelne Personen, sondern die gesamte Landesverwaltung abhängig von dieser unkontrollierbaren Behörde. ${ }^{159}$ Warnke griff noch weiter aus: Das Personalamt sollte nicht nur die politischen Qualifikationen und die verwaltungstechnische Ordnung überwachen, sondern zusätzlich für die Ausbildung der Dienstkräfte und des Nachwuchses sorgen. Dies schränkte den Einfluß der Leiter der Fachabteilungen und Dienststellen insofern ein, als damit das Reservoir für die zukünftigen Besetzungen vorbereitet wurde. Ihr fachlich begründetes Vorschlagsrecht beschränkte sich damit zeitlich auf die umbruchbedingte Mangelsituation. Mit dem Ende der ersten Kurse würde die Abteilung Inneres jede reguläre Stelle mit den selbst verlesenen und ausgebildeten Dienstkräften besetzen. ${ }^{160}$

Keine dieser Aufgaben war im ursprünglichen Protokoll benannt gewesen, das ausschließlich zu Einstellungen und Entlassungen Stellung genommen hatte. Warnke besorgte seinem Personalamt durch einen nachträglich eingereichten und anscheinend nicht diskutierten Änderungsantrag eine offiziell genehmigte Ausweitung seines Arbeitsgebietes. ${ }^{161}$ Die Änderungsvorschläge betrafen aber auch die Einstellungs- und Ent-

${ }^{159}$ Die in diesem Fall verweigerten Unterlagen betrafen eine Personengruppe, die die Einseitigkeiten der kommunistischen Faschismustheorie verdeutlichte. Die Wahrnehmung der ngemaßregelten bzw. aus politischen Gründen nicht angestellten " Personen hätte Hinweise auf Verweigerungshaltungen und Resistenzen geben können, die sich unterhalb der Schwelle des (kommunistischen) Widerstands manifestiert hatten und daher zu einer Differenzierung der dichotomen NS- und Gesellschaftsanalyse zwangen. Gerade in dem stark agrarisch geprägten Gebiet war es möglich, zahlreiche Personen zu finden, die keineswegs links oder demokratisch waren, wohl aber bewußt gegen den Nazismus gestanden hatten.

160 Bereits am 23. 5. 1946 berichtete das Personalamt von seiner Ausbildung der ersten Lehrlinge (MLHA, MinPräs 1309, Bl. 154-157), und im September 1948 wurde bei dem inzwischen zur ,Hauptabteilung Personal' umbenannten Amt eine „Entwicklungskartei“ über die „Fähigkeiten und Entwicklungsmöglichkeiten der Angestellten“ angelegt (MLHA, MdI 678). Ulbricht begründete am 12. 10. 1948 die Eröffnung der ersten - seit 1950 nach ihm benannten - Verwaltungsakademie der SBZ damit, daß nach dem Ende der Entnazifizierung ein nicht nur politisch, sondern auch fachlich versiertes Verwaltungspersonal notwendig sei (Glaeßner, Herrschaft, S. 304f.). Ein großer Teil der Literatur über Kader und Bürokratie in ,volksdemokratischen" Staaten bezieht sich auf diese Zeit der bereits etablierten Herrschaft und thematisiert dabei die Veränderung des Anforderungsprofils, das neben der politischen Zuverlässigkeit zunehmend stärker auf fachliche Qualifikationen zielte (Glaeßner, Herrschaft, S. 36; Ludz, Parteielite, S. 153-258; Richert, Macht; Schultz, Funktionär).

${ }^{161}$ Dieser Tendenz entsprechend stieg die Anzahl der Dienstkräfte des Personalamts im ersten Jahr der Besatzung von sieben auf 24. Eine Aufzählung vom Mai 1946 nennt seine Arbeitsgebiete, deren Reihenfolge zeigt, wie stark die Bedeutung der Entnazifizierung innerhalb eines Jahres geschwunden war: „1) Einstellungen und Entlassungen, 2) Bewerbungen, 3) Gehälter, nach Beamtenbesoldung und Angestelltentarif, 4) Höhergruppierungen und Ernennungen, 5) Festsetzungen des BLA, 6) Urlaubsfragen, 7) Wohnungsangelegenheiten, 8) Kranken- und Sozialversicherung, 9) Organisation, 10) Personalausweise, 11) Personalbetreuung, 12) Kartei und Auskunft, 
lassungsmodalitäten: Die gefaßten Regelungen wurden beibehalten, einigen Sätzen wurde ihre Schärfe gegen das Amt genommen, ${ }^{162}$ während andere die Beschränkung der ohnehin recht engen personalpolitischen Autorität der Fachabteilungsleiter betonten. Mit den abschließenden Formulierungen des neuen Protokolltextes bezog sich Warnke auf die Interessenunterschiede zwischen Höcker und der Abteilung Innere Verwaltung im Herbst 1945 über die Integration von Gewerkschaften und Parteienblock in die Einstellungs- und Entlassungsverfahren: Das Personalamt habe „von sich aus [...] engstens mit dem Betrieblichen Gewerkschaftsausschuß bzw. dem Betriebsrat zusammenzuarbeiten“, während die Übereinstimmung mit dem Antifa-Ausschuß nur „möglichst“ herbeizuführen sei.

Außer einer sprachlichen Straffung übernahm Höcker alle Formulierungen Warnkes unverändert, obwohl sie weit über den im vorherigen Protokolltext aufgezeichneten Beschluß hinausgingen. ${ }^{163}$ Keine Hinweise sprechen dafür, daß die anderen Teilnehmer der Präsidialsitzung befragt wurden, obwohl an jeder Sitzung gewöhnlich mindestens der Präsident, seine drei Stellvertreter und zum Teil auch weitere Vertreter einzelner Ressorts teilnahmen. ${ }^{164}$ Inhalt und Stil dieser Veränderung des Präsidialsitzungsbeschlusses zeigen die weitgehend unangefochtene Stellung Warnkes und seiner in der Abteilung Innere Verwaltung formierten Hausmacht. Weder das Präsidialkollegium noch die Parteien wagten weiteren Widerspruch, obwohl sie die Klagen des Personalamtes über die eigene mangelhafte Funktionstüchtigkeit auch in eine Kritik seines weitgehenden Anspruchs und einer mangelhaften Arbeitsweise hätten umwandeln können. Statt dessen wiederholten sie ihr bereits eingeübtes Schweigen und überließen Warnke zahlreiche Facetten der gegenwärtigen und angesichts des Ausbildungsprivilegs sämtliche Bereiche der zukünftigen Personalpolitik.

Warnke und das Personalamt hatten sich damit im Frühsommer 1946 zur einzigen Institution gemacht, die das Personalwesen des öffentlichen Dienstes in MecklenburgVorpommern lenkte und kontrollierte. Damit war nicht nur die Möglichkeit unkontrollierbarer Eingriffe in alle anderen Verwaltungsbereiche verbunden, sondern auch eine ideale Konstellation für die Fortführung der Entnazifizierung geschaffen, die sich bereits Anfang 1946 durch den Erlaß der Kontrollratsdirektive Nr. 24 vom 12. Januar 1946 ankündigte. $\mathrm{Da}$ die neue Entnazifizierungswelle nicht mehr anhand eines einzigen Kriteriums, der Mitgliedschaft in NS-Organisationen, durchgeführt werden sollte, sondern der umfangreiche alliierte Kriterienkatalog differenziertere Urteile forderte, bedurfte es einer Institution zur Organisierung der Infrastruktur, zur Instruktion des urteilenden Personals und zur Auswertung der laufenden Arbeiten. ${ }^{165}$ Für diese Aufgabe gab es nunmehr weder in Schwerin noch in den Kreisen und Städten eine Konkurrenz zum Lan-

13) politische Bereinigung sowie Verfügungen aller Art, die mit diesen Punkten in Zusammenhang stehen" (MLHA, MinPräs 1309, Bl. 154-157).

${ }^{162}$ Zum Beispiel wurde der abschließende Satz: „über die Einstellung oder Entlassung entscheidet in keinem Fall das Personalamt" nicht wiederholt. Dadurch wurde der Sachverhalt nicht geändert, da er in der ersten Formulierung redundant war; durch diese Redundanz hatte der Text allerdings einen kritischen Unterton gegen die bisherige Praxis.

163 MLHA, MinPräs 642, Bl. 136.

${ }_{164}$ MLHA, MinPräs 642, passim.

${ }^{165}$ Zur neu aufgenommenen Entnazifizierung siehe Kapitel III. 
despersonalamt. Ende August 1946, kurz vor der Installierung der neuen Entnazifizierungskommissionen, klärte das Präsidialkollegium erneut die Ressortverteilung und zementierte damit die allgemeine und die personalpolitische Vorherrschaft Warnkes. Er zeichnete neben der Polizeiabteilung, der Kommunalaufsicht, der Allgemeinen und Inneren Verwaltung, der Justiz, dem Umsiedleramt und der noch zu schaffenden Bauabteilung weiterhin auch für sämtliche Personenstandsangelegenheiten und die Personalabteilung verantwortlich, so daß sein alleiniges Verfügungs- und Informationsmonopol in allen Personalfragen bestätigt wurde. ${ }^{166}$

\section{Antifaschismus und Reintegration: Die ehemaligen Parteigenossen in der neuen Gesellschaft}

Schon Ende 1945 war die Verwaltungspolitik in Mecklenburg-Vorpommern nicht mehr vom Blick auf die NS-Vergangenheit geprägt, sondern von Vorstellungen, wie die bürokratischen Apparate in Zukunft funktionieren sollten. Ganz offensichtlich verfolgten die Landespolitiker und vor allem die Kommunisten damit weitreichende gesellschaftspolitische Ziele. Für die Umgestaltungspolitik war aber neben einem funktionstüchtigen Verwaltungsapparat auch notwendig, daß die Bevölkerung der Regierung wohlgesonnen und loyal gegenüberstand. Darum war es unmöglich, einen großen Teil der Bevölkerung aufgrund seiner politischen Haltung bis 1945 gesellschaftlich auszugrenzen. Dies mußte Folgen für den Umgang mit den Pgs haben: Ihre entnazifizierungsbedingten Entlassungen wurden zwar nicht rückgängig gemacht, ihre gesellschaftliche Marginalisierung aber ausdrücklich abgeschwächt, um aus den vielen ehemaligen NSDAP-Mitgliedern kein Protestpotential entstehen zu lassen. Dazu wurde ein Weg zwischen individueller Bestrafung und gesellschaftlicher Reintegration gewählt, der diesem politischen Kalkül ebenso Rechnung trug wie dem lauthals propagierten Antifaschismus.

Neben der Entnazifizierung des öffentlichen Dienstes fand auch die Überprüfung anderer Berufsgruppen im Norden der SBZ schon zum ersten Jahreswechsel nach der Kapitulation ihr Ende: Die NS-bedingten Entlassungen der Lehrer wurden Anfang Januar 1946 mit einer weitreichenden Verordnung noch einmal forciert und dann vorerst beendet; „nach den Entlassungen im Herbst und Winter 1945 wurde die politische Säuberung des Justizapparates erst [...] Anfang 1947 erneut aufgenommen "; 167 und die Entnazifizierung der Betriebe konzentrierte sich schon seit September 1945 auf Eigentums- und weniger auf Personalfragen. Als NS-belastet Definierte waren also bereits entlassen und

${ }^{166}$ Höcker unterstanden dagegen nur seine Präsidialabteilung mit der Informationsabteilung und dem Büro der Beratenden Landesversammlung, die Finanzabteilung, das Statistische Landesamt, einige technische Einrichtungen der Landesverwaltung (Telefonzentrale, Hausverwaltung, Vervielfältigungsstelle etc.) sowie die noch zu schaffende Planungs- und Kontrollabteilung; Otto Möller war für Landwirtschaft und Forsten sowie Handel und Versorgung, Grünberg für Kultur und Volksbildung, Gesundheitswesen sowie Arbeit und Sozialfürsorge verantwortlich (MLHA, MinPräs 642, Bl. 129f.).

167 Welsh, Wandel, S. 137; siehe auch Wille, Entnazifizierung, S. 76-82. Der entscheidende SMADBefehl Nr. 49 vom 4. 9. 1945 in: Um ein antifaschistisch-demokratisches Deutschland, S. 142f. 
wurden darüber hinaus auch noch durch Ausbildungsbeschränkungen oder Aufräumarbeiten und Sonderarbeitseinsätze ${ }^{168}$ sanktioniert.

Gleichzeitig verstärkten sich aber vor allem in der KPD die Reflexionen darüber, daß die mehreren Millionen Mitglieder der NSDAP und anderer NS-Organisationen nicht dauerhaft zu marginalisieren waren. ${ }^{169}$ Gesellschaftliche Reintegrationsangebote sollten ihre politische Radikalisierung und das endgültiges Ausscheiden zahlreicher Fachkräfte aus dem Arbeitsmarkt verhindern. Seit dem Winter 1945/46 traten besonders die Kommunisten systematisch an die Pgs heran, um sie für ihr politisches Programm und den gesellschaftlichen Neuaufbau zu gewinnen. Dabei waren die ehemaligen Nazis mehrfach umworben: als mögliche Mitglieder in den neuen Parteien, als Stimmberechtigte bei den Landtags-, Kreis- und Gemeindewahlen im Herbst 1946 und als loyale Untertanen der neuen Regierung. Schon bald zeichneten sich dafür Mindestanforderungen ab: keine strafrechtliche Belastung, politische Abkehr vom Faschismus, Loyalität gegenüber Besatzungsmacht und KPD/SED und eine besondere Bereitschaft zur Mitarbeit beim Neuaufbau. All dies wurde unter dem Stichwort der, Bewährung zusammengefaßt und damit so dargestellt, als läge die Erfüllung der Anforderungen alleine in der Verantwortung des einzelnen.

Entsprechend der Verschiebung im Überprüfungsprofil für Verwaltungsmitarbeiter hatten sich auch die Kriterien zur Beurteilung politischer Belastung und gesellschaftlicher Marginalisierung verändert. Die Auswahl derjenigen, denen die Rückkehr in die ,Normalität ${ }^{‘}$ angeboten wurde, hing davon $a b$, wie $m$ an die vergangenen zwölf Jahre charakterisierte: Damit gewannen die alten, angesichts der Ereignisse bis 1945 vielfach rein akademisch erscheinenden Theoriedebatten zum Verständnis des NS-Regimes wieder eine gewisse Wirkungsmacht. In der SBZ war dies trotz aller Debatten und Differenzierungen seit den zwanziger Jahren die marxistische Faschismustheorie kommunistischer Prägung, in die zudem problemlos der neue Ost-West-Gegensatz zu integrieren war.

Die kommunistische Faschismustheorie hatte 1945 einen entscheidenden Vorteil: Durch sie konnten die Kommunisten jedem anpassungsbereiten ehemaligen Nazi im Gegensatz zu den ,Konzernherren' und ,Junkern' eine große ,Harmlosigkeit' attestieren,

${ }_{168}$ Die Sonderarbeitseinsätze waren eine öffentlichere und eindeutigere Form der Sühne als Berufsverbote und Entlassungen. Sie wurden wiederholt zur Abrechnung mit NS-Belasteten oder anderen unbeliebten Personen gefordert und konnten in der lokalen Gesellschaft deutlich wahrgenommen werden. Außerdem betrafen sie auch diejenigen Pgs, die kein Eigentum und keine berufliche Stellung zu verlieren hatten und daher erst mit der Errichtung der Kommissionen 1946/47 von der Entnazifizierung erfaßt wurden. Seit Anfang 1946 wurden die Einsätze immer seltener (Meinicke, Entnazifizierung [Diss], S. 25); das Präsidialkollegium in Schwerin und das Landesarbeitsamt beschränkten sie seit dem Mai 1946 ausdrücklich auf höhere NS-Funktionsträger (MLHA, MinPräs 642, Bl. 132ff., 143). 1946 wurden die Sonderarbeitseinsätze in der SED zunehmend kritischer beurteilt, weil sie die Wahlchancen beeinträchtigten (z. B. MLHA, LL SED IV/2/3/77, Bl. 47; MLHA, LL SED IV/2/3/77, Bl. 46).

${ }_{169}$ Nach Broszat, Staat, S. 253f., gab es bei Kriegsende sechs Millionen NSDAP-Mitglieder; Staritz, Gründung, S. 100, beziffert die Zahl der Pgs bei Kriegsende auf 6,5 Millionen, von denen sich 1,5 Millionen in der SBZ aufgehalten hätten; Kleßmann, Staatsgründung, S. 87, nennt acht Millionen NSDAP-Mitglieder und weitere etwa vier Millionen in den verschiedenen Unterorganisationen. Nach Badstübner, Geschichte, S. 343f., befanden sich 1945 insgesamt vier Millionen Mitglieder der NSDAP und ihrer Gliederungen auf dem Gebiet der SBZ. 
weil die neuen Herren das Land in wenigen Monaten tiefgreifend umgestaltet und ihre eigene politische Herrschaft dabei systematisch ausgebaut hatten. Durch die agrar-, wirtschafts- und personalpolitischen Struktureingriffe war der Wiederaufrichtung der NS-Herrschaft gemäß marxistischer Faschismustheorie die Grundlage entzogen. Dies ermöglichte einen gelassenen Umgang mit den Pgs. Die politische Priorität der Kommunisten lag nun nicht mehr in der Absicherung des Neuanfangs gegen alte NS-Kräfte, sondern darin, diese für sich zu gewinnen. Nach den umfassenden Entlassungen bot sich nun die Möglichkeit, Ungerechtigkeiten auszugleichen und neue politische Akzente zu setzen. In erster Linie ging es dabei um politische Sympathiewerbung. Von den Reintegrationsbemühungen ausgeschlossen blieben die Personen, die strafrechtlicher Delikte überführt werden konnten ${ }^{170}$ oder die unter die niemals präzise definierte Kategorie der "aktiven Nazis" fielen; sie unterlagen weiterhin einer großen Bandbreite möglicher Sanktionen, die von Sonderabgaben und Berufsverboten über Enteignung, Internierung und Verschleppung in die Sowjetunion bis zur Todesstrafe reichten.

Um ehemalige NS-Mitglieder im neuen gesellschaftlichen Projekt einzuspannen, war eine Unterscheidung zwischen mehr und weniger belasteten Nazis zu treffen. Da eine generelle Amnestie oder gesellschaftliche Reintegration aller Nazis dem Selbstverständnis und der antifaschistischen Selbstdarstellung der KPD widersprochen hätte, wurde auf die schon im Exil ${ }^{171}$ formulierte Unterscheidung zwischen aktiven und bloß nominellen Pgs zurückgegriffen, die seit den ersten Monaten der Besatzung in der SBZ bereits virulent gewesen, in Mecklenburg-Vorpommern durch den Rigorismus in der Personalpolitik allerdings weitgehend wirkungslos geblieben war. Auch die Alliierten hatten diese Unterscheidung in gemeinsamen Abkommen formuliert. ${ }^{172}$ Für sie und für die mit der Entnazifizierung verantwortlich befaßten Deutschen war die mangelhafte begriffliche Präzision kein Thema. Die Ungenauigkeit gewährte große Interpretations- und Handlungsspielräume, die alle Protagonisten in ihrem Sinne auszufüllen suchten.

Nicht nur die Kriterien waren unklar; es gab auch keine Instanz, die definitiv über das Ende der politischen Sanktionierung und Marginalisierung entscheiden konnte. 1946/47 bemühten sich vor allem die Parteien um eine Klärung dieser Kompetenz, da sie an der regulären Aufnahme ehemaliger NSDAP-Mitglieder in die eigenen Reihen interessiert waren. Aufnahme fanden Pgs in den neuen Parteien praktisch seit ihrer Zulassung im Sommer 1945, indem die Mitgliedschaft in einer NS-Organisation gerade bei den jeweils

170 Strafrechtliche Delikte waren in allen vier Besatzungszonen Deutschlands keine Entnazifizierungsangelegenheiten, sondern wurden zumeist von alliierten und teilweise auch von deutschen Gerichten geahndet (Zur Geschichte der Rechtspflege, S. 215; durch den SMAD-Befehl Nr. 201 wurde die Rolle der deutschen Justiz bei der Ahndung von NS-Verbrechen gestärkt; siehe Kapitel III.3). Vor allem zwei Gründe machten das Strafrecht zur Abrechnung mit dem Nazismus unbrauchbar: Erstens hätten strafrechtliche Verfahren die Gerichte zum Nachweis der individuellen Schuld verpflichtet, wozu große Untersuchungs- und Anklagebehörden nötig geworden wären. Zweitens wäre durch eine strafrechtliche Verfolgung eine zu kleine Personengruppe getroffen worden, um den Neuanfang im Sinne der jeweiligen Besatzungsmacht auch personell abzusichern.

${ }^{171}$ Meinicke, Entnazifizierung (Diss), S. IVf., 23-33.

${ }_{172}$ Zur entsprechenden Passage im Potsdamer Abkommen siehe Kapitel I.2, S. 96; die Unterscheidung findet sich auch in der US-amerikanischen Besatzungsdirektive JCS 1067 vom 26. 4.1945 (Vollnhals, Entnazifizierung, S. 98ff.) und in der Kontrollratsdirektive Nr. 24 (Rößler, Entnazifizierungspolitik, S. 64-81). 
eigenen Kandidaten als Kriterium zur Beurteilung der vergangenen politischen Haltung für unbrauchbar erklärt wurde. Entweder sie galten als ,Trojanische Pferde ${ }^{c}{ }^{173}$ oder die Mitgliedschaft wurde durch ihre Hilfsbereitschaft während des ,Dritten Reiches' gegenüber antifaschistischen Kräften aufgewogen. ${ }^{174}$ Dabei spielten die Unbedenklichkeitsbescheinigungen eine unbedeutendere Rolle als die ,Persilscheine“ im Westen. Dennoch forderten zahlreiche Behörden und Organisationen gegen den Willen und wiederholten Protest des Personalamtes solche Bescheinigungen als Einstellungsvoraussetzung von allen Bewerbern; gewöhnlich reichte dabei aber nicht die Erklärung einer einzelnen Person oder Partei, sondern nur die des gesamten lokalen Parteienblocks. Die Bescheinigungen wurden nur teilweise anerkannt; ${ }^{175}$ diese uneinheitliche Handhabung entsprach den Verzögerungen seitens der Besatzungsmacht bei der Entscheidung über die Aufnahme- und politischen Rehabilitationskompetenzen der Parteien. Durch die Verweigerung endgültiger ,Absolution' behielten die Betroffenen einen Makel, der stets als politisches Druckmittel einsetzbar war und daher zur besonders eifrigen Erfüllung der mit der ,Bewährung verbundenen Kriterien anspornte.

Die neuen Parteien nutzten die Vermittlung politischer Rehabilitation auch zur Sympathiewerbung. In einer ausführlichen Stellungnahme ging Ulbricht darauf bereits am 22. Dezember 1945 während einer Konferenz mit Bezirkssekretären der KPD ein, als er über die notwendigen Rahmenbedingungen der Entnazifizierung sprach, die in anderen Ländern und Provinzen der SBZ noch nicht abgeschlossen war: ${ }^{176}$ „Was die Frage der Arbeiter und Angestellten in den Betrieben betrifft, die Nazimitglieder waren, so können wir momentan in der Öffentlichkeit unsere Taktik nicht ändern, aber es ist notwendig, daß in den Betrieben eine Differenzierung durchgeführt wird, daß unsere Genossen

${ }^{173}$ Auch Warnke, der nicht nur in der Verordnung vom 30. 8. 1945 ein holzschnittartiges Bild der NS-Belastungen entworfen hatte, sondern sich auch sonst durch sein dichotomes Gesellschaftsund Politikverständnis auszeichnete, ließ nach dem Ende der Entnazifizierung Differenzierungsbemühungen erkennen. In einer seiner außerordentlich seltenen schriftlichen Eingaben bei der SMAM erläuterte er am 10.12. 1945 einige "Sonderfälle" von NSDAP-Mitgliedern, die „zweifellos nicht als Faschisten anzusehen" und deren Entlassungen rückgängig zu machen seien, da sie teils mit Sonderaufträgen illegaler Organisationen, teilweise auch „aus eigenem Antrieb" der NSDAP beigetreten seien, um sich als, Trojanische Pferde' Kenntnisse zur Unterstützung inhaftierter "Gesinnungsfreunde“ zu verschaffen (MLHA, MdI 752).

${ }^{174}$ Der spätere Leiter des Landesumsiedleramtes, Karl Brincker, bescheinigte beispielsweise als politischer Leiter der KPD-Ortsgruppe Gadebusch dem Fischermeister Emil O. im September 1945, seit 1941 der Widerstandsbewegung Westmecklenburg angehört, als Kurier gedient, antifaschistische Schulungsabende durchgeführt und „uns bis zum Zusammenbruch mit Waffen versorgt" zu haben. Daher befürwortete Brincker seine Aufnahme in die KPD, obwohl O. bereits 1932 NSDAP-Mitglied geworden war (MLHA, RdK Güstrow 139, passim, Zitat Bl. 117). In den meisten Fällen wurde auf glaubwürdigere und weniger dramatische Taten verwiesen, die sich vor allem bei Konservativen, die weder der Weimarer Republik noch den ersten Veränderungen 1933 grundsätzlich ablehnend gegenübergestanden hatten, häufig auf den Kampf gegen ein vermeintlich noch größeres Übel oder den Erhalt kultureller oder kirchlicher Freiheiten bezogen.

175 Die wechselnde Beurteilung dieser Bescheinigungen durch die Kommunisten entsprach ihrer häufig artikulierten Abneigung gegenüber schriftlichen Festlegungen; sie scheuten die Ausstellung von Zeugnissen und Bescheinigungen, da diese zukünftig als materielle Argumente gegenüber möglicherweise veränderten Entscheidungen gelten konnten und somit unerklärte politische Kursänderungen erklärungsbedürftig gemacht hätten.

176 Welsh, Wandel, S. 49, 55f.; Errichtung, S. 93-97; siehe Kapitel I.2, S. 106. 
persönlich mit diesen Leuten sprechen, sie beeinflussen, daran anknüpfen, daß sie geglaubt haben, sie könnten mit Hilfe des Nazismus damals aus der Krise herauskommen. [...] Wenn wir nicht systematischer diese persönliche Beeinflussung durchführen, wird eine solche Lage eintreten, wie wir sie in einer Reihe von Betrieben zu verzeichnen haben, daß die früheren Nazis nur deshalb Sozialdemokraten wählen, weil sie der Meinung sind, die Kommunisten, die kämpfen, wollen sie alle vernichten! Diese Auffassung, daß wir sie alle vernichten wollen, $d$. h. durch die Arbeiter, die betrogen sind, muß man wegbringen. [sic] Momentan können wir das noch nicht auf dem Wege der Presse, aber in den Betrieben muß das bereits offen gesagt werden, muß auch in den Belegschaftsversammlungen evt. zu solchen Leuten gesprochen werden, besonders da, wo eine große Anzahl von solchen Leuten im Betrieb ist. " ${ }^{177}$ Ulbricht benannte seine strategischen Gesichtspunkte offen: Das Vorgehen richtete sich gegen antikommunistische Vorurteile und gegen eine Stärkung der Sozialdemokratie aufgrund eines zu militanten Auftretens der KPD; die Pgs sollten durch eine aktive, aber wenig rigorose politische Arbeit in den Betrieben beeinflußt werden.

In der Öffentlichkeit wurde noch das Bild der unerbittlich antifaschistischen KPD geboten, intern wurde aber bereits ein freundlicherer Ton angeschlagen. Während sich die Kommunisten in Mecklenburg-Vorpommern zum Beispiel durch Warnkes Politik als rigorose Antifaschisten und Entnazifizierer darstellten, bereitete Ulbricht eine sanftere Linie vor, da die Differenz zwischen der öffentlichen antifaschistischen Legitimierung und den Konsequenzen der Entnazifizierung in einzelnen Orten und Betrieben zu Spannungen führte, die nicht nur ökonomische und administrative Probleme, sondern auch eine ungewollte Stärkung der anderen Parteien mit sich brachte. Hintergrund dieser Sympathiewerbung und Großzügigkeit gegenüber vielen ehemaligen Nazis bildete ein Gemenge von gesellschaftstheoretischen, internationalen und innenpolitischen Faktoren: die marxistische Faschismustheorie, die beginnende Teilung der Welt und die ökonomische, soziale und politische Notwendigkeit der Reintegration. Außerdem wurde damit der von der Entnazifizierung betroffene Personenkreis überschaubar gehalten und das Mitgliederwachstum der neuen Parteien verstetigt. Dieser Umgang mit den Pgs war seitens der KPD-Leitung sorgfältig vorbereitet und aus strategischen Erwägungen beschlossen worden; den Anlaß dazu hatten die Nationalratswahlen in Österreich am 25. November 1945 geboten, bei denen die Kommunisten nur vier, die Sozialdemokraten aber 76 Sitze erhielten. Diese Wahlniederlage der österreichischen Kommunisten wurde auf ihren zu kritischen Umgang mit den ehemaligen Nazis zurückgeführt, ${ }^{178}$ den die KPD/SED daraufhin in der SBZ grundlegend änderte. ${ }^{179}$

177 SAPMO-BA, RY 1/I2/5, 41, Bl. 22.

${ }_{178}$ Erdmann, Ende des Reiches, S. 78, 137; Stiefel, Entnazifizierung, S. 42.

${ }^{179}$ Dazu beauftragte das Sekretariat des ZK am 30. 11. 1945 Wolfgang Leonhard, „Material über die Pg's (ihre Stellung in Verwaltungen, Aufnahme in bestehende Parteien) mit exakten Unterlagen in sämtlichen Besatzungszonen des Reiches zusammenzustellen" (SAPMO-BA, RY 1/I2/5, 50, Bl. 94). Daraufhin erschien Leonhards Schulungsheft und sein Artikel in der Deutschen Volkszeitung über den Umgang mit den ehemaligen Pgs (Kriegsverbrecher, aktivistische Nazis und nominelle Pgs, Vortragsdisposition Nr. 7, Berlin 1946; Deutsche Volkszeitung, 16. 2. 1946; siehe auch SAPMO-BA, NY 4036 [NL Pieck], 718, Bl. 46; Leonhard, Revolution, S. 376f., 395ff.; Meinicke, Entnazifizierung [Diss], S. 28). 
Ein Instrukteur berichtete im März 1946 aus Anklam, daß die starke Zunahme der SPD-Mitgliedschaften auch durch das „untaktische Auftreten eines Referenten in einer öffentlichen Versammlung, der die deutschen Soldaten im allgemeinen als Verbrecher hinstellte" ${ }^{180}$ verursacht sei. Beispielhaft war Höckers Rückgriff auf die Schuldfrage in einer Rededisposition vom Sommer 1946: Er erinnerte seine Zuhörer an den Kriegsjubel bei den Siegesnachrichten und forderte sie auf zu prüfen, ob „Ihr Gesicht das von 1938 ist und Sie selbst sich wieder erkennen". Schuldig sprach er aber nur diejenigen, denen er wegen ihrer aktuellen „unterirdische[n] Wühlarbeit“ gegen den Neuaufbau in der SBZ untersagte, „über Unzulänglichkeiten, die noch nicht beseitigt sind, zu urteilen“. ${ }^{181}$

Immer seltener wurde über die Rolle einzelner im ,Dritten Reich“ nachgedacht, und der Rückgriff auf die Zeit bis 1945 diente statt dessen der Wahrnehmung der Gegenwart in dichotomen Kategorien. Die ideologische Teilung der Welt, die die KPD bereits in der Weimarer Republik zur Leitlinie ihrer Politik gemacht hatte, erreichte nach ihrer Unterbrechung im Zeichen der Volksfrontstrategie nun wieder die Politik und Sprache der Kommunisten. ${ }^{182}$ Als Ulbricht auf dem Vereinigungsparteitag der KPD am 19./ 20. April 1946 darauf hinwies, daß die in Nürnberg Angeklagten nicht die Alleinverantwortlichen seien, richtete er sich nicht gegen die Vielzahl der Kriegsverbrecher, NS-Aktivisten, Mitläufer und weiteren Pgs, sondern betonte vielmehr die Überzeugung, „daß neben den Hitler und Göring, Keitel und Jodl die imperialistischen Auftraggeber der Nazipartei, die Herren der Großbanken und Konzerne [...] die Schuldigen sind und die Verantwortung für den Krieg tragen. Auch die Nazi-Ideologie ist nicht nur das Produkt des Kriegswahnsinns Hitlers, sondern die konsequente Weiterführung der Ideologie der preußischen Junker und der deutschen Konzernherren sowie ihrer Krieger- und Kolonialvereine. "183 Auf der ersten Reichskonferenz der KPD am 2./3. März 1946 sprach Ulbricht - nachdem Pieck am Tag zuvor Anton Ackermanns Artikel über den besonderen deutschen Weg zum Sozialismus in der ersten Nummer des KPD-Organs Einheit ${ }^{184}$ zur Lektüre empfohlen hatte - über die besonderen Entwicklungsbedingungen in Deutschland und bezeichnete dabei die Struktureingriffe in Landwirtschaft, Industrie, Handel, Handwerk und Verwaltung als konstitutiv für die Abschaffung des Faschismus. Der Nazismus wurde nur noch im Zeichen gegenwärtiger Auseinandersetzungen wahrgenommen und - wie bereits 1933 - auf eine gewöhnliche Etappe im immer noch andauernden Klassenkampf reduziert. Dies verdeutlicht auch Ulbrichts verharmlosende Nennung der NS-Führer bei der Gegenüberstellung mit den alten und neuen Wirtschaftseliten: Die „alten faschistischen und imperialistischen Kräfte" verkümmerten in seiner Rede zu einer unbedeutenden Gruppe, da „über die Naziführer [...] in den verschiedenen Prozessen, die gegenwärtig laufen, das gerechte Urteil gefällt" werde, während „jene wahren Herren Deutschlands, die 1932 den Hitlerfaschismus unterstützten und ihm Anfang 1933 zur Macht verhalfen, [...] heute noch starke Positionen in Deutschland

${ }_{180}$ MLHA, LL KPD I/9.

${ }^{181}$ MLHA, MinPräs 1059a, Bl. $199 f$.

${ }^{182}$ Siehe dazu ausführlich Grunenberg, Antifaschismus.

${ }^{183}$ SAPMO-BA, RY 1/I1/1, 46, Bl. 22f.

${ }^{184}$ Ackermann, Weg. Ackermann sprach auch am 2.3. 1946 in diesem Sinn, indem er betonte, die Kommunisten müßten selbst lernen und die nationalen und historischen Gegebenheiten mehr berücksichtigen (SAPMO-BA, RY 1/I1/2, 8, Bl. 71f.). 
[haben] und [...] die Hauptgefahr für die gesamte Entwicklung in Deutschland “ seien. ${ }^{185}$ Durch die immer häufigere ausschließliche Einordnung des ,Dritten Reiches' in den internationalen Systemgegensatz nahm das Interesse an den konkreten Tätern wie auch an den konkreten Opfern ab. ${ }^{186}$ Auch die Resolution des Parteitages im März 1946 wußte sich bei der Nennung des Faschismus nur noch auf den Ost-West-Gegensatz zu beziehen; sie stellte eine "große Ungleichmäßigkeit“ $z$ wischen den vier Zonen Deutschlands fest, weil sich die SBZ durch ihren Antifaschismus auszeichnete, während in den Westzonen „die faschistisch-reaktionären Kreise“ auftraten, „eifrig bemüht, die Grundlagen des deutschen Imperialismus zu retten ". ${ }^{187}$

Diesen Schwerpunkt der marxistischen Faschismustheorie hatte bereits das für Schulungen, Agitation und Propaganda verantwortliche Mitglied des Zentralkomitees der KPD, Fred Oelsner, bei einem Schulungsabend am 26. Oktober 1945 über „die Aufgaben zur Vorbereitung auf den Winter" betont. ${ }^{188}$ Er hatte die Entnazifizierung als einen Erfolg der „Einheitsfrontpolitik“ dargestellt, wobei die Frage der „kleinen Pg“ die Öffentlichkeit beunruhige. Vor allem in der US-amerikanischen Presse werde ein Bild gezeichnet, „als ob die drei anderen Parteien eine wirkliche Ausrottung der Nazis wollen und die Kommunisten die Verteidiger der Pg seien“. Dies sei „ein Manöver“, da ihr Interesse nicht der Schonung der kleinen Nazis gelte, sondern der Ablenkung von den großen: „Es beginnt jetzt ein Kampf der Großbanken. Diese Frage ist uns viel wichtiger (aber ihnen auch!). Darum wollen sie jetzt eine Hetze gegen die kleinen Pg entfalten, um abzulenken. Die kleinen Pg sind jetzt Blitzableiter wie 1933 die Juden. Sie wollen ablenken von den Aufgaben, die wirklich vor uns stehen." 189 Der schon im Exil bewährte kommunistische Ideologe, Propagandist und Parteilehrer Oelsner bereitete damit bereits in der Hochphase der ersten Entnazifizierung das ideologische Terrain zur Rückkehr ehemaliger Nazis, indem er die Polarität zwischen Faschismus und Antifaschismus nicht rückblickend, sondern gegenwartsbezogen darstellte: Nicht vormalige Haltungen

${ }^{185}$ SAPMO-BA, RY 1/I1/2, 8, Bl. 333, 336f. In der Abschrift des stenographischen Protokolls bezieht sich Ulbricht auf den Vortagsredner „Genosse Fisch“, aus dem handschriftlich wieder Wilhelm „Pieck“ wurde: Zahlreiche solcher Kleinigkeiten zeigen, wie stark selbst in der Parteispitze auf Fachkräfte, hier Stenotypisten, zurückgegriffen werden mußte, die keine Verbindungen zur KPD und keine Kenntnisse über die Partei hatten.

${ }^{186} \mathrm{Zu}$ diesem Umgang mit der Vergangenheit, der Täter und Opfer des Faschismus zu Chiffren im politischen Kampf reduzierte, siehe Kapitel I.2, S. 68-76; beispielhaft für die Monopolisierung der Vergangenheit, vor allem der antifaschistischen Opfer, ist die Zensurbestimmung vom 18. 12. 1946, wonach geplante Veröffentlichungen von $\mathrm{KZ}$-Erinnerungen der Landesregierung (Abteilung Arbeit und Sozialfürsorge, Landesausschuß ,Opfer des Faschismus') zur Begutachtung vorzulegen seien, „um zu verhindern, daß von irgendwelchen Personen mit Veröffentlichungen oder Erlebnisberichten aus Nazigefängnissen oder Konzentrationslagern Spekulationen getrieben werden“ (MLHA, MinPräs 750).

187 Aber nicht nur die Konzerne wurden unter Faschismusverdacht gestellt: Trotz der offiziell abgelegten Sozialfaschismusthese wurden auch die Vereinigungsgegner in der SPD schon im März 1946 als „Blutspender für die geschwächte, aber noch nicht endgültig zerschlagene Reaktion“ bezeichnet („Die nächsten Aufgaben der KPD beim Neuaufbau Deutschlands“, in: Institut für Marxismus-Leninismus beim ZK der SED, Geschichte, S. 404f.).

${ }_{188}$ SAPMO-BA, RY 1/12/2, 27, Bl. $98 f$.

${ }^{189}$ Das Zitat unterstreicht, wie selbstverständlich Antisemitismus und Shoah als bloße Unterkapitel der Auseinandersetzung zwischen sozialen Klassen angesehen wurden; siehe dazu die Arbeiten von Groehler und Keßler. 
und Taten, sondern die gegenwärtige Option im beginnenden Kalten Krieg war entscheidend. Die in die gegenwärtigen internationalen und innerdeutschen Konflikte verlängerte Auseinandersetzung um den Nazismus verlieh ihm die Definitionsmacht, „wirklich[e]“ von unbedeutenden Aufgaben zu unterscheiden. Dazu gehörte neben der Enteignung der Großbanken die gesellschaftliche Integration von „immerhin Millionen Hitleranhänger[n] (wenn auch nicht Mitglieder[n]), die man schließlich nicht alle bestrafen und aufhängen kann“. Obwohl er eine „Werbekampagne unter den Pg“ und die Aufnahme erwachsener Pgs in die KPD als „lächerlich“ bezeichnete, stellte er die Weichen für die schon bald eingeschlagene Politik: „Aber in welchem Lager die Hitleranhänger morgen stehen werden, das ist von entscheidender Bedeutung. Darum sagen wir ganz klar: Jawohl, wir wollen nicht eine Hetze und Strafe gegen die kleinen Pg. Wir wollen ihnen die Möglichkeit geben, sich mit aktiv am Aufbau zu bewähren und nach einer gewissen Bewährungsfrist in unsere Partei zu kommen.' [...] Man kann doch diesen Millionen nicht für ewig den Weg versperren.“

\section{Parteigenossen als neue Parteimitglieder}

Die angestrebte Reintegration stand nicht ausschließlich im Zeichen von Antikapitalismus und Kaltem Krieg. Obwohl nur selten thematisiert, bot die Unterscheidung zwischen bloß nominellen und aktiven Nazis auch Möglichkeiten, die im Zuge der Entnazifizierung ausgesprochenen Berufsverbote für Spezialisten zu lockern. Dies erleichterte nicht nur die Arbeit staatlicher Dienststellen, ${ }^{190}$ sondern auch den wirtschaftlichen Neuaufbau, weil dadurch entlassene Fachkräfte in Behörden und Betriebe zurückkehren konnten. Ferner waren in allen Zonen zahlreiche Klagen über die Verarmung infolge von Entnazifizierung und Sequestrierungen zu hören: Rückgängig gemachte Beschlagnahmungen und berufliche Anstellungen ermöglichten vielen Betroffenen wieder die Eigenversorgung und stärkten die wirtschaftlichen Aktivitäten im Land. Der ökonomischen und sozialen Reintegration entsprach das politische Ziel, die Entstehung eines großen dissidenten oder gar widerständigen Rechtsblocks zu verhindern. Die Bedrohung wurde besonders hoch eingeschätzt, da die schnelle Abkehr der Deutschen vom ,Dritten Reich' nicht nur in der SBZ, sondern auch in den Westzonen überraschte. Das bereits in der leninistischen Parteikonzeption strukturell angelegte Mißtrauen gegenüber der Bevölkerung wurde bei den Kommunisten durch diese schnelle Anpassungsbereitschaft nach der zuvor jahrzehntelang erfolgreichen antikommunistischen Indoktrination verstärkt. Die Entstehung eines rechten Blocks ehemaliger NSDAP-Mitglieder in der SBZ wurde auch daher als wahrscheinlich betrachtet, weil die im Laufe der fünfziger Jahre immer selbstverständlicher gewordene Möglichkeit, politische Dissidenz innerhalb des nationalen Rahmens, aber westlich der Zonen- und Staatsgrenze zu leben, in dem später erreichten Ausmaß zu Beginn der Besatzungszeit noch nicht denkbar war.

190 In der Landesverwaltung forderten Grünberg und Ministerialdirektor Hans Manthey (Abteilung Kultur und Volksbildung) am entschiedensten Möglichkeiten zur Wiedereinstellung von nominellen Pgs; dabei bezogen sie sich vor allem auf die zahlreichen vakanten oder mit unfähigen Neulehrern besetzten Stellen in den Schulen auf dem Land (beispielhaft MLHA, LL SED IV/2/3/77, Bl. 50ff.; MLHA, MdI 654; SAPMO-BA, DY 30/IV2/13, 109, Bl. 82). 
Tatsächlich war die Behandlung der ehemaligen Nazis darauf ausgerichtet, die neue Gesellschaft nicht gegen, sondern mit ihnen aufzubauen. Gniffke erläuterte es den mecklenburgischen Genossen Ende Mai 1946 anschaulich: „Wir müssen auch hier unseren Funktionären zunächst einmal sehr klar zu verstehen geben, daß wir Demokratie nur mit dem Menschenmaterial betreiben können, das wir besitzen, und ein besseres Menschenmaterial, das wir gegenwärtig haben, haben wir eben nicht. Das Menschenmaterial, das 12 Jahre nazistisch verseucht ist und unter Druck gesetzt war und nun, nachdem wir eine neue Demokratie aufbauen wollen, können wir kein neues Menschenmaterial heranholen, sondern nur neu formen für unsere Demokratie." [sic]191 Obwohl diese großzügige Haltung gegenüber ehemaligen NSDAPlern bei einigen alten Mitgliedern der Arbeiterparteien Verärgerung hervorrief, wurde sie realisiert. Der langjährige Kommunist, Spanienkämpfer und Lehrer an einer Antifa-Schule im sowjetischen Exil, Anton Switalla, erwiderte, daß es „in der Partei einen großen Widerstand“ gegen die so schnell angestrebte Harmonie gebe: „Besonders bei uns alten SPD- und KPD-Leuten entsteht eine solche Stimmung, daß wir fragen, wollen wir jetzt vor dem Faschismus zurückweichen? Das dürfen wir nicht machen. Sie betrachten diese Wendung einfach als Zurückweichen vor dem Faschismus. Wo man hinkommt, in jedem Ort herrscht diese Stimmung. "192 Auch die Stellungnahme von Erich Glückauf, einem Mitglied des SED-Landessekretariats, zeugt von den Schwierigkeiten der alten Parteimitglieder, sich nach Jahrzehnten der Opposition mit den Kompromissen und Uneindeutigkeiten abzufinden, die zur Sicherung von Herrschaft und zur Durchsetzung politischer Ziele gehörten: „Ich möchte zur Frage der nominellen Nazis sprechen. [...] Ich bin der Meinung, daß man deutlich zu erkennen gibt, daß wir den verbrecherischen Elementen zeigen, daß wir die Kraft haben, Unterschiede zu machen. "193 Daß offener Protest und die öffentliche Artikulation dieser Verärgerung in Mecklenburg-Vorpommern ausblieben, lag wohl vor allem an der geringen Anzahl alter Genossen und an den zahlreichen Aufgaben, vor denen die Mitglieder der gerade vereinigten Regierungspartei standen. ${ }^{194}$

Während die neuen Parteien 1945 Kundgebungen mit ehemaligen KZ-Häftlingen und anderen Opfern des Faschismus veranstaltet hatten, setzten sie nun nicht mehr auf deren kathartische Wirkung, sondern auf die Vorbilder erfolgreicher Umorientierung und Anpassung. Bürger schlug vor, in Städten und Dörfern bekannte Menschen wie „Ärzte, Wissenschaftler usw. “ öffentlich auftreten und von ihrer NS-Belastung und ihrer Bekehrung zur SED berichten zu lassen. ${ }^{195}$ Dabei ging es nicht nur um Sympathie-, sondern auch um Mitgliederwerbung. Wiederholt wurde beklagt, daß die politische Organisation vor allem auf dem Land nicht ohne Rückgriff auf NS-Belastete möglich sei, da die große Mehrheit der erwachsenen Bevölkerung Mitglied in NS-Organisationen gewesen sei. Wie Dahlem im Januar 1946 auf der KPD-,Reichskonferenz' feststellte, bestanden

191 MLHA, LL SED IV/2/3/77, Bl. 69.

192 MLHA, LL SED IV/2/3/77, Bl. 63.

${ }_{193}$ MLHA, LL SED IV/2/3/77, Bl. 72.

194 Nach Fritzsch, Entnazifizierung, S. 22, rief die SED-Erklärung vom Juli 1946 über „SED und nominelle PGs“ (siehe unten) einen „Sturm der Entrüstung“ hervor (Dokumente der Sozialistischen Einheitspartei Deutschlands, Bd. 1, S. 50f.).

195 MLHA, LL SED IV/2/1/10, B1. 114. Siehe beispielhaft den Bericht über eine öffentliche Kundgebung des Parteienblocks in Ückermünde am 22. 6. 1946 (MLHA, MinPräs 1375). 
besonders auf dem Land Organisationsschwierigkeiten, wodurch die Aufnahme von Pgs zwar öffentlich zurückgewiesen, geheim aber dennoch praktiziert wurde: „Es handelt sich da besonders um Bauern, und das trifft besonders für das Land zu, wo unsere Genossen, wenn sie eine Ortsgruppe bilden wollen, oft keinen anderen Ausweg sehen, in Dörfern, die zu 90\% nazistisch organisiert waren, solche Leute, die sie als ehrliche Leute kennen, aufzunehmen. Aber das ist aus politischen Gründen noch nicht möglich. Wir müssen hier einen Übergang schaffen, und die Leute, die schon in der Partei sind, muß man auf geschickte Weise in Bezirksausschüsse oder andere Ausschüsse bringen, wo sie sich bewähren können und den Nachweis erbringen, daß sie wirklich aktiv am Neuaufbau im Dorf oder im Kreis mitarbeiten." 196 Warnkes Antwort während der anschließenden Diskussion auf die Frage nach der Anzahl ehemaliger Pgs in dörflichen KPD-Gruppen unterstreicht das abnehmende Interesse an der möglichen NS-Vergangenheit neuer Funktionsträger und Parteimitglieder, solange sie den gemeinsamen Weg in die Zukunft mitzugehen bereit waren: „Bei uns ist die Lage deshalb besonders schwierig, weil in unserem Gebiet die Einwohnerzahl augenblicklich sozusagen halbiert ist. Die Hälfte der Leute sind Umsiedler, die noch nicht länger als drei Monate im Lande sind, und wer mit Umsiedlern zu tun hat, weiß, daß sie vielfach ihre Parteizugehörigkeit verschweigen. [...] Wir wissen, daß wir noch diesen und jenen herausfinden müssen, aber das werden wir tun. Dabei werden wir allerdings nicht unsere Tore verschliessen aus Angst, wir könnten einige Nazimitglieder aufnehmen. “197

Die gesellschaftliche Reintegration der NS-Belasteten war nicht nur eine quantitative Frage von Parteimitgliedszahlen, sondern hing eng mit dem Ziel der Durchdringung der gesamten, auch der ländlichen Gesellschaft mit staatstragenden und staatsnahen Organisationen zusammen. Wie schon zu Beginn der Besatzungszeit wiederholt von seiten der Kommunisten formuliert worden war, entschied der politische Zugriff auf alle gesellschaftlichen Bereiche nicht nur über die politische Machtfrage, sondern vor allem über den Erfolg des zentral geplanten und gelenkten gesellschaftlichen Neuaufbaus. Die intendierte Reintegration ehemaliger Nazis war daher nicht einfache Bauernfängerei. Weil das von Besatzungsmacht und KPD favorisierte Gesellschaftsmodell eine breite Mobilisierung und Organisierung auch der ländlichen Gesellschaft voraussetzte, sollte dieser Prozeß nicht ungesteuert, sondern in festgelegten Bahnen verlaufen.

196 SAPMO-BA, RY 1/12/2, 17, Bl. 34. Es entsprach dem politischen Wechsel von der Entnazifizierung zur Reintegration, daß Grünberg die Oberbürgermeister und Landräte erst am 10.1.1946 von der Jugendamnestie informierte, die die Alliierte Kommandantur in Berlin bereits Anfang September 1945 beschlossen hatte (MLHA, MfV 48, Bl. 19; siehe zur politischen Werbung unter Jugendlichen und dem besonderen Interesse an den ehemaligen $\mathrm{HJ}$ - und BDM-Mitgliedern auch: SAPMO-BA, RY 1/I2/2, 17, Bl. 28; MLHA, LL SED IV/2/3/77, Bl. 58; ähnlich für die SPD in den Westzonen: Holtmann, Lassalleaner).

${ }^{197}$ SAPMO-BA, RY 1/12/2, 17, Bl. 45. Auf der SED-Sekretariatssitzung am 29. 5.1946 nannte Dahlem den mecklenburgischen Genossen Bayern als Reintegrationsvorbild, „wo das gros der Nazianhänger in der CSU war und ist“. Die Kommunisten hätten „schwere Rückschläge bekommen [...], weil sie die Verantwortung trugen für die Maßnahmen gegen die Nazis; weil es ein politischer Fehler war, daß der einzige kommunistische Minister ausgerechnet der Minister für die Entnazifizierung war" (MLHA, LL SED IV/2/3/77, Bl. 46f.; siehe Niethammer, Mitläuferfabrik, S. 338-375). 
Was in den programmatischen Reden gesagt wurde, blieb nicht nur Idee. In Mecklenburg-Vorpommern wurden bereits vor dem Erlaß der offiziellen SED-Entschließung „zur Frage der ehemaligen nominellen Mitglieder der NSDAP“ vom 20. Juni 1946 und vor dem Besuch Dahlems und Gniffkes am 29. Mai 1946 politische Schritte zur Erleichterung der Reintegration bloß nomineller Nazis unternommen. Initiativ wurde der Landesvorstand der SED, als er Major Katznelson bei der SMAM am 13. Mai 1946 über die „Probleme, die vor der SED Mecklenburg-Vorpommern stehen“, berichtete. ${ }^{198}$ Bereits der erste Punkt betraf die „Frage der nominellen Nazis“. In vielen Dörfern gebe es „keine Möglichkeit der Werbung für die Partei mehr, weil früher der größte Teil der Bauern und Landarbeiter erzwungenermaßen Mitglied der Nazipartei war“. Da zahlreiche von ihnen aber dem Neuaufbau positiv gegenüberstünden, schlug der SED-Vorstand vor, bloß nominell Belastete, die seit 1945 „sowohl in ihrer Gesinnung als auch in ihrer praktischen Hilfe beim Neuaufbau guten Willen gezeigt haben, die keine Verbrechen begangen und im demokratischen Sinne erziehbar sind, als sogenannte Sympathisierende ohne Abstimmungsrecht in unsere Partei aufnehmen zu dürfen“. Sogleich wurde einschränkend versichert, jedes Aufnahmegesuch individuell zu behandeln.

Der Brief zeigte unmittelbar Wirkung: In den folgenden Tagen fand ein Gespräch bei der SMAM statt, ${ }^{199}$ in dem neue Regelungen beschlossen wurden, die einen offeneren Umgang mit den NSDAP-Mitgliedern ermöglichten. Während sich die SED schriftlich an die Besatzungsmacht wandte, teilte diese ihre Entscheidungen mündlich mit, überließ die Mitteilung an andere Stellen ihrem bevorzugten deutschen Gesprächspartner, der SED, und verzichtete auf einen offiziellen Befehl zur Umsetzung der neuen Regelung. Bürger kommentierte es als „erfreulich, daß wir in dieser Frage immer mehr und mehr Freiheiten bekommen “. Dieses Vertrauen habe die SMAM ,auf Grund unseres bisherigen Verhaltens, daß wir hier ganz konkret handeln und eine solche Kraft haben, daß wir mit dieser Frage fertig werden“ - womit er wohl die rigorose Entnazifizierung meinte. ${ }^{200}$ Wider die Darstellungen von der vollständigen Abhängigkeit der deutschen Politiker von der Besatzungsmacht ${ }^{201}$ zeigt dies, daß die SED selbständig initiativ werden konnte. Trotz der geographischen und politischen Nähe zwischen Landesleitung und SMAM und trotz Bürgers durch die Zeit im sowjetischen Exil erleichterten Kontakte zu ihr war die Antwort vorher noch nicht mit der SMAM abgeklärt gewesen. ${ }^{202}$

Das Protokoll vom 17. Mai $1946^{203}$ hielt fest, daß bloß nominelle Pgs in die neuen Parteien aufgenommen werden könnten, wenn jeder Einzelfall vom Parteienblock begut-

\footnotetext{
198 MLHA, LL SED IV/2/5/161, Bl. 29.

199 Am 17. 5. 1946 berichtete Bürger in der Sekretariatssitzung von dem Gespräch bei der SMAM und deren Genehmigung, nominelle Pgs in die neuen Parteien aufzunehmen (MLHA, LL SED IV/2/3/77, Bl. 34ff.); am 18./19. 5. 1946 informierte er darüber auf einer Sitzung des Landesvorstandes mit SED-Kreissekretären (MLHA, LL SED IV/2/1/9, Bl. 82f.).

${ }^{200}$ MLHA, LL SED IV/2/1/9, Bl. $82 \mathrm{f}$.

201 Siehe beispielhaft Schwarz, Reich, S. 24f.

${ }^{202}$ Auch die am 11.7. 1946 von der SMAM wieder untersagte Regelung (ADL, LDP 10370) deutet auf Handlungsspielräume deutscher Politiker aufgrund von Differenzen in den Kommandanturen, die in den meisten Einzelfällen wegen des unzureichenden Archivzugangs nur vermutet werden können; die Hinweise bei Foitzik, Inventar, bestätigen grundsätzlich das Kompetenzchaos innerhalb der SMAD und der Landeskommandanturen.

${ }^{203}$ MLHA, LL SED IV/2/3/77, Bl. 34ff.
} 
achtet werde. Darüber hinaus gab Bürger den Kreissekretären weitere Instruktionen über die Behandlung der Aufnahmekandidaten, die ihm im Gespräch bei der SMAM aufgetragen worden waren:204 Die ehemaligen Nazis seien regelmäßig in Versammlungen zusammenzuholen, in denen „sie gleichsam eine Einfühlung in unser Wollen, in unsere Absichten, in unseren Staat" bekämen. Dabei sei "geschickt" vorzugehen, denn es nütze nichts, „wie in einigen Orten vorgekommen“, den Leuten vorzuhalten, „was sie für Verbrecher seien“. Vielmehr sei eine Mischung aus Aufklärung und Verständnis angebracht: Es solle „in geeigneter und guter Form den Leuten im richtigen Moment vor Augen“ geführt werden, wohin ,ihr vorheriges Verhalten geführt" habe, um „ihre geistige und politische Arbeit [zu] revidieren“. Dabei sei „ein Gefühl in ihnen [zu] erwekken, daß wir Verständnis haben für die Zwangsmaßnahmen, die bestanden“. Dies bezog sich nicht auf die Zeit seit, sondern vor 1945: Die große Zahl der NSDAP-Mitglieder wurde nicht mehr als Täter oder Mitverantwortliche, sondern als Betroffene, Gezwungene oder Verführte behandelt.

Unter der eingangs protokollierten Leitfrage „Wie gewinnen wir diese Leute für uns, damit sie nicht reaktionären Kräften in die Arme laufen?“ betrachtete Bürger nicht nur die NS-Vergangenheit als Herrschaft einer kleinen diktatorischen Gruppe, zu deren Opfern selbst die große Zahl der NSDAP-Mitglieder zu zählen sei, ${ }^{205}$ sondern negierte rückwirkend sogar die Mitgliedschaft selbst. Für diesen salvatorischen Akt, der nicht mehr historische Einsicht und praktische Umkehr verlangte, sondern nur noch das, richtige ' Verständnis der unfreiwilligen NS-Mitgliedschaft, zog er sogar die gegenwärtigen Schwierigkeiten seiner expandierenden Partei als Parallele heran und verglich damit explizit die vormalige mit der gegenwärtigen hegemonialen Partei: „Sie waren wohl Mitglied der NSDAP, aber keine Faschisten. Es soll ja auch bei uns Genossen geben, die Mitglieder sind und keine Sozialisten. Wir wollen diese aber erziehen, daß es Sozialisten werden, die bei uns sind und so auch die Sache der Nazis anfassen. Wir müssen die Leute langsam zu uns heranbringen. “Von den NSDAPlern seien die „Besten, die durch unsere Versammlungen erfaßt werden und etwas von uns erwarten“, zu gewinnen, bei der Polizei von den Listen der ehemaligen NSDAP-Mitglieder zu streichen, vom Sonderarbeitseinsatz zu befreien und nach der Entscheidung des Kreises in die Partei aufzunehmen. „Mit dieser Rehabilitierung muß praktisch verbunden sein, [...] daß endlich einmal Schluß damit ist, daß sie Mitglieder der Nazipartei waren oder als Faschisten gelten": Sie sollten nachträglich dem ,Dritten Reich“ entrinnen. ${ }^{206}$

${ }^{204}$ MLHA, LL SED IV/2/1/9, Bl. $82 \mathrm{f}$.

205 Ähnlich äußerte sich Ulbricht, der das Wahlrecht für bloß nominelle Nazis am 3. 3. 1946 damit begründete, daß die „einfachen Nazimitglieder [...] vom Faschismus betrogen" worden seien (SAPMO-BA, RY 1/I1/2, 8, Bl. 353).

206 Bürger entwarf damit ein politisches Programm, das nicht in seiner Einseitigkeit umgesetzt werden konnte; beispielsweise wurde der Vorschlag, ehemalige Organisationsmitgliedschaften rückwirkend für nichtig zu erklären, nirgends weiter verfolgt. Dies zeigt, daß die konkreten politischen Entscheidungen im Land, die nicht von der Besatzungsmacht geregelt wurden, weiterhin nicht der SED-Landesvorsitzende, sondern Warnke traf. Die zurückhaltenderen Formulierungen im SED-Beschluß über „SED und nominelle Pgs“ zeigen die im Vergleich zur Schweriner Landesleitung größere Nähe der zonalen SED-Leitung zur aktuellen Politik (Dokumente der Sozialistischen Einheitspartei Deutschlands, Bd. 1, S. 50f.). Pieck benannte selbst in seiner Wahlkampfrede, die er zwischen dem 29. 8. 1946 und dem 14. 9. 1946 in 23 Orten, unter ande- 
Dieser allgemein formulierten Eindeutigkeit entsprach allerdings keineswegs die konkrete Praxis der Parteien, die sich seit Beginn ihrer Existenz mit der Aufnahme tatsächlich oder vermeintlich NS-Belasteter in die eigenen Reihen beschäftigten. Die häufig begehrten organisatorischen Fähigkeiten der bereits im ,Dritten Reich' politisch Geschulten, das ehrgeizig angestrebte Mitgliederwachstum der neuen Parteien, die dauernden Unterstellungen gegenüber den jeweils anderen Parteien, besonders viele NS-Belastete aufzunehmen, und die Unfähigkeit des Parteienblocks, verbindliche und dauerhafte Aufnahmeregeln festzulegen, machten das Thema zu einem politischen Dauerbrenner. ${ }^{207}$ Der CDU-Landesvorsitzende Lobedanz teilte allen Kreisleitungen bereits am 31. Januar 1946 mit, daß im antifaschistischen Landesausschuß die Einberufung eines paritätisch besetzten Sonderausschusses zur Überprüfung der Aufnahme ehemaliger NSDAPler in eine der neuen Parteien genehmigt worden sei; ${ }^{208}$ ebenso unterrichtete der Landesgeschäftsführer Jäkel die LDP-Gruppen per Rundschreiben Mitte Februar von einem „mit Einverständnis der Sowjetischen Militäradministration“ festgelegten Bereinigungsverfahren „für die Rehabilitierung und Aufnahme sogenannter nomineller ehemaliger Mitglieder der NSDAP“.209 Trotz dieser frühen Zusagen und dem Gespräch Bürgers bei der Landeskommandantur Mitte Mai lehnte die SMAM den vom Landesantifablock eingereichten Gesetzentwurf über die Aufnahme nomineller Pgs am 11. Juli 1946 in einer Unterredung mit dem Mitglied des Präsidiums der Beratenden Landesversammlung und des LDP-Landesvorstands, Ernst Harzmann, ab. ${ }^{210}$ Dies war mit keinem generellen Verbot verbunden, denn gleichzeitig wurde „den politischen Parteien freigestellt, nach eigenem Ermessen, eigener Verfahrensregelung und unter eigener Verantwortung mit der Aufnahme nomineller Pg.'s zu beginnen“. Als Kriterien hielt das Protokoll nur fest, daß die Aufzunehmenden „ab Mai 1945 in Wort und Tat den Willen zur Demokratie bezeugt" hätten und die Anzahl der nominellen Nazis „in einem gesunden Verhältnis zum alten Mitgliederbestand“ stehe: „Zu starke Aufnahmen von Pg.'s kann die Auflösung der betreffenden Ortsgruppe zur Folge haben.“

Die Verweigerung einer generellen Entscheidung hatte System und bestand auch in den folgenden Monaten und Jahren weiter. ${ }^{211}$ Noch am 2. September 1946 - drei Tage, nachdem die Errichtung der Kreisentnazifizierungskommissionen gemäß Kontrollratsdirektive Nr. 24 angeordnet worden war ${ }^{212}$ - erläuterte der Landesausschuß des mecklenburgischen Antifablocks einem Betroffenen, daß die Ausarbeitung der zur Rehabili-

rem in Wismar, Schwerin, Greifswald, Wolgast, Zinnowitz, Ahlbeck und Usedom, hielt, noch die "ernste Schuld“ der Pgs und schloß die Löschung der ehemaligen NSDAP-Mitgliedschaft trotz der intendierten gesellschaftlichen Reintegration ausdrücklich aus (SAPMO-BA, NY 4036 [NL Pieck], 428, Bl. 89, 103f.).

${ }^{207}$ Siehe beispielsweise die zahlreichen Hinweise darauf in den Blockprotokollen im Register von Suckut, Blockpolitik, S. 638.

${ }^{208}$ Dabei nannte er schon die Modalitäten: Lebenslauf, mehrere Bürgen, Stellungnahmen verschiedener Parteiinstanzen (ACDP, III/036, A129); dies gaben die CDU-Kreisverbände im Februar an die Ortsgruppen weiter (ACDP, 1/350, 004/4; ACDP, III/036, A137).

${ }^{209}$ ADL, LDP 18656.

${ }^{210} \mathrm{ADL}, \mathrm{LDP} 10370$.

${ }^{211}$ Der stellvertretende LDPD-Vorsitzende Arthur Lieutenant erläuterte am 27. 10. 1947 gegenüber der SMAD und den Landeskommandanturen, daß die Parteien aufgrund der unklaren Linie der Besatzungsmacht zu eigenständigen Entscheidungen gezwungen seien (ADL, LDP 10370).

212 Siehe Kapitel III.1. 
tierung und Parteiaufnahme erforderlichen Richtlinien "wahrscheinlich noch einige Zeit" dauern werde. ${ }^{213}$ Die gegenüber dem LDP-Landesvorstand ausgesprochene Auflösungsdrohung zeigt, daß die Besatzungsmacht die Unsicherheit in diesem sensiblen Bereich für ihre stete Überwachung und latente Bedrohung besonders der beiden kleinen Parteien instrumentalisierte. ${ }^{214}$ Einer ähnlichen Ungewißheit waren die Pgs ausgesetzt, deren Anpassungsleistungen durch die unklaren Kompetenzen und Anforderungen niemals ihre vollständige Rehabilitation garantierten, sondern angesichts der diffusen Ansprüche stets wiederholt und gesteigert werden mußten.

\section{Parteigenossen als Wähler}

Der Parteivorstand der SED veröffentlichte im Juli 1946 einen offiziellen Beschluß über „SED und nominelle Pgs“, der die vor Ort bereits seit längerem realisierte Praxis offen ansprach:215 Ein Jahr nach dem Zusammenbruch sei die Macht der „Kriegstreiber und aktiven Nazis“ in der SBZ durch Bodenreform, Entnazifizierung und Sequestrierungen gebrochen und der Zeitpunkt gekommen, „das Problem der Eingliederung der Massen der ehemaligen einfachen Mitglieder und Mitläufer der Nazipartei in den demokratischen Aufbau Deutschlands einer Lösung entgegenzuführen“. Allen bloß nominellen Nazis sei „die Möglichkeit zur Mitarbeit und zu einem neuen Leben“ zu geben, indem sie als Staatsbürger anerkannt würden. Dies entspreche der Regelung beim Volksentscheid in Sachsen, von dem bloß „Kriegsverbrecher und aktive Nazis“ ausgeschlossen seien.

Der Verweis auf den Volksentscheid deutete auf eine Zielsetzung, die über die Mitgliederwerbung hinausging. Die hegemoniale Partei suchte nach breiter Anerkennung in der Bevölkerung, deren Mehrheit in den Jahrzehnten zuvor - auch in Mecklenburg-Vorpommern - weder der KPD noch der Sowjetunion wohlgesonnen gewesen war. Die Stellungnahme war daher auch ein Teil der Wahlvorbereitungen, die langfristig geplant wurden, weil die Wahlen in der SBZ bereits seit Anfang 1946 erwartet wurden. ${ }^{216}$ Nicht zufällig veröffentlichte der Parteivorstand die bereits länger vorbereitete Erklärung gleichzeitig mit der Bekanntgabe der Termine zu den Gemeindewahlen gleichsam als Wahlkampfauftakt. ${ }^{217}$ Der CDU-Reichsgeschäftsstelle war der Textentwurf bereits zuvor bekanntge-

${ }^{213}$ MLHA, LL SED IV/2/13/623, Bl. 4.

214 „Wir wissen, daß die Anwürfe durch die SED in dieser Hinsicht oft falsch gewesen sind und daß ihnen vielfach eine rein demagogische Auslegung der Begriffe Pg, Reaktionär, Faschist, Militarist, Imperialist usw. zugrunde liegt, die sie in ihren eigenen Reihen ignorieren" (Mitteilungsblatt der LDPD-Parteileitung, Nr. 1, 28. 9. 1946). CDU-Generalsekretär Georg Dertinger äußerte auf einer Geschäftsführertagung seiner Partei im Dezember 1946, daß das Fehlen einer einheitlichen Regelung dazu führe, daß , wir bei der Aufnahme rehabilitierter Pgs nicht mit der gleichen Großzügigkeit vorgehen können, die etwa die SED an den Tag legt" (ACDP, 07/011, 1326).

${ }^{215}$ Dokumente der Sozialistischen Einheitspartei Deutschlands, Bd. 1, S. 50 f.

${ }^{216}$ In einer Besprechung Piecks bei der SMAD wurde am 23. 1. 1946 eine schnelle Vereinigung der Arbeiterparteien angeordnet und dabei "Wahlen Ende Mai“ angekündigt (Badstübner/Loth, Pieck, S. 63; siehe auch Loth, Kind, S. 52); Dahlem sprach bereits am 8./9.1. 1946 von den bevorstehenden Wahlen (SAPMO-BA, RY 1/12/2, 17, B1. 33f.).

${ }^{217}$ Landes-Zeitung, 22. 6. 1946; Fritzsch, Entnazifizierung, S. 22. Die Gemeindewahlen wurden in Mecklenburg-Vorpommern und Brandenburg am 15.9. 1946, in Sachsen am 1. 9. 1946 und in Sachsen-Anhalt und Thüringen am 8. 9. 1946 abgehalten; am 20. 10.1945 wurden die fünf Landund die Kreistage der SBZ gewählt. Die zahlreichen Hinweise auf die Wahlen in den Sachregistern von Badstübner/Loth, Pieck, und Suckut, Blockpolitik, zeigen ihre große politische Be- 
macht worden; parteiintern informierte sie darüber, warnte aber vor jeder „Indiskretion“, da das Vorhaben „absolut parteiintern und vertraulich zu behandeln“ sei und die SED die Zusage erteilt habe, „keinen isolierten Schritt [zu] unternehmen“.218 Daran hielt sich die hegemoniale Partei aber nicht und setzte sich damit als erste der drei zugelassenen Parteien öffentlich für die Rehabilitierung der Mehrzahl der NSDAPler ein.

Die SED suchte eine breitere öffentliche Anerkennung als nur bei den Menschen, die selbst Mitglieder einer der neuen Parteien waren. Zur Fortsetzung ihrer politischen Arbeit als hegemoniale Partei suchte sie die Legitimation durch Wahlen und die Stimmenmehrheit in den Parlamenten. Für die Wahlen auf Landes-, Kreis- und Gemeindeebene waren daher auch die Stimmen der bloß nominellen NSDAPler willkommen, denen das aktive Stimmrecht nicht vorenthalten wurde. ${ }^{219}$

Gemeindewahlen in der SBZ in Prozent, 1.-15. September 1946:220

\begin{tabular}{|c|c|c|c|c|c|c|}
\hline & $\begin{array}{l}\text { Branden- } \\
\text { burg }\end{array}$ & MVP & Sachsen & $\begin{array}{l}\text { Sachsen- } \\
\text { Anhalt }\end{array}$ & Thüringen & SBZ \\
\hline SED & 59,8 & 69,9 & 53,7 & 59,2 & 50,5 & 57,1 \\
\hline LDPD & 17,4 & 10,5 & 22,4 & 23,3 & 25,7 & 21,1 \\
\hline CDU & 18,8 & 16,7 & 21,9 & 15,5 & 18,2 & 18,7 \\
\hline VdgB & 2,9 & 1,9 & 1,0 & 1,2 & 3,5 & 1,8 \\
\hline $\begin{array}{l}\text { Frauenaus- } \\
\text { schüsse }\end{array}$ & 1,0 & 1,3 & 0,8 & 0,8 & 2,0 & \\
\hline Kulturbund & - & - & 0,2 & - & 0,1 & 0,1 \\
\hline Sonstige & 0,1 & - & - & 0,0 & - & 0,0 \\
\hline Ungültig & 9,3 & 9,4 & 9,8 & 9,9 & 8,3 & 9,5 \\
\hline
\end{tabular}

Der Wahlerfolg der SED war nicht zu übersehen, da sie in allen Ländern die meisten Stimmen erhielt, was nicht nur auf die Benachteiligungen der bürgerlichen Parteien zu-

deutung und die durchgängigen Behinderungen der beiden bürgerlichen Parteien. Siehe für Mecklenburg-Vorpommern z. B. das Protokoll einer Besprechung bei General Michail Skossyrew am 4. 9. 1946 über die Gemeindewahl, in der so detaillierte Vor- und Angaben gemacht wurden, daß selbst die Plakatierung nicht vergessen wurde (MLHA, MinPräs 195, Bl. 4ff.; Weber, DDR, S. 17f.; Braun, Wahlen, S. 383-388).

${ }^{218}$ ACDP, 07/011, 1286.

${ }^{219}$ Das Wahlalter war in der SBZ auf 21 Jahre festgelegt; gemäß Kontrollrats-Gesetz Nr. 10 waren Kriegsverbrecher, alle Mitglieder von SS, SD und Gestapo, die Funktionäre diverser NS-Organisationen und „sonstige Aktivisten des Faschismus und Kriegsinteressenten“, die der Gemeindeverwaltung vom Parteienblock zu benennen waren, von den Gemeindewahlen ausgeschlossen ("Wahlordnung für die Gemeindewahlen in der Sowjetischen Besatzungszone Deutschlands“ und Erläuterungen in: Amtsblatt, Nr. 2 [1946], S. 33; die Wahlordnung für die Landtags- und Kreistagswahlen in der SBZ mit den Durchführungsbestimmungen für Mecklenburg-Vorpommern in: Amtsblatt, Nr. 7 [1946], S. 105-112; Braun, Wahlen, S. 384). Ulbricht hatte am 3. 3. 1946 das Wahlrecht für alle Personen ab 18 Jahren und für die bloß nominellen Nazis gefordert und dabei die Differenz zur US-Zone betont, in der ${ }_{n}$ ein großer Teil der kleinen Nazis von der Wahl ausgeschlossen wurde, während die großen Kriegsinteressenten das Wahlrecht hatten " (SAPMO-BA, RY 1/I1/2, 8, Bl. 352f.).

220 Braun, Wahlen, S. $396 f$. 
rückzuführen war. ${ }^{221}$ Der hohe Stimmenanteil für die SED war besonders auf die zahlreichen Flüchtlinge zurückzuführen, denen in vielen Städten und Gemeinden als erste Hilfe Funktionsträger der SED begegneten, da sie die meisten wichtigen Posten besetzt hatten; außerdem war die SED die aktivste Protagonistin der Bodenreform, der Sequestrierungen und der Entnazifizierung, durch die viele Menschen eine neue Arbeit erhielten, die ihnen den Neuanfang nach dem Krieg erleichterten. „In der gesamten sow. Zone wurde gewählt und wir sind wieder an der Spitze. Es liegt zum größten Teil an unserer Bodenreform, daß sie den Flüchtlingen und Siedlern noch allerhand geben können“.222

Landtagswahlen in der SBZ in Prozent, 20. Oktober 1946:223

$\begin{array}{lcccccr} & \begin{array}{l}\text { Branden- } \\ \text { burg }\end{array} & \text { MVP } & \text { Sachsen } & \begin{array}{l}\text { Sachsen- } \\ \text { Anhalt }\end{array} & \text { Thüringen } & \text { SBZ } \\ \text { SED } & 43,9 & 49,5 & 49,1 & 45,8 & 49,3 & 47,6 \\ \text { LDPD } & 20,6 & 12,5 & 24,7 & 29,9 & 28,5 & 24,6 \\ \text { CDU } & 30,6 & 34,1 & 23,3 & 21,8 & 18,9 & 24,5 \\ \text { VdgB } & 4,9 & 3,9 & 1,7 & 2,5 & 3,3 & 2,9 \\ \text { Frauenaus- } & - & - & 0,6 & - & - & 0,2 \\ \text { schüsse } & & - & 0,6 & - & - & 0,2 \\ \text { Kulturbund } & - & - & 6,5 & 5,8 & 4,4 & 5,6 \\ \text { Ungültig } & 4,6 & 5,5 & & & & \end{array}$

Die Pg-freundliche Politik dürfte dagegen keine große Bedeutung für dieses Wahlergebnis gehabt haben: Der Stimmenanteil der SED war in keinem Land der SBZ höher als in Mecklenburg-Vorpommern, obwohl die Entnazifizierung dort weitaus schärfer durchgeführt wurde als beispielsweise in Sachsen und Thüringen. Außerdem hatte Warnke die Wiederaufnahme der Entnazifizierung bereits am 30. August 1946, also mehrere Wochen vor den Wahlen, initiiert, wodurch er der SED eher schaden konnte, weil den

221 Nach den Wahlen und der Konstituierung des Landtags teilte Höcker am 9. 12. 1946 dem Landtagspräsidenten Moltmann die Gründung der ersten Nachkriegsregierung des Landes mit, die die Arbeit der bisherigen Landesverwaltung ohne Brüche fortsetzte. Neben Höcker gehörten der Regierung die Minister Warnke, Grünberg, Alfred Starosson, Witte, Friedrich Burmeister, Hans Gotthilf Strasser und Möller an (MLHA, Meckl. Landtag 41, Bl. 498; Kornow, Arbeiterklasse, S. 129-132). Burmeister war von der CDU als Ersatz für den späteren Landrat von Usedom, Werner Jöhren, vorgeschlagen worden, nachdem SED und SMAM ihr Mißfallen geäußert hatten (ACDP, III/036, A113). Bürger hatte seinen Partner im paritätisch besetzten SED-Landesvorsitz als Landtagspräsidenten vorgeschlagen, wodurch ein weiteres hohes politisches Amt mit einem schwachen und anpassungsbereiten Sozialdemokraten besetzt war (MLHA, LL SED IV/2/3/77, Bl. 134-138). Die Vollmachten der fünf Landespräsidenten in der SBZ waren am 27. 11. 1946 durch den SMAD-Befehl Nr. 332 an die Landtage und neugebildeten Regierungen übertragen worden (Um ein antifaschistisch-demokratisches Deutschland, S. 347; Amtsblatt, Nr. 1 [1947], S. 15).

222 Moltmann auf der Sekretariatssitzung der SED-Landesleitung am 21. 10. 1946 (MLHA, LL SED IV/2/3/77, Bl. 125).

${ }^{223}$ Braun, Wahlen, S. 396f. 
Oberbürgermeistern, Landräten und Bürgermeistern, die fast alle derselben Partei angehörten, der Vorsitz der Entnazifizierungskommissionen übertragen wurde. Einen Tag nach den Wahlen vom 20. Oktober forderte Bürger eine Fehlerdiskussion im Sekretariat der SED-Landesleitung wegen des Stimmenverlustes gegenüber den Gemeindewahlen vom 15. September. Dabei führte er das schlechtere Ergebnis unter anderem auf den Umgang mit den Pgs zurück: „Unsere Politik den nominellen Nazis gegenüber ist eine zwiespältige Politik. Auf der einen Seite wurde um sie geworben, auf der anderen wurden sie abgestoßen. - Wir haben vor der Wahl erklärt: es hat sich nichts geändert an unserer Politik zu ihnen und im gleichen Moment hat man in den Betrieben Entnazifizierungskommissionen eingesetzt und diese Nazis entlassen. “224 Trotz dieser Schwankungen stärkte die Solidarität der SED mit den ,kleinen Nazis` ihre Verankerung in der Bevölkerung und sicherte deren Loyalität.

\section{Parteigenossen als loyale Antifaschisten und Untertanen}

Neben dem gesellschaftlichen Zusammenbruch infolge von NS-Herrschaft und Krieg und der Präsenz der unbeliebten Besatzungsmacht machte vor allem die Übernahme der Regierungsverantwortung durch eine jahrzehntelang politisch marginalisierte und teilweise verfolgte revolutionäre Partei vertrauensbildende Maßnahmen zwischen der Bevölkerung und diesen neuen Herrschern notwendig. Eine überragende Bedeutung kam dabei der materiellen Absicherung des Neuanfangs vieler alter und neuer Bewohner auf dem Gebiet der SBZ zu, die durch die Bodenreform kleine landwirtschaftliche Betriebe aufbauen oder Arbeitsplätze und Betriebe der geflohenen, enteigneten und entlassenen Personen übernehmen konnten. 225

Neben dem schnellen Ende der Entnazifizierung und den Reintegrationsangeboten an die anpassungsbereiten NS-Belasteten infolge der Differenzierung zwischen aktiven und bloß nominellen Pgs gab es noch weitere politische Harmonisierungsversuche im Rahmen der Auseinandersetzung mit der NS-Vergangenheit. Weniger individuell und auf eine größere Personengruppe bezogen als die Entnazifizierung war eine öffentliche Kampagne während des ersten Prozesses des Internationalen Militärgerichtshofes gegen die Hauptkriegsverbrecher, der vom November 1945 bis Anfang Oktober 1946 in Nürnberg stattfand und bei dem die Alliierten mehrere Spitzenfunktionäre des NS-Staates anklagten. Im Rahmen dieser Prozesse wurden umfangreiche Dokumente bekannt, die auch der Öffentlichkeit das Ausmaß und die Systematik der NS-Kriminalität und Brutalität aufzeigten.226

Die parallel zum Ende der Entnazifizierung entfaltete Kampagne erfaßte größere Bevölkerungskreise als die politisch motivierten Überprüfungen, Entlassungen und Neu-

${ }^{224}$ MLHA, LL SED IV/2/3/77, Bl. 122.

${ }^{225}$ Jochen-Christoph Kaiser spricht über die Landverteilung im Rahmen der Bodenreform als "Klientelbildung ${ }^{\alpha}$ der KPD/SED (Historikertag 1994 in Leipzig).

${ }^{226}$ In diesem Zusammenhang erschien die umfangreiche Quellensammlung zum ,Dritten Reich', die jahrelang Standardwerk auch der historischen Forschung blieb, Nürnberger Prozesse; siehe Birke, Nation, S. 74-79; Henke, Trennung, S. 69-75; Jung, Rechtsprobleme; Kleßmann, Staatsgründung, S. 78ff.; Smirnow, Prozeß; Taylor, Nürnberger Prozesse; Urteil von Nürnberg; Zur Geschichte der Rechtspflege, S. 208-213. 
einstellungen. Die KPD trat besonders aktiv auf, aber auch die SPD und die anderen Parteien beteiligten sich.227 Dies erweiterte die politische Bedeutung des Antifaschismus, da er nicht mehr nur als eine politische Negativbestimmung wirkte, die zu Sanktionen gegenüber den NS-Belasteten führte. Die Kampagne machte ihn zu einem positiven Identifikationsangebot für die große Mehrheit der Bevölkerung der SBZ, das zu einem der wichtigsten und langlebigsten ihrer Geschichte wurde. ${ }^{228}$

Die Berechtigung zu dem offensiven Umgang mit dem Antifaschismus sprach sich vor allem die KPD zu, weil sie sich selbst, ihre Vergangenheit und ihre politischen Ziele zur Inkarnation des Antifaschismus erklärte. Obwohl nicht sie, sondern die alliierten Armeen NS-Deutschland besiegt hatten und obwohl jede selbstkritische Reflexion der eigenen politischen Verantwortung an der Niederlage von 1933 ausblieb, gab die KPD vor, als Repräsentantin des Antifaschismus und im Namen der Opfer des ,Dritten Reiches ${ }^{6}$ zu sprechen. Dies gründete in ihrer Interpretation des Faschismus und seiner Gegner, die sich primär an Eigentums- und Klassenkampfkategorien orientierte, wodurch sie sich selbst zur Hauptgegnerin und zum wichtigsten Opfer erklärte. Durch diese Selbstdarstellung machte sich die KPD implizit auch zu der Instanz, die Vergeltung fordern und Vergebung spenden durfte. Andere in- und ausländische Opfergruppen blieben dabei ausgespart, und sowohl die moralische Qualifikation als auch das Recht zur Vergebung wurde nicht den einzelnen Kommunisten, sondern ihrer Partei zugesprochen. Die Kampagne zum Militärtribunal, bei der immer wieder die Todesstrafe für alle in Nürnberg Angeklagten gefordert wurde, erlaubte es, diese politisch-moralische Bestimmung des Verhältnisses zwischen KPD und Bevölkerung öffentlichkeitswirksam zu inszenieren.

Das Unternehmen war von oben organisiert: Die KPD-Leitungen gaben Pläne, Anweisungen, sogar einzelne Losungen für Transparente heraus, die sich vorwiegend auf die Mord- und Vernichtungspolitik des,Dritten Reiches' bezogen und in variierenden Formeln die Todesstrafe, den Tod durch den Strang etc. für die Angeklagten forderten. Nicht nur Parteigruppen, sondern möglichst viele Organisationen und Gruppen wurden von Parteivertretern agitiert, ihre Unterstützung für das internationale Gerichtsverfahren und die Verurteilung des Faschismus kundzutun; alle erreichbaren Menschen sollten zu kollektiven Stellungnahmen aktiviert werden. Die Agit-Prop-Abteilung der Rostocker KPD-Kreisleitung wies ihre Ortsgruppen zum Jahreswechsel zu einer Verstärkung dieser Maßnahmen an: „Jetzt muß jede Ortsgruppe darangehen, die Bevölkerung zu mobilisieren, in kurzen Resolutionen die eine Forderung zu erheben: Tod den Kriegsverbrechern in Nürnberg! Das ganze Deutsche Volk verlangt, daß alle Angeklag-

${ }^{227}$ Gericke, Presseberichterstattung. Die Grenze zwischen den Parteien und den Verwaltungsbzw. Staatsorganen war, wie sehr häufig in der SBZ, auch bei dieser Kampagne unklar, denn auch Verwaltungsorgane traten als Organisatoren auf: Beispielsweise trug die Landesabteilung Kultur und Volksbildung die Kampagne Anfang Januar 1946 in die Schulen; Lehrer hatten Vorträge zum Internationalen Gerichtshof zu halten, deren Texte Grünbergs Abteilung zur Kontrolle zuzusenden waren (MLHA, MfV 48, Bl. 26).

${ }_{228}$ Dazu mit umfangreichen Literaturangaben Danyel, Vergangenheit; Danyel/Groehler/Kessler, Antifaschismus; Grunenberg, Antifaschismus, S. 120-144; Meuschel, Stalinismus; Schubarth, Antifaschismus; Wittich, Initiationen; zu der durch die Quellenedition über die ,Roten Kapos“ im KZ Buchenwald (Niethammer, Antifaschismus) angestoßene Debatte siehe Danyel, Wandlitz. 
ten in Nürnberg, die sich die grausamsten Verbrechen an der Menschheit zuschulden haben kommen lassen, nur eines verdienen: Tod durch den Strang! [...] In jeder öffentlichen Versammlung, ganz gleich, mit welchem Thema, ist eine Resolution in diesem Sinne von den Versammelten annehmen zu lassen und uns zuzusenden. "229 Ähnlich forderte die Landesgeschäftsstelle der SPD am 10. Dezember 1945 ihre Ortsgruppen zu Veranstaltungen auf, „um diese Verbrechen der nationalsozialistischen Machthaber dem deutschen Volk noch einmal nachdrücklich vor Augen zu führen". ${ }^{230}$ Dem kamen die Parteigruppen auch nach, so daß die Schweriner SPD beispielsweise auf einer Kundgebung am 20. Dezember 1945 die Todesstrafe für die Kriegsverbrecher einklagte. ${ }^{231}$ Unterstützung fanden diese Veranstaltungen einzelner Gruppen durch eine breite publizistische Kampagne: Seit Oktober wurde in den Tageszeitungen regelmäßig über Nürnberg berichtet und auch der begleitenden Kampagne innerhalb der SBZ viel Platz eingeräumt. Immer wieder wurden die von den Parteiführungen eingeforderten Resolutionen, Forderungen und Losungen als freiwilliger Ausdruck der deutschen Bevölkerung veröffentlicht.

Zum 5. Januar 1946 wurde auch für Schwerin eine Großkundgebung organisiert, zu der alle kommunistischen Stadtteil-, Betriebs- und Ortsgruppenleitungen genaue Instruktionen erhielten. ${ }^{232}$ Unter anderem wurden sie dazu aufgefordert, der Kreisleitung „Stimmen aus allen Bevölkerungskreisen über diesen Prozeß mit dem Verlangen auf schärfste Aburteilung“ zukommen zu lassen. Das Ziel war, noch über die Aktivierung einzelner Grúppen hinauszugehen und die einheitliche Unterstützung dieser antifaschistischen Kampagne durch die gesamte Bevölkerung der SBZ darzustellen: „Was sagen Geschäftsleute, Beamte und Arbeiter über den Nürnberger Prozeß?“ Geschäftsleute und staatliche Dienstkräfte waren in Mecklenburg-Vorpommern neben den Großgrundbesitzern am stärksten von den gesellschaftlichen Umwälzungen der ersten Nachkriegsmonate betroffen; nun sollten sie selbst in aller Öffentlichkeit und ungeachtet der gegen sie gerichteten Entnazifizierungs- und Sequestrierungsmaßnahmen in genau diesen Konsens integriert werden.

Dazu wurde der Antifaschismus eingesetzt, der allerdings nicht nur einseitig der KPD diente, sondern auch seinerseits ein Angebot an die Bevölkerungsmehrheit enthielt: Die Teilnahme an der Kampagne ermöglichte es jedem, selbsttätig und aktiv an diesem neuen gesellschaftlichen Konsens teilzuhaben; durch die eigene Unterschrift oder die Teilnahme an Versammlungen und Demonstrationen konnte man durch einen einfachen und sinnlich wahrnehmbaren Akt auf die Seite des Antifaschismus treten. Durch die öffentlich akklamierte Ablehnung des, Dritten Reiches' gewährte man sich selbst bzw. gewährten die selbsternannten Hauptvertreter des Antifaschismus eine moralische Salvation, die unabhängig von der eigenen Vergangenheit zu erlangen war.

229 MLHA, LL KPD I/22, Bl. 250.

${ }^{230}$ MLHA, LV SPD II/1, Bl. 116.

${ }^{231}$ MLHA, LV SPD II/2, Bl. 184ff. Siehe die Aufmarschpläne, Komiteeprotokolle, Einladungslisten, Plakate, Flugblätter und anderen Unterlagen für eine detaillierte Vorbereitung der Schweriner Kampagne „Volk klagt an", an der sich alle gesellschaftlichen Organisationen, einschließlich der Kirchen, beteiligten (Archiv der Stadt Schwerin, R1-72).

232 MLHA, LL KPD I/27, Bl. 56. 
Durch die Konzentration auf den Nürnberger Prozeß mit nicht mehr als zwei Dutzend Angeklagten wurde die Wahrnehmung des,Dritten Reiches' auf seine politischen und wirtschaftlichen Führer eingeengt. Dies diente dazu, den Dualismus zwischen der Mehrheit der Bevölkerung und den wenigen Antifaschisten, die im Mai 1945 aus den $\mathrm{KZs}$, Gefängnissen und dem Exil zurückkamen und die politische Herrschaft übernommen hatten, zu verschieben. Durch den popularisierten Antifaschismus stand nunmehr die Bevölkerung gemeinsam mit den Regierenden den in Nürnberg Angeklagten gegenüber. Die Schnittstelle, um zwischen gut und böse, zwischen faschistisch und antifaschistisch zu unterscheiden, bildete nicht mehr das eigene Verhalten bis 1945, sondern der Komplex der großen NS- und Kriegsverbrechen, an denen nur ein geringer 'Teil der Bevölkerung selbst aktiven Anteil gehabt hatte. Dieser scharfe Dualismus erklärt auch die stereotype Forderung der Todesstrafe. Indem die in Nürnberg angeklagte NS-Elite und die umfangreichen Kriegs- und NS-Verbrechen ins Zentrum des öffentlichen Interesses gerückt wurden, ging der Alltag des ,Dritten Reiches' mit den kleinen und großen Kompromissen aller Überlebenden aus dem Blickfeld verloren. Dabei wurde keine Vermittlung zwischen den großen Verbrechen, dem lokalen Filz und dem individuellen Verhalten bis 1945 gesucht, was der bereits bei Kriegsende festgestellten Verweigerungshaltung der Bevölkerung entsprach, differenziert und alltagsorientiert über die eigene Schuld nachzudenken. ${ }^{233}$ Die Kampagne bot vielmehr die Möglichkeit, sich aktiv und öffentlich von der NS-Vergangenheit zu distanzieren. Dies zielte meistens eher auf den Nachweis der eigenen Reinheit als auf die konkrete Anschuldigung anderer. Beispielsweise erklärten sich in Tessin die Parteivertreter Anfang September 1945 außerstande, „weiterhin mit den Faschisten in loyaler Gemeinschaft zu leben ". ${ }^{234}$ Solch eine Stellungnahme hatte zwar keine praktischen Auswirkungen, markierte aber eine klare Grenze, die es ermöglichte, die eigene Vergangenheit samt Schattenseiten zu verleugnen.

Dieser kollektive politisch-moralische Seitenwechsel war nur möglich, weil die KPD der Bevölkerung ihre antifaschistische Moral lieh.235 Die Verschiebung des Belastungsprofils im Rahmen der Entnazifizierung hatte die Loyalität zu Besatzungsmacht und KPD zum zunehmend wichtigeren Kriterium gemacht. In ähnlicher Weise war nun auch der Antifaschismus umgedeutet worden: Die aktive Unterstützung des Neuaufbaus in der SBZ war Ausdruck eines konkreten Antifaschismus. Die Annahme dieser entliehenen Moral implizierte allerdings die Anerkennung der Vorrangstellung der ,alten', das heißt der schon vor 1945 bewährten Antifaschisten vor allem aus der KPD, sowie ihrer im Namen des demokratischen Zentralismus aufgebauten Diktatur. ${ }^{236}$ Diese Legitimation der neuen Herrscher wurde zwar ebensowenig expliziert wie die dadurch erteilte moralische Salvation aller Mitläufer; dennoch war sie offensichtlich: Der KPD hätte die

\footnotetext{
${ }^{233}$ Siehe Kapitel I.2, S. 73-76.

${ }^{234}$ MLHA, LL KPD I/22, Bl. 84.

${ }^{235} \mathrm{Zwahr}$, DDR-Kulturpolitik, beschreibt die disziplinierende Wirksamkeit dieser Übertragung und Entleihung der antifaschistischen Moral bis in die achtziger Jahre der DDR.

${ }^{236}$ Die "wenigstens zeitweise erhebliche Massenmobilisierung“ gehört zu modernen Diktaturen (Kocka, Geschichte, S. 23): Während es bei der Mobilisierung großer Bevölkerungsgruppen für Bodenreform und Sequestrierungen um reale politische Veränderungen ging, an denen sie aktiv partizipierten, hatte diese Massenkampagne als erste einen rein akklamatorischen Charakter, weil der Bevölkerung jeder Einfluß auf die Urteilsfindung in Nürnberg fehlte.
} 
Legitimation gefehlt, diese Kampagne zu organisieren, wenn sie nicht die wichtigste Vertreterin des Antifaschismus gewesen wäre, und den ehemaligen Mitläufern mußte dieses Akklamations- und Loyalitätsritual gegenüber den alten Antifaschisten die moralische Reinheit gewähren, weil ihnen sonst die Legitimation für einen Appell an die Siegermächte gefehlt hätte.

Durch die einseitige Hervorhebung der verbrecherischen Seiten des ,Dritten Reiches und durch die Integration der politisch loyalen Bevölkerung in den hegemonialen ,antifaschistischen' Block begann in der SBZ das Schweigen über die nazistische Diktatur. Mit großem publizistischem Aufwand und lautstarken Resolutionen setzte die Gesellschaft der SBZ damit zu dem Zeitpunkt einen Schlußstrich unter die konkrete Vergangenheit der vorhergegangenen dreizehn Jahre, als die Entnazifizierung beendet wurde. Der Nazismus wurde nunmehr zu einem vielfach beschworenen politischen Bezugspunkt, der allerdings nicht durch vergangene Handlungen und Unterlassungen, sondern durch gegenwärtige politische Positionen bestimmt war. Dies entsprach dem weitgehenden und schon im Sommer 1945 einsetzenden Desinteresse an den individuellen Tätern und Opfern. Beide wurden wiederholt für gegenwärtige politische Zwecke gebraucht, da ,Drittes Reich ' und Antifaschismus zentrale Legitimationsgrößen der SBZ und DDR waren. Das konkrete Leben, Leiden und Kämpfen der Opfer verlor aber ebenso seine Bedeutung wie die zahlreichen Verwicklungen der Mitläufer und Täter, deren neu erworbene antifaschistische Identität sich beim Neuaufbau ,bewähren' mußte. 237

${ }^{237}$ Beispielhaft dafür sind das Leben und die autobiographischen Erzählungen von Ludwig Haber, wie sie Niethammer nacherzählt (Niethammer/von Plato/Wierling, Volkseigene, S. 182-220). 
